AMBOS, Kai. "Las prohibiciones de utilización de pruebas en el proceso penal alemán fundamentación teórica y sistematización".

Polít. crim., Vol. 4, № 7 (Julio 2009) Art. 1, pp. 1-56.

[http://www.politicacriminal.cl/Vol_04/n_07/Vol4N7A1.pdf]

\title{
Las prohibiciones de utilización de pruebas en el proceso penal alemán - fundamentación teórica y sistematización
}

\author{
Prof. Dr. Kai Ambos \\ Catedrático de Derecho Penal y Derecho Procesal Penal, Comparado e Internacional, \\ Universidad de Gotinga (Alemania); Juez del Tribunal Estadual (Landgericht) de Gotinga \\ kambos@gwdg.de
}

\section{Resumen}

El artículo examina la prohibición de valoración de las pruebas en el derecho alemán. A modo de introducción se exponen, a partir de la teoría de la "prohibición de prueba" de Beling, los fundamentos de una teoría de la prohibición de valoración de pruebas. Luego, se define el concepto y se sistematizan las prohibiciones de valoración de pruebas existentes (1.). Se distingue a continuación entre prohibiciones de valoración explícitas e implícitas (fundadas en el ordenamiento constitucional), y se exponen detalladamente (2. y 3.). Finalmente, se discute la posibilidad de que estas prohibiciones tengan un efecto reflejo o extensivo (teoría del "fruto del árbol prohibido") (4.).

Palabras Clave: Proceso penal, Derechos humanos, Derecho probatorio, Prohibición de valoración de la prueba, reglas de exclusión de pruebas.

\begin{abstract}
The paper analyzes prohibitions regarding the use of evidence ("exclusionary rules") in German Law. In the introduction, the theoretical foundations, starting from Beling's doctrine of the "prohibitions on evidence", are explained. Then, the concept of prohibitions on evidence is defined and the existing prohibitions are systematized (1.). Next, a distinction between explicit and implicit prohibitions (based on constitutional law) is proposed, and both are explained in detail (2. and 3.). Finally, the possibility of an extensive effect ("fruit of the poisoned tree") of these prohibitions is discussed (4.).
\end{abstract}

Keywords: Criminal procedure, Human rights, Evidence law, Evidence prohibitions, exclusionary rules.

\footnotetext{
* La versión original de este trabajo ha sido preparada en 2006 y fue publicada en Gómez Colomer (coord.), Prueba y Proceso Penal, Valencia: Tirant lo blanch, 2008, pp. 325-360. Aquella versión ha sido completamente revisada, actualizada y ampliada al 10 de abril de 2009. Agradezco a mis colaboradores Nils Meyer-Abich, María Laura Böhm y Rodrigo González-Fuente Rubilar por su ayuda para preparar esta versión.
} 
AMBOS, Kai. "Las prohibiciones de utilización de pruebas en el proceso penal alemán - fundamentación teórica y sistematización”.

\section{Sumario:}

Introducción: Contexto teórico e histórico.- 1. Definición terminológica y sistemática.- 2. Prohibiciones escritas de utilización de pruebas, con especial referencia al $\S 136 a ; 2.1$. El $\S$ 136a: 2.1.1. Generalidades; 2.1.2. Acuerdos; 2.1.3. Destinatarios; 2.1.4. Ardid o engaño; 2.2. Vigilancia de telecomunicaciones y grabaciones secretas; 2.3. Otras prohibiciones escritas de utilización de pruebas.- 3. Prohibiciones no escritas de utilización de pruebas: 3.1. Intentos de explicación; 3.2. Ejemplos de prohibiciones de utilización de pruebas dependientes: 3.2.1. Falta de instrucción del imputado; 3.2.2. Instrucción deficiente de testigos con derecho a negarse a declarar o de dar ciertas informaciones ( $\S 52-55) ; 3.2 .3$. Ejecución ilícita de medidas coercitivas: a) Infracción contra la prohibición de comiso ( 997 I); b) Práctica ilícita de exámenes corporales $(\S$ 81a); c) Vigilancia ilícita de telecomunicaciones ( $\$ \$ 100$ a, b, g, h); d) Registro ilícito de domicilio ( $§ 102$ ss.); e) Investigaciones secretas: (1) Principio nemo tenetur; (2) Incumplimiento de la obligación de instrucción $(\S \S 136,163 \mathrm{a}) ; 3.3$. Ejemplos de prohibiciones probatorias autónomas.- 4. ¿Efecto reflejo o extensivo?

\section{Introducción: Contexto teórico e histórico}

Hace más de cien años Ernst Beling acuñó por primera vez, en una conferencia inaugural, el término "prohibición probatoria"1, expresión con la cual quería manifestar que existen limitaciones a la averiguación de la verdad dentro de la investigación en el proceso penal, debido a intereses contrapuestos de índole colectiva e individual. ${ }^{2}$ La determinación de estas limitaciones depende principalmente de la posición que otorga el ordenamiento jurídico al individuo frente al poder Estatal. ${ }^{3}$ Esta posición se plasma dentro del Estado de Derecho, en su manifestación más elaborada, en los derechos fundamentales garantizados constitucionalmente, sobre todo los de la dignidad humana y el libre desarrollo de la personalidad. ${ }^{4}$ En esta clase de ordenamiento existen áreas que están

\footnotetext{
${ }^{1}$ Así SENGE, Lothar, en: Karlsruher Kommentar zur Strafprozessordnung, 6. ed. München: Beck, 2008, antes del $\S 48 \mathrm{~nm}$ 20, refiriéndose a BELING, Ernst, Die Beweisverbote als Grenzen der Wahrheitsfindung im Strafprozess, Breslau: Schletter, 1903; JAHN, Matthias, "Beweiserhebungs- und Beweisverwertungsverbote im Spannungsfeld zwischen den Garantien des Rechtsstaates und der effektiven Bekämpfung von Kriminalität und Terrorismus", en: Verhandlungen zum 67. Deutschen Juristentag Erfurt 2008, tomo I, Gutachten Teil C, Erfurt: C. H. Beck, 2008, C 21. Ya anteriormente BENNECKE, Hans; BELING, Ernst, Lehrbuch des Dt. Reichs-Strafprozessrechts, Breslau: Schletter, 1900, §§ 83 3., p. 327 s. Recientemente en detalle sobre ello LÖFFELMANN, Markus, Die normativen Grenzen der Wahrheitserforschung im Strafverfahren, Berlin: De Gruyter Recht, 2008.

${ }^{2}$ Cfr. también HENKEL, Heinrich, Strafverfahrensrecht, Stuttgart: Kohlhammer, 1968, p. 271, según el cual "las razones para la admisión de prohibiciones de prueba residen en la consideración de intereses diversos que están en conflicto con los intereses de averiguación de la verdad y que son contemplados como superiores frente a aquella". Ver también OTTO, Harro, "Grenzen und Tragweite der Beweisverbote im Strafverfahren”, Goldammer's Archiv für Strafrecht (GA), (1970), pp. 289-305, p. 289.

${ }^{3}$ Cfr. OTTO, "Grenzen und Tragweite", cit. nota $\mathrm{n}^{\circ}$ 2, p. 291, referiéndose a Beling.

${ }^{4}$ Cfr. BELING, Die Beweisverbote, cit. nota ${ }^{\circ}$ 1, p. 37: "Existirá acuerdo en torno a que también el proceso penal debe tener en consideración la dignidad humana, y que consecuentemente de allí surge un conflicto insoluble entre dignidad humana e intereses del proceso penal, que conlleva a una prohibición de prueba. (...) Pero, aun dejando de lado la dignidad humana, la opinión moderna seguirá afirmando- y
} 
Polít. crim., Vol. 4, $\mathrm{N}^{\circ} 7$ (Julio 2009) Art. 1, pp. 1-56.

[http://www.politicacriminal.cl/Vol_04/n_07/Vol4N7A1.pdf]

protegidas ante las injerencias estatales por parte del legislador, dentro de las cuales, por ende, el esclarecimiento de los hechos a través de determinados medios probatorios resulta inadmisible y prohibida. ${ }^{5}$ El inculpado es sujeto activo y no simplemente objeto del proceso penal ${ }^{6}$, su libertad de decisión y de acción son intangibles e invulnerables, razón por la cual de ninguna manera deben ser objeto de menoscabo o de manipulación. ${ }^{7}$ La manipulación de la voluntad libre del inculpado, por ejemplo a través de amenaza, coerción, engaño o tácticas similares, debe prohibirse y correspondientemente sancionarse. ${ }^{8}$ En consecuencia, las prohibiciones probatorias tienen en su resultado un componente individual y un componente colectivo: por un lado, sirven para la garantía de los derechos fundamentales ${ }^{9}$, en tanto protegen al inculpado ante la utilización de pruebas ilegalmente obtenidas en su contra - en el sentido amplio de prohibiciones de cargo - aunque, no obstante el reconocimiento de este servicio, debido al principio de culpabilidad deben permanecer siempre ${ }^{10}$ utilizables (y de esa forma disponibles) a los efectos de la exculpación ${ }^{11}$; por otro lado preservan - componente colectivo - la integridad constitucional ${ }^{12}$, en particular a través de la realización de un proceso justo (fair trial). ${ }^{13}$

seguramente con razón- que la esfera de la personalidad de cualquier individuo debe ser asegurada ante la intervención estatal, también en el proceso penal." Cfr. también ROGALL, Klaus, "Gegenwärtiger Stand und Entwicklungstendenzen der Lehre von den strafprozessualen Beweisverboten", Zeitschrift für die gesamte Strafrechtswissenschaft (ZStW), (1979), pp. 1-44, p. 9; EISENBERG, Ulrich, Beweisrecht der StPO, 6. ed., parte 1, cap. 3, München: Beck, 2008, nm. 330; KÜHNE, Hans-Heiner, Strafprozessrecht, eine systematische Darstellung des deutschen und europäischen Strafverfahrensrechts, 7. ed., Heidelberg: Müller, 2007, nm. 880.

${ }^{5}$ ROGALL, "Gegenwärtiger Stand", cit. nota nº 4, p. 6.

${ }^{6}$ Más recientemente sobre ello KELKER, Brigitte, "Die Rolle der Staatsanwaltschaft im Strafverfahren", $Z S t W$, (2006), pp. 389-426, p. 420 s.; fundamental también MURMANN, Uwe, "Über den Zweck des Strafprozesses", GA, (2004), pp. 65 ss.

${ }^{7}$ SCHMIDT, Eberhard, "Anmerkung zu OGHBrZ.“, Süddeutsche Juristenzeitung (SJZ), (1949), C 347 ss., p. 450.

${ }^{8}$ GLEß, Sabine, en LÖWE-ROSENBERG, Strafprozessordnung und das Gerichtsverfassungsgesetz, Tomo 2, 26. ed, Berlin: de Gruyter, 2007, § 136a nm. 1.

${ }^{9}$ Así originalmente ROGALL, "Gegenwärtiger Stand", cit. nota n 4, pp. 16 ss.

${ }^{10}$ Esto puede verse diferente en el caso de las prohibiciones absolutas de utilización de pruebas, como la de la tortura, cfr. sobre el punto AMBOS, Kai, "Die transnationale Verwertung von Folterbeweisen", Srafverteidiger (StV), (2009), pp. 151-161; versión en inglés: "The 'transnational' use of torture evidence", Israel Law Review, (2009) (próximo a publicarse).

${ }^{11}$ Fundamental ROXIN, Claus; SCHÄFER, Gerhard; WIDMEIER, Gunter, "Die Mühlenteichtheorie, Überlegungen zur Ambivalenz von Verwertungsverboten“", StV, (2006), pp. 655-660, pp. 656, 659, 660; también ROXIN, Claus, "Beweisverwertungsverbot bei bewußter Mißachtung des Richtervorbehalts", Neue Zeitschrift für Strafrecht (NStZ), (2007), pp. 616 ss., p.618; sustancial JAHN, Beweiserhebungs- und Beweisverwertungsverbote, cit. nota $\mathrm{n}^{\circ} 1, \mathrm{C} 112$ ss. (114).

${ }_{12}$ Ver también SCHMIDT, Eberhard, Lehrkommentar zur Strafprozeßordnung und zum Gerichtsverfassungsgesetz, $t$. II, Göttingen: Vandenhoeck \& Ruprecht, 1970, § 136a nm. 21, con su teoría de la superioridad moral del Estado "limpio" y que persigue la necesidad de un procedimiento respetuoso con las formalidades de la justicia (ibid., tomo I, nm. 40, 44, 49); en la misma dirección va la teoría de FEZER, Gerhard, Grundfragen der Beweisverwertungsverbote, Heidelberg: Müller, 1995, pp. 20 ss., relacionada con la función de auto-limitación del Estado.

${ }^{13}$ BEULKE, Werner, Strafprozessrecht, 10. ed., Heidelberg: Müller, 2008, nm. 454; FINGER, Thorsten, "Prozessuale Beweisverbote - Eine Darstellung ausgewählter Fallgruppen", Juristische Arbeitsblätter (JA), (2006), pp. 529-539, p. 530. 
AMBOS, Kai. "Las prohibiciones de utilización de pruebas en el proceso penal alemán - fundamentación teórica y sistematización”.

La tensa relación entre el interés en una administración de justicia funcional y eficaz en que se cumpla el fin de esclarecer hechos delictivos por una parte, y la garantía de los derechos fundamentales del imputado recién $\operatorname{citados}^{14}$ por otra, lleva a complejas decisiones de ponderación, que pocas veces dejan completamente satisfechas a ambas partes - a la persecución penal y a la defensa -. Esta tensa relación también se puede describir por medio de la antítesis entre justicia material (realización de la pretensión penal), y garantía del debido proceso (aseguramiento de los derechos del imputado). ${ }^{15}$ Traducido a la terminología de la moderna teoría de los fines de la pena (en sentido funcionalista), se puede hablar del dilema de una doble función estabilizadora de la norma: el Estado debe estabilizar no solo las normas jurídico penales a través de una persecución penal efectiva, sino también, en el mismo plano, los derechos fundamentales de los imputados por medio del reconocimiento y ante todo la aplicación de prohibiciones de utilización de prueba en caso de violaciones de los derechos del individuo. ${ }^{16}$ Con ello, al mismo tiempo, las prohibiciones de utilización llevan aparejada una cierta función de control disciplinario de las autoridades de persecución penal - en el sentido de la prevención general negativa ${ }^{17}$ - que puede deplorarse como lo muestran los argumentos en su contra (en especial el debilitamiento de la pretensión social por la realización del derecho penal, así como el control en el sentido de tarea exclusiva del derecho administrativo disciplinario), ${ }^{18}$ pero que de ninguna manera puede negarse. ${ }^{19}$

${ }_{15}^{14}$ BVerfGE 44, pp. 353 ss, p. 374.

15 Cfr. AMELUNG, Knut, "Zum Streit über die Grundlagen der Lehre von den Beweisverwertungsverboten“, en: Festschrift für Claus Roxin, Berlin: de Gruyter, 2001, pp. 1259-1280 p. 1279; JÄGER, Christian, Beweisverwertung und Beweisverwertungsverbote im Strafprozess, München: Beck, 2003, p. 128 (ver también la opinión de JÄGER en nota 180).

${ }^{16}$ Así la (más nueva) "teoría de las consecuencias de los errores normativos" de ROGALL, Klaus, "Abwägungen im Recht der Beweisverbote", en: Festschrift für Ernst-Walter-Hanack zum 70. Geburtstag am 30.August 1999, Berlin: de Gruyter, 1999, pp. 293-309, pp. 300 ss. con más referencias; crítico AMELUNG, “Zum Streit", cit. nota $\mathrm{n}^{\circ}$ 15, pp. 1273 ss.; JÄGER, Beweisverwertung und Beweisverwertungsverbote, cit. nota $\mathrm{n}^{\circ} 15$, p. 109 s.; sobre las doctrinas de prevención general ya DENCKER, Friedrich, Verwertungsverbote im Strafprozeß: ein Beitrag zur Lehre von den Beweisverboten, Köln: Heymann, 1977, pp. 59 ss.; MÜSSIG, Bernd, "Beweisverbote im Legitimationszusammenhang von Strafrechtstheorie und Strafverfahren", GA (1999), pp. 119 - 14, p. 130 s.; ARLOTH, Frank, "Dogmatik in der Sackgasse - Zur Diskussion um die Beweisverwertungsverbote", GA, (2006), pp. 258-261, p. 259.

${ }^{17}$ Cfr. también OTTO, "Grenzen und Tragweite", cit. nota ${ }^{\circ}$ 2, p. 290, refiriéndose al argumento, ya utilizado en los años 60 del siglo pasado, del efecto disuasorio en cuanto a infracciones procesales que pudieran ser cometidas por los órganos estatales.

${ }^{18}$ Cfr. DENCKER, Verwertungsverbote, cit. nota ${ }^{\circ} 16$, pp. 55 ss.; AMELUNG, "Zum Streit", cit. nota ${ }^{\circ}$ 15 , p. 1263; más convincente y concreta es la crítica de JÄGER, Beweisverwertung und Beweisverwertungsverbote, cit. nota $\mathrm{n}^{\circ} 15$, p. 70 s.; en contra también HELLMANN, Uwe, Strafprozessrecht, 2. ed., Berlin: Springer, 2006, § 3 nm., p. 83 s.; SCHUSTER, Frank Peter, Verwertbarkeit im Ausland gewonnener Beweise im deutschen Strafprozess, Berlin: Duncker \& Humblot, 2006, p. 70 s.

${ }^{19}$ Referencia correcta a las consecuencias que presenta para la formación policial en ARLOTH, "Dogmatik in der Sackgasse", cit. nota $\mathrm{n}^{\circ} 16$, p. 259; también PRITTWITZ, Cornelius, "Richtervorbehalt, Beweisverwertungsverbot und Widerspruchslösung bei Blutentnahmen gem. § 81 a Abs. 2 StPO", StV, (2008), pp 486-494, p. 494; JAHN, Beweiserhebungs- und Beweisverwertungsverbote, cit. nota $\mathrm{n}^{\circ} 1$, C. 57 s. ("más actual que nunca"); cfr. también LÖFFELMANN, Die normativen Grenzen, cit. nota n 1, pp. 167 ss. Por el contrario, la declaración de OTTO, "Grenzen und Tragweite", cit. nota n 2, pp. 292, 301, de que las prohibiciones probatorias no son "una medida adecuada para disciplinar a los órganos de persecución penal", es una mera afirmación que debería ser demostrada empíricamente. En este mismo sentido se 
Polít. crim., Vol. 4, $\mathrm{N}^{\circ} 7$ (Julio 2009) Art. 1, pp. 1-56.

[http://www.politicacriminal.cl/Vol_04/n_07/Vol4N7A1.pdf]

En el Derecho Alemán, concretamente en la Ley de Enjuiciamiento Criminal de 1877, inicialmente se dio por supuesta como algo evidente la posición de sujeto del imputado, razón por la cual fue rechazada una regulación expresa. ${ }^{20}$ No obstante, las experiencias con el Derecho Penal Nacionalsocialista, sobre todo en lo referente a su desprecio de la autonomía de la libre determinación del individuo ${ }^{21}$, muy pronto hicieron imprescindible la necesidad de una regulación legal a efectos de asegurar la libertad de decisión individual y, en consecuencia, la prohibición de determinados métodos interrogatorios. A ello se añade que con los adelantos técnicos y científicos, v.gr., con la invención del "detector de mentiras"22 y el "narcoanálisis", surge la necesidad de una regulación legal de las posibles limitaciones relativas a la nueva tecnología para preservar la autonomía individual. ${ }^{23}$ En este sentido se introdujo en 1950, entre otros, el $\S 136$, como norma central para el fortalecimiento de los derechos fundamentales del imputado, así como del Estado de Derecho. Con ello, la tesis de la importancia de los derechos constitucionales fundamentales y del Estado de Derecho encuentran en la temática de las prohibiciones de prueba su constatación legal. $^{24}$

\section{Definición terminológica y sistemática}

La doctrina alemana dominante distingue - bajo el concepto general de "prohibiciones probatorias" - entre prohibiciones de producción de pruebas (Beweiserhebungsverbote) y prohibiciones de utilización de pruebas (Beweisverwertungsverbote). ${ }^{25}$ Las primeras

expresa, sin embargo, la resolución 2 d) de la Sección Derecho Penal del 67mo. DJT (Deutscher Juristen Tag - Jornada de Juristas Alemanes) en Erfurt en 2008, según la cual el desarrollo y mejoramiento de las prohibiciones probatorias no debería tener por objetivo el mantenimiento de la fidelidad a la norma por parte de las autoridades de la persecución penal (42 votos a favor, 31 en contra, 5 abstenciones).

20 SCHMIDT, Lehrkommentar, cit. nota $\mathrm{n}^{\circ} 12$, § 136a explicaciones 1-4 nm. 1; PETERS, Karl, Strafprozeß: Ein Lehrbuch, 4ta. ed., Heidelberg: Müller, Jur. Verl., 1985, § 41 II 1.

${ }^{21}$ Cfr. BGHSt 387: "La disposición debe su existencia a la experiencia dolorosa en un tiempo, en el que la consideración ante la libertad de determinación de un hombre que era considerado sospechoso de la comisión de un hecho punible, fue violada múltiples veces. Por esa razón la norma prohibe expresamente menoscabar la libertad de decisión y de acción mediante la aplicación de ciertos medios que amenacen aquella libertad de determinación".

${ }^{22}$ Sobre la inadmisibilidad en el proceso penal alemán, en especial respecto de una eventual afectación de la decisión y la actuación voluntarias en el sentido del § 136a, véase la controversia en BGH 5, 332 y BGH 44, 308. Sobre la compatibilidad con $\S 136$ a cfr. KÜHNE, Strafprozessrecht, cit. nota $\mathrm{n}^{\circ}$ 4, nm. 901; JÄGER, Beweisverwertung und Beweisverwertungsverbote, cit. nota $\mathrm{n}^{\circ} 15$, p. $220 \mathrm{~s}$; 作 detalle sobre el desarrollo histórico y el actual estado de la opinión en la jurisprudencia y la literatura véase STÜBINGER, Stephan, "Lügendetektor ante portas - Zu möglichen Auswirkungen neurowissenschaftlicher Erkenntnisse auf den Strafprozess", Zeitschrift für Internationale Strafrechtsdogmatik (ZIS), (2008), pp. 538-555, 540 ss., 544 ss.

${ }^{23}$ GLEß, Strafprozessordnung, cit. nota $\mathrm{n}^{\circ} 8, \S 136 \mathrm{a} \mathrm{nm} .2$.

${ }^{24}$ Cfr. también GLEß, Strafprozessordnung, cit. nota $\mathrm{n}^{\circ} 8, \S 136 \mathrm{a} \mathrm{nm}$ 2.; EISENBERG, Beweisrecht, cit. nota $\mathrm{n}^{\circ}$ 4, parte 1, cap. 3, nm 329, 625.

${ }^{25}$ Cfr. VOLK, Klaus, Grundkurs StPO, 6. ed., München: Beck, 2008, § 28 nm. 1 ss.; BEULKE, Strafprozessrecht, cit. nota $n^{\circ} 13$, nm. 455; HELLMANN, Strafprozessrecht, cit. nota $\mathrm{n}^{\circ} 18, \mathrm{~nm} .780 \mathrm{ss}$.; JAHN, Beweiserhebungs- und Beweiserverwertungsverbote, cit. nota $\mathrm{n}^{\circ} 1, \mathrm{C} 27$; con mayor profundidad Die normativen Grenzen, cit. nota $\mathrm{n}^{\circ} 1$, pp. 155 ss. En favor de la diferenciación JÄGER, Beweisverwertung und Beweisverwertungsverbote, cit. nota $\mathrm{n}^{\circ} 15, \mathrm{p} .133$ ss. Sobre la otra categoría de las "regulaciones probatorias" ("Beweisregelungen”) ver OTTO, "Grenzen und Tragweite", cit. nota n², p. 292 s.; así también JAHN, Beweiserhebungs- und Beweiserverwertungsverbote, cit. nota $\mathrm{n}^{\circ} 1, \mathrm{C} 26$ con 
AMBOS, Kai. "Las prohibiciones de utilización de pruebas en el proceso penal alemán - fundamentación teórica y sistematización”.

regulan o limitan el modo de obtención de las pruebas, las segundas el uso judicial de las pruebas que ya fueron obtenidas. ${ }^{26}$ Dentro de las prohibiciones de producción probatoria se distingue entre prohibiciones de temas probatorios, prohibiciones de medios probatorios y prohibiciones de métodos probatorios. ${ }^{27}$ Las prohibiciones de temas probatorios impiden la obtención de pruebas sobre hechos determinados ("temas"), por ejemplo antecedentes penales ya eliminados del Registro Central Federal ( $\$ 51$ Ley del Registro Central Federal). ${ }^{28}$ Las prohibiciones de medios probatorios impiden servirse de medios de prueba determinados, como por ejemplo un testigo que ha hecho uso de su derecho a no declarar (léase $\S \S 52$ ss. $^{29}$ ). ${ }^{30}$ Las prohibiciones de métodos probatorios impiden un cierto modo de obtención de prueba, por ejemplo un método de interrogatorio prohibido conforme al $\S 136 \mathrm{a}$. Adicionalmente se puede distinguir entre prohibiciones de producción de pruebas absolutas y relativas. Mientras las absolutas tienen validez general, las relativas limitan la obtención de pruebas en el sentido de que únicamente determinadas personas están facultadas para ordenar o realizar una producción probatoria, estableciéndose en consecuencia una prohibición para cualquier otro sujeto ${ }^{31}$. Esto tiene validez para casi todas las medidas coercitivas que, en principio, solo pueden ser ordenadas por un juez.

La sistematización establecida sirve ante todo para clarificar las posiciones, pero también conduce el tema - en contra de una opinión ampliamente difundida ${ }^{32}$ - al menos a una doble ganancia en el campo del conocimiento: en primer lugar, se deduce de esta diferenciación entre prohibición de producción y prohibición de utilización probatoria, que una violación de la producción no acarrea necesariamente una prohibición de

más referencias, p. 126; HALLER, Klaus; CONZEN, Klaus, Das Strafverfahren: eine systematische Darstellung mit Originalakte und Fallbeispielen, 6ta. ed., Heidelberg, Neckar: Müller, 2008, nm. 548.

${ }^{26}$ FINGER, "Prozessuale Beweisverbote", cit. nota n' 13, p. 530; HALLER/CONZEN, Das Straverfahren, cit. nota $\mathrm{n}^{\circ}$ 25, nm. 549; JÄGER, Beweisverwertung und Beweisverwertungsverbote, cit. nota ${ }^{\circ} 15$, p. 133 habla, más exactamente, de una "prohibición probatoria en cuanto a los hechos" ("Tatsachenverwertungsverbot"), porque efectivamente se pretenden prohibir las conclusiones provenientes de hechos producto de la práctica probatoria; en el punto así también JAHN, Beweiserhebungs- und Beweiserverwertungsverbote, cit. nota $\mathrm{n}^{\circ} 1, \mathrm{C} 25$ ("Autorestricciones en la determinación procesal de los hechos" - "Selbstbeschränkungen prozessualer Tatsachenfeststellung"), C 26 ("Prohibiciones de valoración de los hechos" - "Tatsachenverwertungsverbote").

${ }^{27}$ VOLK, Grundkurs, cit. nota n ${ }^{\circ} 25, \S 28 \mathrm{~nm} .1$ ss.; BEULKE, Strafprozessrecht, cit. nota n ${ }^{\circ} 13, \mathrm{~nm} .455$; HELLMANN, Strafprozessrecht, cit. nota $\mathrm{n}^{\circ} 18$, Rn. 780; crítico JAHN, Beweiserhebungs- und Beweiserverwertungsverbote, cit. nota $\mathrm{n}^{\circ} 1, \mathrm{C} 28$ ss. La diferenciación remite al dictamen de Peters, en la 46ta. DJT en Essen, ver PETERS, Karl, "Beweisverbote im Strafprozess", en: Verhandlungen zum 46. DJT (Deutscher Juristentag), $t$. I, Parte 3 A, München, 1967, pp. 91, 94.

${ }^{28}$ Sobre ello más recientemente BGH NStZ 2006, 587.

${ }^{29}$ Todas las normas sin referencia legislativa se refieren al Strafprozessordnung ("StPO")= Ordenamiento (Código) Procesal Penal alemán.

${ }^{30}$ Véase KÜHNE, Strafprozessrecht, cit. nota $n^{\circ} 4$, nm. 882 ss. (889), quien alega que todas las prohibiciones probatorias temáticas son al mismo tiempo prohibiciones en cuanto a los medios probatorios $\mathrm{y}$, en consecuencia, este último concepto resulta inútil.

${ }_{31}$ BELING, Die Beweisverbote, cit. nota $\mathrm{n}^{\circ}$ 1, p. 3; STRATE, Gerhard, "Rechtshistorische Fragen der Beweisverbote", Juristen Zeitung (JZ), (1989), pp. 176-179, p. 176 con más referencias. Crít. por la desvaloración que implica JAHN, Beweiserhebungs- und Beweiserverwertungsverbote, cit. nota $\mathrm{n}^{\circ} 1, \mathrm{C} 30$ s., 126, quien prefiere clasificarlas como prohibiciones de métodos probatorios.

${ }^{32}$ VOLK, Grundkurs, cit. nota $\mathrm{n}^{\circ} 25, \S 28 \mathrm{~nm}$. 3; HELLMANN, Strafprozessrecht, cit. nota $\mathrm{n}^{\circ} 18, \mathrm{~nm}$. 780; FINGER, "Prozessuale Beweisverbote", cit. nota n 13, p. 530. 
utilización, como si sucede en el derecho italiano ${ }^{33}$, sino que la transgresión en contra de una prohibición (primaria) de producción probatoria en el mejor de los casos indica pero no implica automáticamente - la no utilización posterior. ${ }^{34}$ Según Jäger $^{35}$ se puede hablar por ende de un principio de abstracción o separación, según el cual se distingue estrictamente entre producción probatoria y utilización de pruebas, conforme a la diferenciación en el derecho civil (alemán) entre obligación y cumplimiento. Para llegar realmente a una prohibición de utilización de pruebas, es necesaria o bien una disposición legal expresa (en caso de prohibiciones de utilización de pruebas escritas, véase ap. 2) o bien una fundamentación teórica (en caso de las prohibiciones de utilización no escritas) con base en la doctrina de las prohibiciones de utilización de pruebas (véase ap. 3). Un reconocimiento (mayormente aceptado) de esta doctrina es la posterior diferenciación entre prohibiciones de utilización de pruebas dependientes e independientes. Las primeras son la consecuencia de la infracción de una prohibición de producción probatoria, mientras que las segundas se basan en una infracción objetiva de las normas constitucionales de forma independiente. ${ }^{36} \mathrm{El}$ reconocimiento de la prohibición de utilización probatoria independiente, finalmente, es una consecuencia adicional de la diferenciación originaria entre la prohibición de la producción y de la utilización, pues sólo bajo esta condición se deja fundamentar la utilización probatoria independientemente de una prohibición de producción, precisamente dependiente. ${ }^{37} \mathrm{La}$ categoría de las prohibiciones de utilización probatoria, por el contrario, todavía no ha podido imponerse. $^{38}$

33 Cfr. Art. 191 CPP ("Prove illegittimamente acquisite"):

Inc. 1: "Le prove acquisite in violazione dei divieti stabiliti dalla legge non possono essere utilizzate."

Inc. 2: "L'inutilizzabilita' e' rilevabile anche di ufficio in ogni stato e grado del procedimento."

${ }^{34}$ Cfr. por todos BEULKE, Strafprozessrecht, cit. nota $\mathrm{n}^{\circ} 13, \mathrm{~nm}$. 457: "No cualquier error en la práctica probatoria lleva inevitablemente a la no utilización del medio probatorio obtenido." Cfr. también ROXIN, Claus, Strafverfahrensrecht: ein Studienbuch, 25. ed., München: Beck, 1998, § 24 nm. 19; KINDHÄUSER, Urs, Strafprozessrecht, Baden-Baden: Nomos, 2006, § $23 \mathrm{~nm}$. 11; ARLOTH, "Dogmatik in der Sackgasse", cit. nota $\mathrm{n}^{\circ} 16$, p. 258; JÄGER, Beweisverwertung und Beweisverwertungsverbote, cit. nota $\mathrm{n}^{\circ}$ 15, p. 135; PRITTWITZ, "Richtervorbehalt", cit. nota $\mathrm{n}^{\circ} 19$, p. 488; JAHN, Beweiserhebungs- und Beweiserverwertungsverbote, cit. nota $\mathrm{n}^{\circ}$ 1, C. 34 ss.; BVerfG Neue Juristische Wochenschrift $(N J W)$, (2000), p. 3557; NStZ, (2007), pp. 159 ss., p. 160; BGHSt 44, 243 [249]; BGH, NJW, (2007), pp. 2269 ss., p. $2271=S t V$ 2007, 337, 338 col. izq.; OLG Hamm, NStZ, (2007), p. 355; OLG Hamburg, StV (2008), pp. 454 ss., 456 col. izq.; sobre efectos indiciarios en esta cuestión véase también FINGER, "Prozessuale Beweisverbote", cit. nota ${ }^{\circ} 13$, p. 531. Sobre la dependencia interna de las prohibiciones de producción y de utilización de pruebas con vistas al "efecto previo" que la prohibición de utilización tiene sobre la prohibición de producción véase JAHN, Beweiserhebungs- und Beweiserverwertungsverbote, cit. nota $\mathrm{n}^{\circ} 1$, C $86 \mathrm{~s}$.

35 JÄGER, Beweisverwertung und Beweisverwertungsverbote, cit. nota ${ }^{\circ} 15$, p. 137 s.; en contra JAHN, Beweiserhebungs- und Beweiserverwertungsverbote, cit. nota $\mathrm{n}^{\circ}$ 1, C. 36.

${ }^{36}$ BGHSt 28, 122, 124; ROGALL, "Gegenwärtiger Stand", cit. nota $\mathrm{n}^{\circ}$ 4, p. 3; siguiéndolo ROXIN, Strafverfahrenstrecht, cit. nota $\mathrm{n}^{\circ} 34, \S 24 \mathrm{~nm}$. 23; VOLK, Grundkurs, cit. nota $\mathrm{n}^{\circ} 25$, § $28 \mathrm{~nm} .4$ s.; BEULKE, Strafprozessrecht, cit. nota $\mathrm{n}^{\circ} 13, \mathrm{~nm}$. 457; cfr. también MEYER-MEWS, Hans, "Beweisverwertungsverbote im Strafverfahren", Juristische Schulung (JuS), (2004), p. 39-42, p. 39; SCHUSTER, Verwertbarkeit, cit. nota $\mathrm{n}^{\circ} 18$, p. 51 ss.; JAHN, Beweiserhebungs- und Beweiserverwertungsverbote, cit. nota $\mathrm{n}^{\circ} 1$, C 32, 37 s.; MURMANN, Uwe, Prüfungswissen Strafprozessrecht, München: Beck, 2008, nm. 184.

${ }^{37}$ ARLOTH, "Dogmatik in der Sackgasse", cit. nota n ${ }^{\circ}$ 16, p. 258.

38 Véase, sin embargo, EISENBERG, Beweisrecht, cit. nota $\mathrm{n}^{\circ}$ 4, nm. 335; LÖFFELMANN, Die normativen Grenzen, cit. nota ${ }^{\circ}$ 1, pp. 161 ss.; SCHLOTHAUER, Reinhold, "Strafprozessuale Verwertung 
AMBOS, Kai. "Las prohibiciones de utilización de pruebas en el proceso penal alemán - fundamentación teórica y sistematización”.

Luego de todo esto, es evidente que existe una colisión entre las prohibiciones de pruebas y el principio de investigación ( $\S 155$ II, 160 II, 244 II). Las prohibiciones de producción probatoria limitan la actividad de las autoridades de investigación penal en el esclarecimiento de los delitos, al igual que las prohibiciones de utilización de pruebas impiden que los tribunales penales realicen una valoración de conjunto sobre el material probatorio recopilado. ${ }^{39}$ Lo anterior tiene por efecto que "la veracidad queda incompleta y lleva rasgos ficticios" $" 40$ y esto fundamenta, según la opinión de la jurisprudencia de los tribunales superiores, su carácter excepcional. ${ }^{41}$ Así, las prohibiciones probatorias confirman que la verdad (procesal), de acuerdo a las famosas palabras del Tribunal Supremo Federal, no debe ser investigada "a cualquier precio", 42 sino que debe considerar los intereses individuales previamente indicados. Sin embargo, las prohibiciones sirven al mismo tiempo para la protección de la averiguación de la verdad, puesto que impiden la utilización de informaciones incompletas, indirectas o distorsionadas, ${ }^{43}$ lo que se demuestra rotundamente con el $\S 136$ a (véase a continuación ap. 2.1).

\section{Prohibiciones escritas de utilización de pruebas, con especial referencia al $§ 136 a$ III.}

En general hay consenso en el hecho de que la existencia de una prohibición de utilización probatoria no depende - en el sentido formal - de su expresa codificación, ${ }^{44}$ sino que más bien ello está determinado en sentido material de acuerdo con la razón de ser de la norma procesal violada y en consideración a aquellos intereses contrapuestos que obstaculizan la averiguación de los hechos. De otra manera, si se exigiese una disposición legal expresa de la prohibición de la utilización probatoria, es decir, una prohibición de utilización probatoria codificada, esto implicaría la finalización de las discusiones político-criminales y dogmático-procesales de manera más bien rápida,

selbstbelastender Angaben im Verwaltungsverfahren", en: Festschrift für Gerhard Fezer, Berlin: de Gruyter Recht, 2008, pp. 267-287, p. 269 con una nota en la que refiere a WOLFF, Heinrich A., Selbstbelastung und Verfahrenstrennung, Berlin: Duncker \& Humblot, 1997, p. 136; en detalle recientemente SINGELNSTEIN, Tobias, "Strafprozessuale Verwendungsregelungen zwischen Zweckbindungsgrundsatz und Verwertungsverboten", ZStW, (2008), pp. 854-893, p. 865 ss. con más referencias en nota 55, quien señala la "enorme importancia procesal" de las numerosas regulaciones de utilización probatoria contenidas en el StPO (ib, pp. 854, 865 ss., 883). Las regulaciones sobre la utilización probatoria se refieren (a diferencia de la prohibición de utilización) a la cuestión de "si y bajo qué exigencias la información obtenida puede ser utilizada con otros fines.” (ib, p. 865). La categoría se desprende del verbo "utilizar" en algunas regulaciones de utilización (p. ej. § 81a III, 100 d VI), cfr. JAHN, Beweiserhebungs- und Beweiserverwertungsverbote, cit. nota $\mathrm{n}^{\circ} 1$, C 32 s. Sobre las nuevas reglas de utilización de los $\S \S 161$ párr. 2 y 477 párr. 2 véase infra III.2.

39 ARLOTH, "Dogmatik in der Sackgasse", cit. nota ${ }^{\circ} 16$, p. 258; también SENGE, en Karlsruher Kommentar, cit. nota $\mathrm{n}^{\circ} 1, \mathrm{~nm} .22,27$.

${ }^{40}$ VOLK, Grundkurs, cit. nota n ${ }^{\circ} 25, \S 28 \mathrm{~nm} .6$.

${ }^{41}$ Recientemente BGH (Corte Suprema), NJW, (2007), pp. 2269 ss., p. 2271; OLG (Oberlandesgericht $=$ Tribunal Superior estatal) Hamburg, StV, (2008), p. 456 col. izq. con más referencias.

${ }^{42}$ BGHSt 14, 358, 365; 31, 304, 309; 38, 214, 220.

43 AMELUNG, "Zum Streit", cit. nota $\mathrm{n}^{\circ} 15$, p. 1263. Hasta aquí no existe ningún antagonismo entre las prohibiciones de utilización y la averiguación de la verdad (acertado JAHN, Beweiserhebungs- und Beweiserverwertungsverbote, cit. nota $\mathrm{n}^{\circ} 1, \mathrm{C} 25$ ).

${ }^{44}$ BEULKE, Strafprozessrecht, cit. nota $\mathrm{n}^{\circ} 13$, nm. 457. 
Polít. crim., Vol. 4, $\mathrm{N}^{\circ} 7$ (Julio 2009) Art. 1, pp. 1-56.

[http://www.politicacriminal.cl/Vol_04/n_07/Vol4N7A1.pdf]

puesto que las regulaciones de prohibición legalmente establecidas son, además de pocas, (relativamente) inequívocas.

\subsection{El $§ 136$ a}

\subsubsection{Generalidades}

Es clásica la formulación del $\S 136 a$ III: "Las declaraciones que se hubieran producido trasgrediendo esta prohibición, tampoco podrán ser aprovechadas aunque el inculpado aprobara su utilización." La incondicionalidad de la norma se deduce, en todo caso, de las consideraciones de prevención general, pues si la violación de la prohibición quedara sin efectos procesales, existirían muy pocas razones para cumplir con ella. ${ }^{45}$ Se trata de una prohibición de utilización de pruebas dependiente, ya que es la consecuencia de la prohibición de la producción probatoria, contemplada en el $\S 136 \mathrm{a}$ I, referente a ciertos métodos prohibidos de interrogatorio que lesionan la "libertad de decisión y de acción del inculpado" ("Freiheit der Willensentschließung und der Willensbetätigung"). En consecuencia, resulta claro que también puede ser posible la utilización de conocimientos de descargo por los motivos ${ }^{46}$ anteriormente mencionados. ${ }^{47}$ El problema de la norma estriba menos en la consecuencia, esto es, en la prohibición de valoración probatoria, que en la determinación exacta de los métodos de interrogatorio que han de considerarse como prohibidos. También esto queda claro en la más reciente discusión en EE.UU. sobre el máximo de intensidad admisible o la "resistencia" a los métodos de interrogatorio prohibido de los sospechosos de terrorismo. ${ }^{48}$ Los métodos de interrogatorio mencionados en el inciso 1 (maltrato, fatiga, tortura, etc., el así llamado "interrogatorio en tercer grado") en todo caso no son definitivos ${ }^{49}$ lo decisivo es si estas u otras "técnicas de interrogatorio" socavan la libertad de decisión del interrogado. Con respecto a la (amenaza de) tortura, recientemente el Tribunal Constitucional Federal (BVerfG, Bundesverfassungsgericht) recalcó que con ella "se denigra a la persona interrogada a un puro objeto en la lucha contra el crimen, violándose así sus garantías constitucionales de ser valorada y respetada como persona", y se destruyen por tanto "los presupuestos fundamentales de la existencia individual y social del ser humano". ${ }^{50}$ Una declaración basada en tal menosprecio no podría ser utilizada como medio de prueba. Sin embargo, es posible que la declaración del acusado alegada legalmente en la vista principal se convierta en la base de una condena, a condición de que a éste se le hayan hecho las indicaciones correspondientes sobre su derecho a no declarar, ${ }^{51}$ incluso sobre la

\footnotetext{
${ }^{45}$ De acuerdo con ello VOLK, Grundkurs, cit. nota ${ }^{\circ} 25, \S 28 \mathrm{~nm} .24$.

${ }^{46}$ Cfr. nota 11 y texto principal.

47 Al respecto sobre una restricción teleológica de la norma, ROXIN/SCHÄFER/WIDMEIER, "Die Mühlenteichtheorie", cit. nota ${ }^{\circ} 11$, p. 656.

${ }^{48}$ Cfr. DANNER, Mark, Torture and Truth: America, Abu Ghraib and the War on Terror, Nueva York: New York Review Books, 2004; LANGBEIN, John, Torture and the Law of Proof : Europe in the ancient regime, Chicago: University Of Chicago Press, 2006 (reimpresión), pp. IX, XI.

49 DIEMER, Herbert, Karlsruher Kommentar zur Strafprozessordnung, 6. ed. München: Beck, 2008, § 136a nm. 9; sobre los grupos de casos VOLK, Grundkurs, cit. nota n ${ }^{\circ} 25, \S 9 \mathrm{~nm} .14$ s.

${ }^{50}$ BVerfG, 2 BvR 1249/04 vom 14.12.2004 (caso del Jefe de la policía de Frankfurt), nm. 7.

${ }^{51}$ BVerfG, 2 BvR 1249/04 vom 14.12.2004, nm. 3. Sobre la cuestión acerca de si, con qué alcance y bajo qué requisitos una violación de la obligación de instruir adecuadamente puede acarrear una prohibición de
} 
AMBOS, Kai. "Las prohibiciones de utilización de pruebas en el proceso penal alemán - fundamentación teórica y sistematización”.

no utilización de su anterior declaración. ${ }^{52}$ De esta forma se descarta por tanto una violación de los derechos fundamentales, cuando la prohibición de utilización de pruebas aplicada por el tribunal penal competente ha compensado la infracción procesal original en la obtención probatoria de forma inadmisible. Se debe recalcar a este respecto que en la prohibición de utilización de pruebas del $\S 136$ a se trata no solamente, en un sentido plenamente idealista, de la protección de la dignidad humana del imputado, sino también del contenido verídico de la declaración, pues en efecto es bien sabido que los imputados coaccionados están más motivados a hablar para poner fin al dolor, que por sentirse obligados a decir la verdad. ${ }^{53}$

Respecto del $\S 136 a$ I, 2da. oración, (utilización únicamente de la fuerza permitida) es discutido si la ilegalidad, y por tanto la inaceptabilidad de la medida coercitiva, por ejemplo de la prisión preventiva ilegal, hace inutilizables las declaraciones obtenidas en su contexto. Según el punto de vista del BGH (Bundesgerichtshof, Tribunal Supremo Federal) este no es el caso - en forma automática -, sino más bien sólo cuando la coerción ha sido aplicada "expresamente como medio para obtener una declaración". 54 Este criterio de intencionalidad no se desprende, sin embargo, ni de la letra ni de la interpretación sistemática del $\S 136$ a I, 2da. oración, ${ }^{55}$ la inadmisibilidad absoluta de la medida coercitiva lleva más bien a una prohibición de utilización, pues según la clara letra de la 2 da. oración la coerción no puede ser aplicada, y la declaración hecha bajo su influencia representa una violación al derecho de no declarar, que debe ser compensada mediante la prohibición de la utilización. ${ }^{56}$

utilización véase ROXIN, Claus, "Beschuldigtenstatus und qualifizierte Belehrung", Juristische Rundschau $(J R),(2008)$, pp. 16-19, p. 18 s., quien junto con la mayoría argumenta a favor de una prohibición general de utilización.

${ }^{52}$ Sobre la instrucción calificada véase MEYER-GOßNER, Lutz, Strafprozessordnung mit GVG und Nebengesetzen, 51. ed., München: Beck, 2008, § 136 nm. 9; ROXIN, Strafverfahrenstrecht, cit. nota n ${ }^{\circ}$ 4, $\S 24 \mathrm{~nm} .27$.

${ }_{53}$ Cfr. tambien KÜHNE, Strafprozessrecht, cit. nota ${ }^{\circ} 4$, nm. 890.

${ }_{55}^{54}$ BGH, NJW, 1995, 2933, 2936 = StV , (1996), 73 (76).

55 BUNG, Jochen, "Objektiv unzulässiger oder intentionaler Zwang als Voraussetzung eines Beweisverwertungsverbots nach $\S 136$ a Abs. 3 Satz 2 i.V.m. Abs. 1 Satz 2 stopp”, StV, (2008), pp. 495499, p. 496 s.

${ }^{56}$ BUNG, "Objektiv unzulässiger oder intentionaler", cit. nota $n^{\circ}$ 55, p. 498. Es controvertido hasta qué punto esto también tiene validez para el material de descargo obtenido en violación de la prohibición; véase sobre el punto la reciente sentencia BGH, StV, (2009), p. 113 (con comentarios críticos y referencias jurisprudenciales de ROXIN, p. 113 ss.), de acuerdo con la cual si bien el Tribunal investigador está obligado a la investigación de los hechos según el § 244 StPO (recepción del material probatorio), tiene sin embargo prohibido llevar adelante tal investigación por el § 136a III 2. ("Declaraciones que hayan tenido lugar en violación a esta prohibición tampoco podrán ser utilizadas aunque el acusado esté de acuerdo con dicha utilización." ["esta prohibición" se refiere a la prohibición de interrogar coactivamente, NdeT], sin embargo es posible "imaginar casos en los cuales en contra de la clara letra de la ley la utilización de tales resultados podrían ser evaluados en atención a principios constitucionales o de Derechos Humanos de mayor rango". No obstante, tal situación "deberá ser en todo caso considerada" si el acusado 1. "sin lugar a dudas da a entender que renuncia a la protección individual que se le concede mediante el § 136a párr. 3, 2a. oración StPO" y 2. "señala que se vería privado de una defensa efectiva si no se utiliza la evidencia en sí bloqueada, y que por tanto los principios de un proceso penal propio de un Estado de Derecho que le son garantizados por el § 136a párr. 3, 2a. oración StPO y que objetivamente también son garantizados con vistas al interés general deben retroceder - en la ponderación de bienes - frente a su derecho a una defensa efectiva, igualmente contemplada en el principio de Estado de Derecho." 
Polít. crim., Vol. 4, $\mathrm{N}^{\circ} 7$ (Julio 2009) Art. 1, pp. 1-56.

[http://www.politicacriminal.cl/Vol_04/n_07/Vol4N7A1.pdf]

\subsubsection{Acuerdos.}

El $§ 136 a$ también es la "piedra de toque procesal" para una confesión hecha con motivo de un acuerdo formal, ${ }^{57}$ por supuesto sobre la base del principio constitucional del derecho a no declarar en el sentido del principio nemo tenetur. ${ }^{58}$ La contracara de la confesión del acusado es generalmente una disminución de la pena y, dado el caso, una abreviación del proceso. El objetivo que une a los actores procesales es la conclusión de conformidad y rápida del proceso. A pesar de las importantes dudas respecto de la práctica del acuerdo en la literatura, ${ }^{59}$ el $\mathrm{BGH}$ se ha manifestado básicamente a favor de ella y se ha esforzado por ligar su admisibilidad a determinadas condiciones. ${ }^{60}$ Aquí ha remarcado explícitamente que incluso en el marco de un acuerdo formal la predisposición a la confesión no puede ser forzada mediante los métodos prohibidos por el $\S 136 a{ }^{61}$ Una confesión hecha con base en un acuerdo de tales condiciones es por lo tanto inutilizable sin más.

En el marco de los acuerdos el § 136a I, 3ra. oración, 2da. Alternativa StPO adquiere una relevancia especial, ya que mediante la "promesa de una ventaja no prevista en la ley" se puede ejercer una fuerte presión sobre el acusado a fin que se muestre cooperador al prestar declaración. De esta manera se lesiona la libre voluntad protegida por el $\S 136 \mathrm{a}$, como en los otros métodos de indagación mencionados en el $§ 136 \mathrm{a}$. Al mismo tiempo se argumenta sobre esto, que la presión ejercida en el marco del acuerdo para la obtención de la confesión no alcanza el grado de intensidad requerido para que pueda considerarse una lesión de la libre declaración en el sentido del $\S 136 a{ }^{62}$ Como en los casos antes mencionados de métodos interrogatorios "más rudos", el problema reside también aquí en determinar con la mayor precisión posible los límites entre una forma permitida de estimular la confesión y una influencia no permitida sobre la libre voluntad. Según la letra de la ley, de todos modos, una influencia no permitida está ya presente, cuando el

\footnotetext{
${ }^{57}$ KUCKEIN, Jürgen, "Zur Verwertbarkeit des Geständnisses bei einer gescheiterten Verständigung im Strafverfahren”, en: Festschrift für Meyer-Goßner, München: Beck, 2001, pp. 63-72, p. 69.

${ }^{58}$ Véase KÖLBEL, Ralf, "Geständnisverwertung bei missglückter Absprache", NStZ, (2003), pp. 232-236, pp. 234 ss; sobre el nemo tenetur en este contexto también EIDAM, Lutz, Die strafprozessuale Selbstbelastungsfreiheit am Beginn des 21. Jahrhunderts, Frankfurt am Main: Lang, 2007, pp. 235 ss.; VERREL, Die Selbstbelastungsfreiheit im Strafverfahren: ein Beitrag zur Konturierung eines überdehnten Verfahrensgrundsatzes, München: Beck, 2001, p. 51 s.

${ }^{59}$ Un panorama respecto de las dudas que en general se presentan sobre los acuerdos procesales formales se encuentra p. ej. en KÜHNE, Strafprozessrecht, cit. nota n ${ }^{\circ} 4, \S 47$, nm. 748 y BEULKE, Strafprozessrecht, cit. nota $\mathrm{n}^{\circ} 13, \S 19 \mathrm{~nm}$. 395. Cfr. así también HASSEMER, Winfried, "Pacta sunt servanda - auch im Strafprozeß?”, JuS, (1989), pp. 890-895; LIE LIEN, Taipei, “Analytische Untersuchung der Ursachen des andauernden Streits um Absprachen - Kritik an den bisherigen Legitimationsmodellen der Absprachen aus sprachanalytischer Sicht", GA, (2006), pp. 129-147, p. 129 ss.; RÖNNAU, Thomas, "Die neue Verbindlichkeit bei den strafprozessualen Absprachen", Zeitschrift für Wirtschafts- und Steuerstrafrecht (wistra), (1998), pp. 49-53, pp. 49 ss.; sobre la admisibilidad y límites p. ej. LESCH, Heiko H., en: KMRKommentar zur Strafprozessordnung, (2008), § 136 a nm. 39.

${ }^{60}$ Fundamentado BGHSt 43, $195=N S t Z$, (1998), p. 31; véase en general también KÜHNE, Strafprozessrecht, cit. nota $\mathrm{n}^{\circ} 4$, $\S 47 \mathrm{~nm} .747$ ss.; VOLK, Grundkurs, cit. nota ${ }^{\circ} 25, \S 30$.

${ }^{61}$ Cfr. BGHSt 43, 195 (204) = NStZ, (1998), pp. 31 ss., p. 33; véase también KÜHNE, Strafprozessrecht, cit. nota $\mathrm{n}^{\circ} 4, \S 47 \mathrm{~nm} .749$.

${ }^{62}$ Véase p. ej. VOLK, Grundkurs, cit. nota ${ }^{\circ} 25, \S 30 \mathrm{~nm} .3$.
} 
AMBOS, Kai. "Las prohibiciones de utilización de pruebas en el proceso penal alemán - fundamentación teórica y sistematización”.

acuerdo contiene una ventaja "no prevista en la ley". Una promesa no permitida - por ser ilegal - se da por ejemplo cuando al acusado se le asegura como contraprestación por su confesión una calificación jurídica del hecho que se sabe inadecuada (pero para él resulta ventajosa). ${ }^{63}$ El límite también está excedido cuando la "brecha penal" entre la pena que puede esperarse y la pena ofrecida en el acuerdo es tan grande, que está dada una influencia no permitida de la libre voluntad. ${ }^{64}$ Así consta por ejemplo en la propuesta de la Fiscalía, que si el acusado confesara, la Fiscalía solicitaría una pena de 3 años y seis meses de pena privativa de la libertad, de lo contrario la solicitud sería de 6 ó 7 años; aquí se trata o bien de una promesa de una ventaja no prevista legalmente, o bien de la amenaza de una pena elevada inadecuada a la culpabilidad y por tanto no permitida. ${ }^{65}$ Por el contrario, según la jurisprudencia, el simple hecho de poner-a-consideración una pena más favorable (pero aún acorde con la culpabilidad) para obtener una confesión, no debería representar una promesa ilegal. ${ }^{66}$

En relación con los acuerdos formales también se puede plantear la cuestión de si respecto de una confesión ("prehecha") brindada acorde con el acuerdo surge una prohibición de utilización cuando, luego - después de haber hecho la confesión -, se advierte que el acuerdo ha fracasado. En caso de engaño intencional al acusado respecto de la efectividad del acuerdo se está frente a un método interrogatorio prohibido en el sentido del $\S 136 a$ I, de manera que la confesión es inutilizable, siempre que el engaño haya causado la confesión. ${ }^{67}$ ¿Cómo se debe proceder, sin embargo, cuando por ejemplo

${ }^{63}$ BGH, NStZ, (2007), pp. 655 ss., p. 657 mencionado allí como ejemplo.

${ }^{64}$ KÜHNE, Strafprozessrecht, cit. nota $n^{\circ} 4, \S 47, \mathrm{~nm}$. 749, quien además señala que de esta manera la confiabilidad de una confesión se vería claramente perjudicada; BEULKE, Strafprozessrecht, cit. nota ${ }^{\circ}$ $13, \S 19$ nm. 396.

${ }^{65}$ BGH, NStZ, (2005), p. $393=$ StV , (2005), p. 201: "Pues una diferencia tan notoria entre las solicitudes finales ya no sería explicable mediante el efecto atenuador de la pena que conlleva una confesión, y debe ser valorado como medio de presión no permitido que tiene por objetivo una confesión que abrevie el proceso"; así también BGH, NStZ, 08, pp. 170 ss., p. 171, en el caso de una diferencia entre 3 años y medio en caso de confesión y 7 a 8 años sin confesión, véase también VOLK, Grundkurs, cit. nota n ${ }^{\circ} 25, \S 9 \mathrm{~nm}$. 15 con otros ejemplos.

${ }^{66}$ BGHSt 43, pp. 195 ss., p. $204=N S t Z$, 98, pp. 31 ss., p. 33; BGH, NStZ, 07, pp. 655 ss., p. 657 . Tal diferenciación, como la que aquí adopta el BGH, es problemática, puesto que "es inmanente a cada oferta de pena menor, que la pena sin confesión sería mayor." (véase SCHMITT, Bertram, "Zu Rechtsprechung und Rechtswirklichkeit verfahrensbeendender Absprachen im Strafprozeß", GA, (2001), pp. 411-426, p. 422 ); véase también KÖLBEL, "Geständnisverwertung", cit. nota $n^{\circ} 58$, p. 235 , quien quiere adjudicar "calidad de intervención también a la propuesta de disminución" y acertadamente dice: "Independientemente de si opera con un favorecimiento o con un empeoramiento, en ambos casos la 'brecha penal' dificulta el uso de los derechos básicos, ya que el sujeto de derechos se ve mejor posicionado si no hace uso de ellos"; WEIGEND, Thomas, "Abgesprochene Gerechtigkeit - Effizienz durch Kooperation im Strafverfahren?”, JZ, (1990), pp. 774-782 ss., p. 778 también señala que cada propuesta de pena más tenue implícitamente contiene una amenaza. También crítico EIDAM, Die Strafprozessuale Selbstbelastungsfreiheit, cit. nota $n^{\circ} 58$, p. 245 s.; en principio también VERREL, Die Selbstbelastungsfreiheit, cit. nota $\mathrm{n}^{\circ} 58$, quien sin embargo también asegura que el principio nemo tenetur no es lesionado por "negociar rebajas penales", "en tanto haya un ejercicio general, o incluso previsiones legales expresas que hagan honor a los comportamientos reparadores implicados en confesiones o reconocimientos de culpa", ya que "la presión sobre la libertad de aceptación" también se da entonces "sin un compromiso regulado de servicio y contraprestación" (p. 52 s.).

67 Cfr. KUCKEIN, "Zur Verwertbarkeit", cit. nota $\mathrm{n}^{\circ}$ 57, p. 70 s.; KUCKEIN, Jürgen; PFISTER, Wolfgang, "Verständigung im Strafverfahren - Bestandaufnahme und Perspektiven -“, en: GEIß, 
Polít. crim., Vol. 4, $\mathrm{N}^{\circ} 7$ (Julio 2009) Art. 1, pp. 1-56.

[http://www.politicacriminal.cl/Vol_04/n_07/Vol4N7A1.pdf]

el representante de la Fiscalía luego de haber sido hecha la confesión ya no se siente ligado al acuerdo porque el acusado expresa que no puede afirmar en forma vinculante que va a aceptar la sentencia? ${ }^{68}$ Respecto de tales casos de fracaso "inconsciente" del acuerdo la jurisprudencia no es unánime. El BGH por ejemplo en el caso de un disenso entre acusado y Fiscalía consideró adecuada - como compensación por la infracción a los principios del juicio justo - la prohibición de utilización respecto de la confesión que el acusado también había brindado en relación con hechos conexos que estaban fuera del proceso en cuestión. ${ }^{69}$ Por el contrario, el BGH decidió en otro caso (en el que el acuerdo fracasó porque había tenido lugar en forma no permitida por no haber participado la Fiscalía), que no se había conformado ninguna situación de confianza que hiciera que la aceptación - necesariamente no vinculante - tuviera que ser sostenida o que la confesión no pudiera ser utilizada, ya que el acuerdo habría tenido lugar "fuera del procedimiento descrito en BGHSt 43, 193." ${ }^{\circ}$ Este punto de vista aparece, sin embargo, algo problemático, dado que por un lado debe reflexionarse si la conducta del tribunal no debe ser valorada como engaño en el sentido del $§ 136$ a I. ${ }^{71}$ Por otro lado, el acusado carga así con todo el riesgo de un fracaso, aun cuando los requisitos para la validez del acuerdo no pudieron ser conocidos por él, por lo menos no cuando no tiene defensa o cuando es defendido en forma deficiente - a diferencia del Tribunal o la Fiscalía, que sí conocían los requisitos de validez del acuerdo. ${ }^{72}$

\subsubsection{Destinatarios.}

El $\S 136$ a tiene como objetivo la protección de la libertad de decisión y de acción "del inculpado", pero es aplicable del mismo modo a los testigos y peritos (§ 69 III, § 72). Las autoridades de persecución penal, en especial la policía, son los destinatarios

Karlmann et al. (Coord.), Festschrift aus Anlaß des fünfzigjährigen Bestehens von Bundesgerichtshof, Bundesanwaltschaft und Rechtsanwaltschaft beim Bundesgerichtshof, Köln et al.: Carl Heymanns, 2000, p. 641-661, p. 652, quienes se refieren a BVerfG, NStZ, (1987), p. 419.

${ }^{68}$ BGH, NStZ, (2008), p. 416, donde, sin embargo, la cuestión de la utilización de la confesión es dejada sin respuesta.

${ }^{69} \mathrm{BGH}$, NJW, (1996), p. 3018 = BGH 42, 191, 194. En este sentido también JAHN, Beweiserhebungs- und Beweiserverwertungsverbote, cit. nota $\mathrm{n}^{\circ} 1, \mathrm{C} 74$ sobre la base de su teoría de las facultades probatorias (sobre esto infra nota $\mathrm{n}^{\circ} 188$ y texto).

${ }^{70} \mathrm{BGH}, \mathrm{St} V,(2003)$, p. 481.

71 Así SCHLOTHAUER, Reinhold, “Anmerkung zu BGH, Urt. v. 7.5.2003 - 5 StR 556/02 (LG Hamburg)", StV, (2003), pp. 481-483, con la fundamentación de que el principio de que sólo una deformación consciente de la verdad conlleva la prohibición de utilización, no es aplicable a cuestiones de derecho. El acusado tiene más bien un derecho a la corrección de las informaciones jurídicas, en especial respecto del Tribunal interviniente (p. 482 s.); confirm esta idea KÜHNE, Strafprozessrecht, cit. nota $n^{\circ} 4$, $\S 47$, nm. 749 en nota 25.

${ }^{72}$ Similar BEULKE, Strafprozessrecht, cit. nota n 13, nm. 396a; SCHLOTHAUER, “Anmerkung zu BGH v. 7.5.2003”, cit. nota $n^{\circ} 71$, p. 482. Para la prohibición de utilización también KÜHNE, Strafprozessrecht, cit. nota $\mathrm{n}^{\circ} 4, \S 47$, nm. 749; KÖLBEL, "Geständnisverwertung", cit. nota $\mathrm{n}^{\circ}$ 58, p. 236 s., quien ve la prohibición de utilización como modo de eliminar las consecuencias de que el Estado - en caso de fracaso del acuerdo - sin motivo legítimo haya influido en la libre voluntad del acusado y así haya creado un estado de información no permitido; otra opinión KUCKEIN, "Zur Verwertbarkeit", cit. nota n 57, p. 71, si bien con la indicación de que la condena generalmente no podrá basarse únicamente en tal confesión, dada la crítica dignidad de una confesión alcanzada en el contexto de un acuerdo. 
AMBOS, Kai. "Las prohibiciones de utilización de pruebas en el proceso penal alemán - fundamentación teórica y sistematización”.

primordiales de la norma, puesto que se trata del "interrogatorio"73 dentro del proceso de investigación penal. ${ }^{74}$ Aquellos no deben permitir que los métodos prohibidos de interrogación sean realizados por ellos mismos, ni a través de otros. ${ }^{75}$ El traslado de imputados a Estados con leyes y prácticas menos severas no interrumpe, en principio, el nexo de imputación, pues el $\S 136$ a es parte de un estándar mínimo jurídico-estatal, ${ }^{76}$ cuya violación - independientemente del lugar de producción de la prueba ${ }^{77}$ - hace imposible una utilización de tales pruebas por tribunales de un Estado de Derecho, como es el caso de Alemania. ${ }^{78}$ Esto también se infiere de una situación legal paralela respecto a posibles infracciones de la Convención Europea de Derechos Humanos en terceros Estados: si un Estado Parte de la Convención expulsa o extradita personas a terceros Estados que violan los derechos humanos, estas violaciones deben ser imputadas a este Estado Parte. $^{79}$

En caso de investigaciones sin orden o fundamento oficial - por terceros particulares o por el defensor - el nexo de imputación se encuentra en principio interrumpido y por ende no resulta admisible un efecto personal del $\S 136$ a frente a terceros ni tampoco una prohibición de utilización de pruebas; ${ }^{80}$ sin embargo, esto tampoco debe resultar en una elusión del $\S 136$ a. Imagínese el caso en el cual el investigador privado contratado por la víctima o sus parientes golpea al inculpado hasta que éste confiesa. ¿No debería en este caso tener validez - al menos en forma análoga - el $\S 136$ a en beneficio del inculpado maltratado, ${ }^{81}$ como ocurre en todos los casos de infracción contra la dignidad humana ${ }^{82} \mathrm{o}$

\footnotetext{
${ }^{73}$ De conformidad con el BGH, BGHSt. (Gran Sala) 42, pp. 139 ss., p. 145 pertenece al "concepto de interrogatorio en el sentido de la StPO (...), que ante la declaración de la persona que otorga la información (...) se presente en función oficial y en esa condición obtenga de ella su información (una 'declaración')" (refiriéndose a BGHSt 40, pp. 211 ss., p. 213 y más referencias). Ver sobre ello también OTTO, "Grenzen und Tragweite", cit. nota $\mathrm{n}^{\circ}$ 2, p. 299.

${ }^{74}$ OLG Oldenburg, $N J W,(1953)$, p. 1237.

${ }^{75}$ MEYER-GOßNER, Strafprozessordnung, cit. nota ${ }^{\circ}$ 52, § 136a nm. 2.

${ }^{76}$ Sobre este estandar SCHUSTER, Verwertbarkeit, cit. nota $\mathrm{n}^{\circ} 18$ p. 122 ss.; recientemente también ESSER, Robert "Verurteilung aufgrund von Aussagen anonymer Zeugen (Besprechung von EGMR vom 17.11.2005 - Haas/Deutschland)", NStZ, (2007), pp. 106-109, p. 108.

${ }^{77}$ Fundamental sobre la utilización de pruebas producidas en el exterior SCHUSTER, Verwertbarkeit, cit. nota $\mathrm{n}^{\circ} 18$, p. 83 ss., 142 ss.

${ }^{78}$ En el mismo sentido OLG Hamburg, NJW, (2005), p. 2326 s., Leitsatz (parte resolutiva) 3, en favor de una aplicación del § 136a por analogía a la práctica extranjera de pruebas.

${ }^{79}$ Cfr. AMBOS, Kai, Internationales Strafrecht, 2. ed. München: Beck, 2008, § $10 \mathrm{~nm} .62,81 \mathrm{ss}$. Sobre el CEDH y el PIDCP como parte del estándar mínimo mencionado ver SCHUSTER, Verwertbarkeit, cit. nota $\mathrm{n}^{\circ} 18$, p. 123 ss.

${ }^{80}$ Fundamental BOCKEMÜHL, Jan, Private Ermittlungen im Strafprozeß: ein Beitrag zu der Lehre von den Beweisverboten, Baden-Baden: Nomos Verl.-Ges, 1996; ver también MEYER-GOßNER, Strafprozessordnung, cit. nota $\mathrm{n}^{\circ} 52, \S 136 \mathrm{~nm}$. 3; BEULKE, Strafprozessrecht, cit. nota $\mathrm{n}^{\circ} 13, \mathrm{~nm} .478$; KINDHÄUSER, Strafprozessrecht, cit. nota $n^{\circ} 34, \S 23 \mathrm{~nm} .33$.

${ }^{81}$ En este sentido al parecer también VOLK, Grundkurs, cit. nota ${ }^{\circ} 25, \S 9 \mathrm{~nm} .17$, así como JAHN, Beweiserhebungs- und Beweiserverwertungsverbote, cit. nota $\mathrm{n}^{\circ}$ 1, C 102 s. ("efecto terciario horizontal"), 127.

${ }^{82}$ OTTO, "Grenzen und Tragweite", cit. nota n ${ }^{\circ}$ 2, p. 299; SENGE, en Karlsruher Kommentar, cit. nota ${ }^{\circ}$ 1, antes del $\S 48 \mathrm{~nm}$. 52; BEULKE, Strafprozessrecht, cit. nota ${ }^{\circ}$ 13, nm. 479; FINGER, "Prozessuale Beweisverbote", cit. nota n ${ }^{\circ} 13$, p. 537.
} 
Polít. crim., Vol. 4, $\mathrm{N}^{\circ} 7$ (Julio 2009) Art. 1, pp. 1-56.

[http://www.politicacriminal.cl/Vol_04/n_07/Vol4N7A1.pdf]

de un comportamiento extremo en violación de los derechos humanos? ${ }^{83}$ ¿No es la obligación de un Estado de Derecho impedir ataques como éstos en contra del imputado $?^{84}$ Otros pretenden con ello argumentar que si la utilización de pruebas fuese presentada como nueva se reiteraría la violación legal ${ }^{85}$, lo que sería cierto si el Estado se apropiara de pruebas que vulneran los derechos humanos. Así se reanudaría el nexo de imputación que posiblemente se interrumpió anteriormente. ${ }^{86}$ Entonces deben volver a valer, en definitiva, también los principios de un proceso justo, con los cuales la utilización de medios de prueba obtenidos delictivamente - sin importar por parte de quién - no puede ser compatible. ${ }^{87}$ Respecto al riesgo de elusión, es obvio que este también se debe atacar con una prohibición de utilización probatoria, si el particular ha sido contratado por las instancias estatales de investigación. ${ }^{88}$

\subsubsection{Ardid o Engaño.}

Son problemáticos en igual medida los casos en los que se manipula al inculpado por medio de ardid o engaño, a fin que tome parte en el procedimiento penal o en su propia condena. Son de relevancia particular "los casos de espionaje acústico": la policía arregla una conversación telefónica entre el imputado y una tercera persona (confidente policial, testigo, etc.) y la graba. Este método se asemeja al "caso del espía en la celda" en el que un informante, luego de recibir instrucción policial, es introducido en la celda del imputado para obtener así una confesión que posteriormente será introducida al juicio oral a través del interrogatorio del informante. Si bien parece tratarse de todas formas de un engaño en el sentido del $\S 136 a$ (análogamente) - lo que el mismo el término sugiere "Hörfalle" ("celada o emboscada auditiva") - la jurisprudencia permite su utilización y construye numerosos argumentos en este campo. ${ }^{90}$ Por una parte, la obligación de advertencia sobre el derecho a no declarar contenida en el artículo § 136 se propone solamente crear un "contrapeso" al interrogatorio practicado por las autoridades oficiales, y un contrapeso de tal naturaleza no es necesario en la actividad de los particulares. ${ }^{91}$ Por otra parte, el concepto de "engaño" debe ser expuesto en el contexto del $\S 136 \mathrm{a}$ en un

\footnotetext{
${ }^{83}$ ROXIN, Strafverfahrenstrecht, cit. nota ${ }^{\circ} 34, \S 24$ nm. 48; KINDHÄUSER, Strafprozessrecht, cit. nota $\mathrm{n}^{\circ}$ 34, § 23 nm. 35; también MURMANN, "Über den Zweck", cit. nota n 6, nm. 223; crít. JÄGER, Beweisverwertung und Beweisverwertungsverbote, cit. nota $\mathrm{n}^{\circ} 15$, pp. $223 \mathrm{ss}$.

${ }^{84}$ Así HASSEMER, Winfried; MATUSSEK, Karin, Das Opfer als Verfolger : Ermittlungen des Verletzten im Strafverfahren, Frankfurt am Main: Lang, 1996, p. 77.

${ }^{85}$ VOLK, Grundkurs, cit. nota n ${ }^{\circ} 25, \S 28$ nm. 35.

${ }^{86}$ Sobre la "utilización indirecta o mediata" por el Estado, véase también KÜHNE, Strafprozessrecht, cit. nota $\mathrm{n}^{\circ} 4$, nm. 904 p. 459.

87 Véase también MURMANN, “Über den Zweck", cit. nota $\mathrm{n}^{\circ}$ 6, nm. 224. Sobre el significado del proceso justo véanse también las resoluciones $-\mathrm{y}$ sus votos - de la reciente $D J T$, cit. nota $\mathrm{n}^{\circ} 19, \mathrm{Nr} .1 \mathrm{~b}$ ) (mayor respeto a los principios constitucionales del proceso justo 42:23:11 votos) así como 9 b) (33:17:15 votos), según la cual una prohibición de utilización también debe ser reconocida "cuando de otro modo los principios del proceso justo" serían lesionados. Sin embargo, la lesión de estos principios no debe hacer inutilizables los resultados obtenidos por personas privadas (solicitud correspondiente $12 \mathrm{~b}$ ) rechazada con 25:35:4 votos).

${ }^{88}$ Por todos KINDHÄUSER, Strafprozessrecht, cit. nota ${ }^{\circ} 34, \S 23 \mathrm{~nm} .34$ con más referencias.

${ }^{89}$ BGHSt 34, 362.

${ }^{90}$ Fundamental BGHSt (Gran Sala) 42, 139; crítico VOLK, Grundkurs, cit. nota n ${ }^{\circ} 25, \S 9$ nm. 19 ss.

91 BGHSt 42, 139, 145 ss.; antes ya OTTO, “Grenzen und Tragweite”, cit. nota n 2, p. 295; igualmente FINGER, "Prozessuale Beweisverbote", cit. nota n' 13, p. 536.
} 
AMBOS, Kai. "Las prohibiciones de utilización de pruebas en el proceso penal alemán - fundamentación teórica y sistematización”.

sentido estricto, no aplicándose por ende a los casos mencionados. ${ }^{92}$ La StPO no prohíbe ninguna actuación encubierta o secreta en el marco de la investigación penal. ${ }^{93} \mathrm{El}$ principio de "nemo tenetur" protege ante la coacción para colaborar en el proceso penal, pero no ante un error sobre el derecho de guardar silencio, aun cuando esta equivocación sea provocada por el Estado. ${ }^{94} \mathrm{Si}$ bien existen limitaciones constitucionales en la utilización de personas particulares para la lucha contra el crimen - estando por ejemplo prohibida la iniciación de una relación amorosa con el fin de obtener informaciones ("casos Romeo") - ${ }^{95}$, debe practicarse finalmente una ponderación de acuerdo con el principio de proporcionalidad, con especial consideración al modo y a la intensidad de la provocación estatal y a la gravedad de los delitos en cuestión. ${ }^{96}$ En particular, el Tribunal Supremo Federal $(\mathrm{BGH})$ determina al respecto lo siguiente:

"En caso de que una persona particular haya tenido, por iniciativa de las autoridades de investigación, una conversación con el sospechoso sin revelar las intenciones de averiguación, cuyo objetivo ha sido la obtención de informaciones referentes al objeto de la investigación, puede utilizarse el contenido de la conversación como prueba testimonial, siempre y cuando se trate del esclarecimiento de un delito de considerable importancia cuya averiguación hubiera sido mucho menos prometedora y esencialmente más difícil si se hubiesen utilizado otros métodos de investigación." 97

El Tribunal Supremo aceptó posteriormente una prohibición de utilización, en un caso en el cual se designó a una reclusa en detención preventiva como "adivina", con el fin de arrancar confesiones escritas de sus codetenidos, entre otras formas, por medio de promesas de una sentencia más benigna. ${ }^{98}$ Además del ya mencionado "caso del espía introducido en la celda", se infiere un principio general, según el cual entra en consideración una prohibición de utilización cuando existe un perjuicio a la libertad de autoincriminación del imputado que va más allá del carácter secreto de la averiguación. La diferencia entre los casos de espionaje acústico (normales) y la "Hörfalle", está en el hecho de que en esta última el imputado además se encuentra en una situación forzada (detención preventiva) y se convierte por ende, debido a la privación de libertad, en mero objeto del proceso. ${ }^{99} \mathrm{Si}$ con el agente infiltrado se provoca además un hecho delictivo, se parte de acuerdo con el Tribunal Europeo de Derechos Humanos de un proceso que

92 BGHSt 42, 149; a favor de una interpretación estricta parcialmente también la literatura, cfr. MURMANN, "Über den Zweck", cit. nota n 6, nm. 228 con más referencias.

${ }^{93}$ BGHSt 42,149 ss.

${ }_{95}^{94}$ BGHSt 42, 151, 153. Cfr. con más detalle infra 3.2.3.e (1) con nota 282 ss. y texto principal.

${ }^{95}$ BGHSt 42, 154 s.

${ }^{96}$ BGHSt 42, 155 ss. Véase sobre esto infra nota 170.

${ }^{97}$ BGHSt 42, 139 (Leitsatz - parte resolutiva -). Véase también resolución DJT, cit. nota n ${ }^{\circ}$ 19, Nr. 12 c) bb), según la cual resultados de investigaciones llevadas adelante por personas privadas también deberían ser utilizables aunque aquellos hayan sido obtenidos por medios ilegales (Sección Derecho Penal, V. 12. c) bb), p. 14; la propuesta respectiva, que preveía la prohibición de utilización en dichos casos, fue rechazada por 24:28 votos ( 9 abstenciones).

${ }_{98}$ BGHSt 44, p. 129.

${ }^{99}$ Cfr. JÄGER, Beweisverwertung und Beweisverwertungsverbote, cit. nota $\mathrm{n}^{\circ}$ 15, pp. 184, 186 y passim; también KÜHNE, Strafprozessrecht, cit. nota $\mathrm{n}^{\circ} 4$, nm. 904, p. 459; FINGER, "Prozessuale Beweisverbote", cit. nota $\mathrm{n}^{\circ}$ 13, p. 537; MURMANN, "Über den Zweck", cit. nota $\mathrm{n}^{\circ}$ 6, nm. 227; en el resultado igualmente FEZER, Gerhard, Strafprozessrecht, 2. ed., München: Beck, 1995, p. 222. 
Polít. crim., Vol. 4, $\mathrm{N}^{\circ} 7$ (Julio 2009) Art. 1, pp. 1-56.

[http://www.politicacriminal.cl/Vol_04/n_07/Vol4N7A1.pdf]

"desde el principio y definitivamente"100 es injusto (violatorio del principio de igualdad de armas y del debido proceso), y se deduce una amplia prohibición de utilización de prueba. ${ }^{101}$ En los así llamados "casos de voz" - en los cuales se graba secretamente la voz del inculpado para un cotejo posterior -, la violación (punible) del derecho individual (violación del secreto de la palabra, § 201 del Código Penal - Strafgesetzbuch, StGB) conduce finalmente a una prohibición de utilización. ${ }^{102}$

En conjunto, esta jurisprudencia es inconsecuente e inconsistente. En un caso de espionaje acústico se lleva a quien hasta ahora es sospechoso, o al ya inculpado, a una autoincriminación, encontrándose éste en un error sobre el carácter de interrogatorio del diálogo; en consecuencia el imputado es engañado. ${ }^{103}$ Por esta razón se ha de aplicar independientemente de la existencia de un interrogatorio formal y de un eventual nexo de causalidad entre la actuación del particular y las autoridades de persecución penal - en cualquier evento y de forma correspondiente el $\S 136 \mathrm{a}$, y se ha de prohibir la utilización probatoria. En todo caso se ha de presumir un nexo de imputación, si el particular es introducido, o dispuesto conscientemente ${ }^{104}$, con el fin de sonsacar al imputado una declaración o una confesión. Aún cuando se niegue la existencia de engaño entra en consideración una infracción contra la obligación de instrucción previa del $\S 136$ (análogamente a cuando se rechaza un "interrogatorio"), con la consecuencia de una prohibición de utilización (explicada más detalladamente en el ap. 3.2.3.e (2)), pues el $\S$ 136 también protege ante la autoincriminación condicionada por el error (provocada por el Estado). ${ }^{105}$ Tampoco puede ser decisivo el nexo de imputación si se invade el campo

100 Teixera de Castro vs. Portugal, sentencia del 9 de junio de 1998, ap. 39; crít. sobre el BGH y su “enfoque de la adecuación a los fines" en la provocación del hecho WOLTER, Jürgen, "Beweisverbote und Umgehungsverbote zwischen Wahrheitsforschung und Ausforschung”, en: GEIß, Karlmann et al. (Coord.), Festschrift aus Anlaß des fünfzigjährigen Bestehens von Bundesgerichtshof, Bundesanwaltschaft und Rechtsanwaltschaft beim Bundesgerichtshof, Köln et al.: Carl Heymanns, 2000, pp. 963-1010, pp. 979 ss.

${ }^{101}$ Cfr. ya AMBOS, Kai, "Europarechtliche Vorgaben für das deutsche Strafverfahren", NStZ, (2002), pp. 628-633, p. 632, con más referencias; en particular, igualmente JÄGER, Beweisverwertung und Beweisverwertungsverbote, cit. nota $\mathrm{n}^{\circ} 15$, p. 207 ss. con más referencias.

102 BGHSt 34, 39; igualmente KINDHÄUSER, Strafprozessrecht, cit. nota n ${ }^{\circ} 34, \S 23 \mathrm{~nm}$. 34; JOERDEN, Jan C., "Verbotene Vernehmungsmethoden - Grundfragen des $\S 136$ a StPO”, JuS, (1993), pp. 927-931, p. 928; en particular también JÄGER, Beweisverwertung und Beweisverwertungsverbote, cit. nota $n^{\circ} 15$, pp. 174 ss., p. 190 s.; de otra opinión FINGER, "Prozessuale Beweisverbote", cit. nota n 13, 538 alegando soprendentemente, sin embargo, que hoy no se puede confiar más en la confidencialidad de la conversación telefónica, pues “muchos teléfonos contienen aparatos de escucha y de grabación”, ¡Pero la protección de los derechos fundamentales no puede depender del nivel técnico o del ámbito fáctico de intervención (en este caso: espionaje telefónico)!

${ }^{103}$ De igual resultado JÄGER, Beweisverwertung und Beweisverwertungsverbote, cit. nota $\mathrm{n}^{\circ} 15$, pp. 169 ss. con una delimitación (complicada) en relación con la astucia permitida; también KÜHNE, Strafprozessrecht, cit. nota $\mathrm{n}^{\circ}$ 4, nm. 896; OTTO, "Grenzen und Tragweite", cit. nota $\mathrm{n}^{\circ}$ 2, pp. 296 ss.

${ }^{104}$ La doctrina tiende a exigir demasiado en cuanto al nexo de imputación, cfr. VOLK, Grundkurs, cit. nota $\mathrm{n}^{\circ} 25, \S 28 \mathrm{~nm} .36$; BEULKE, Strafprozessrecht, cit. nota $\mathrm{n}^{\circ} 13$, nm. 481 ("seleccionadas por las autoridades de persecución penal"), $481 \mathrm{~g}$ ("selectivamente introducidos en una investigación concreta"); véase sobre esto el criterio de imputación formulado por la Corte Europea de DDHH en el caso Allan vs Gran Bretaña en el contexto del principio nemo tenetur: en este capítulo ap. 3.2.3.e.

${ }^{105}$ ROXIN, Strafverfahrenstrecht, cit. nota ${ }^{\circ} 34, \S 24 \mathrm{~nm} .30$; BEULKE, Strafprozessrecht, cit. nota $\mathrm{n}^{\circ} 13$, nm. 481g; en particular, igualmente JÄGER, Beweisverwertung und Beweisverwertungsverbote, cit. nota $\mathrm{n}^{\circ}$ 15 , p. 184, quien deduce del $\S 136$ un mandato formalizado de un interrogatorio estatal y lo ve violado. En detalle infra 3.2.3.e. 
AMBOS, Kai. "Las prohibiciones de utilización de pruebas en el proceso penal alemán - fundamentación teórica y sistematización".

íntimo intangible del imputado con la medida procesal (más detalladamente en ap. 3.3.). ${ }^{106}$ Así también es dudoso si la interpretación estricta del BGH respecto del ámbito de protección del principio nemo tenetur es compatible con la jurisprudencia de la $\mathrm{CEDH}$. El 3er. Senado del BGH manifestó en este sentido dudas fundadas, sin embargo en el caso concreto dejó la cuestión abierta. ${ }^{107}$ Volveremos sobre este punto en el marco de la discusión de las investigaciones secretas (infra 3.2.3.e).

\subsection{Vigilancia de telecomunicaciones y grabaciones secretas.}

Desde el punto de vista de los conocimientos que han sido obtenidos inesperadamente o casualmente a partir de la interceptación de telecomunicaciones (los así denominados hallazgos casuales), el $\S 100$ b V contiene una regla que la jurisprudencia hasta el día de hoy seguía y a la que hacía referencia ${ }^{108}$, relativa a si esos conocimientos son necesarios para la averiguación de los delitos catalogados que habilitan la intercepción. Esta regla ahora se encuentra modificada en el $\S 477$ 2do. ap., 2da. oración, según el cual los datos obtenidos mediante medidas de vigilancia sin autorización del afectado "pueden ser utilizados en otros procedimientos solo para el esclarecimiento de aquellos delitos para cuya determinación hubiera podido ser ordenada tal medida de acuerdo a esta ley". Con respecto a esto, el $\S 1612$ do. ap. limita (en el caso que no exista autorización) la utilización de datos personales obtenidos "de acuerdo a otras leyes" a los casos en los cuales la obtención de los datos hubiera sido permitida "de acuerdo a esta ley". Por tanto en ambos casos se debe examinar (precisamente en el sentido de la teoría del curso causal hipotético de investigación), si la medida hubiera podido ser ordenada de acuerdo con la StPO, diferenciando la utilización de datos "en otros procedimientos penales" de acuerdo con el $\S 4772$ do. ap., 2da. oración y de datos obtenidos "de acuerdo con otras leyes" según el $\S 1612$ do. ap. ${ }^{109}$

Con ello, una utilización es inadmisible para la averiguación sobre hechos delictivos no contenidos en el catálogo del $\S 100$ a y por supuesto también es inadmisible en caso de que la medida de antemano sea materialmente ilegal (véase el ap. 3.2.3.c.). ${ }^{110}$ Sin embargo, la jurisprudencia flexibiliza esta interpretación literal y restringida de la ley. Por una parte, puede ser admisible una utilización de los conocimientos relacionados con hechos delictivos que no aparecen en el catálogo cuando estos se encuentran en relación (procesal) directa o estrecha con un hecho taxativamente catalogado. ${ }^{111}$ Por otro lado, una

\footnotetext{
${ }^{106}$ BEULKE, Strafprozessrecht, cit. nota ${ }^{\circ} 13$, nm. 480.

${ }^{107}$ BGH, NJW (2007), pp. 3138 ss.: "Estas consideraciones de la CEDH podrían dar motivo a examinar, con vistas a otros casos posibles, si la determinación - aparentemente restrictiva - del alcance del principio nemo-tenetur dada por el Gran Senado para asuntos penales puede ser sostenida y cuáles consecuencias se darían para casos del tipo del que se dio en el proceso inicialmente puesto a juzgamiento." (p. 3140).

${ }^{108}$ BGH 26, pp. 298 ss., p. 303; BGH 31, pp. 296 ss., p. 301.

109 Cfr. KNIERIM, Thomas, "Fallrepetitorium zur Telekommunikationsüberwachung nach neuem Recht", StV, (2008), pp. 599-606, p. 601 s.

${ }^{110}$ En general también BGH NStZ 2003, p. 499.

111 BGH, NStZ (1998), p. 426; OLG Düsseldorf, NStZ, (2001), p. 657. Según BVerfG, NJW, (2005), p. 2766 sin reparos constitucionales. Ver también ALLGAYER, Peter, "Die Verwendung von Zufallserkenntnissen aus Überwachungen der Telekommunikation gem. §§ 100af. StPO (und anderen Ermittlungsmaßnahmen)", NStZ, (2006), pp. 603-608, p. 604 con más referencias.
} 
Polít. crim., Vol. 4, $\mathrm{N}^{\circ} 7$ (Julio 2009) Art. 1, pp. 1-56.

[http://www.politicacriminal.cl/Vol_04/n_07/Vol4N7A1.pdf]

prohibición de utilización no debería excluir que se continúe la investigación con base en los conocimientos obtenidos casualmente, para así llegar a conseguir otros medios probatorios (el denominado "rastreo de huellas" - Spurenansatz). Esto significa que no se atribuye un efecto reflejo a la prohibición de utilización. ${ }^{112}$ Esto es preocupante, pues si se permite la utilización de conocimientos obtenidos ilegalmente para investigaciones posteriores, se provoca el desprecio de los presupuestos (materiales) requeridos precisamente para la vigilancia de las telecomunicaciones. ${ }^{113}$

Con respecto a los informes sobre los datos vinculados a las telecomunicaciones ( $\$$ $100 \mathrm{~g}$ ), el anterior $\S 100 \mathrm{~h}$ III también limitaba la utilización de conocimientos en otros procesos penales que sirven a la averiguación de delitos catalogados ( $\$ 100 \mathrm{~g}$ I 1); ahora esto también se desprende del (recién mencionado) $§ 477,2$ do. ap., 2da. oración. ${ }^{114}$ Con referencia a las denominadas escuchas intensivas encubiertas (Lauschangriff) se debe distinguir entre la escucha en domicilios particulares (el así llamado gran Lauschangriff, $\S \S 100 \mathrm{c}, \mathrm{d})^{115}$, y en instalaciones que no son privadas (el así llamado pequeño Lauschangriff, $\S 100$ s.). Las informaciones obtenidas a partir de las escuchas menos intensivas (pequeño Lauschangriff) pueden ser utilizadas en otros procedimientos de hechos punibles únicamente si se trata de la averiguación de delitos catalogados en el $\S 100$ a $\left(\S 477\right.$ II). ${ }^{116}$ En lo que concierne a las escuchas de mayor intensidad (el gran Lauschangriff), el Tribunal Constitucional Federal declaró la regulación legal anterior parcialmente inconstitucional por violación del art. 13 en relación con el art. 11 de la Grundgesetz. (Ley Fundamental o Constitución alemana), exigiendo, entre otros requisitos, una protección absoluta del "núcleo de la vida privada", así como una correspondiente prohibición de utilización. ${ }^{117}$ A efectos del cumplimiento de dicha sentencia, el legislador ${ }^{118}$ excluye explícitamente este campo esencial de la vigilancia (\$ 100c IV 1). Hay que interrumpir las respectivas medidas de vigilancia inmediatamente (\$ 100c V 1), anular las respectivas grabaciones $(\S 100 \mathrm{c} V 2)$, no debiéndose usar los respectivos conocimientos $(\$ 100 \mathrm{c} V 3)$. Siguiendo otra decisión del Tribunal Constitucional que ve lesionado el núcleo de la vida privada por la vigilancia preventiva de las telecomunicaciones de acuerdo al § 33a I Niedersächsisches Gesetz über die

112 BGHSt 27, 355, 358; 32, 68, 70; asimismo BVerfG, NJW, (2005), p. 2766; más restrictivo OLG Karlsruhe, $N J W$, (2004), 2687. De la misma opinión ALLGAYER, “Die Verwendung”, cit. nota n 111, p. 608 con más referencias, "quien únicamente pretende prohibir una utilización como base inicial para una investigación cuando está expresamente establecida una prohibición de utilización, y no sólo una prohibición en consideración al medio probatorio."

${ }^{113}$ Crítico también VOLK, Grundkurs, cit. nota ${ }^{\circ} 25, \S 10$ nm. 47; BEULKE, Strafprozessrecht, cit. nota $\mathrm{n}^{\circ} 13, \mathrm{~nm} .476$.

$114 \S 477$ II reúne las regulaciones individuales anteriores, siguiendo a la jurisprudencia del BGH sobre el $\S$ 100a (MEYER-GOßNER, Strafprozessordnung, cit. nota $\mathrm{n}^{\circ}$ 52, § 477, nm. 5; BT-Drucks. 16/5846, p. 66).

115 Desde el punto de vista empírico ver MEYER-WIECK, Hannes, Der große Lauschangriff, Berlin: Duncker \& Humblot, 2005. Según esta investigación la medida tiene una aplicación y también un efecto limitado (ver también HEGHMANNS, Michael, Comentario al libro Der große Lauschangriff de Hannes Meyer-Wieck (Berlin: Duncker \& Humblot, 2005), GA, (2006), pp. 826-828, p. 826).

116 MEYER-GOßNER, Strafprozessordnung, cit. nota $\mathrm{n}^{\circ} 52, \S 100 \mathrm{f}, \mathrm{nm} .21, \S 477$, nm. 5 ss; véase cit. nota $\mathrm{n}^{\circ} 114$.

${ }^{117}$ BVerfG 109, $279=$ NJW, (2004), 999; a favor VOLK, Grundkurs, cit. nota n ${ }^{\circ} 25, \S 10$ nm. 51.

118 "Gesetz zur Umsetzung des Urteils des BVerfG", BGB1. 2005 I p. 1841, modificando los $\S \S 100 \mathrm{c}-\mathrm{f}$ StPO. 
AMBOS, Kai. "Las prohibiciones de utilización de pruebas en el proceso penal alemán - fundamentación teórica y sistematización”.

öffentliche Sicherheit und Ordnung (Nds. SOG = Ley de seguridad y orden públicos de Baja Sajonia) - y por tanto la considera inconciliable con el Art. 10 GG (Grundgesetz = Constitución), ${ }^{119}$ el actual $\S 100$ a IV prevé para el caso de avances sobre este ámbito una prohibición de producción y una absoluta prohibición de utilización de pruebas; eventuales grabaciones deben ser borradas inmediatamente. ${ }^{120}$

\subsection{Otras prohibiciones escritas de utilización de pruebas.}

Adicionalmente existen otras prohibiciones explícitas de utilización de pruebas, en especial:

- El uso de extracciones de sangre o de células del cuerpo humano quedan limitadas al respectivo proceso penal ( $(81 \mathrm{a}$ III);

- Las intervenciones corporales y extracciones de sangre practicadas a menores de edad, pueden utilizarse a efectos de un proceso penal posterior únicamente con el consentimiento del representante legal ( $\$ 81 \mathrm{c}$ III frase 5);

- Los datos personales obtenidos que sean grabados a través de medios mecánicos, tienen restricción para su utilización "en otros procesos penales" (Art. 98b III frase 3 anterior, ahora $\S 477$ II);

- No se permite la utilización de objetos vinculados a una interrupción de embarazo, encontrados en un consultorio médico "con ocasión de un registro" ( $\$ 108 \mathrm{I})$, como prueba en un proceso penal contra la paciente por este hecho ( $\$ 108$ II);

- Las informaciones personales, obtenidas por medio de un agente encubierto, se deben utilizar en otros procesos penales solamente en referencia a delitos contenidos en el $\S$ 110 a I ( $\$ 110$ e anterior, ahora $\S 477$ II 2, 3).

Es digno de mención el $\S 252$, según el cual un testigo informado sobre su derecho a negarse a declarar ( $§ 52-53 \mathrm{a}$, véase el 3.2.2.), puede hacer uso de ese derecho dentro de

\footnotetext{
${ }^{119}$ BVerfGE 113, 348 (pp. 375 ss, pp. 390 ss.).

$120 \mathrm{La}$ reforma se basa en un proyecto del Gobierno Federal "Gesetz zur Neuregelung der Telekommunikationsüberwachung und anderer verdeckter Ermittlungsmaßnahmen sowie zur Umsetzung der Richtlinie 2006/24/EG” del 18.4.2007 („Ley sobre la nueva regulación de la vigilancia de las telecomunicaciones y otra medidas investigativas encubiertas así como sobre la aplicación de la directiva 2006/24/EG“) (BT-Drucks. 16/5846; véase infra nota 239). La mencionada directiva (Abl. EU L 105/54 del 13.4.2006) se refiere al archivo (de reserva) de datos que son generados o procesados por la puesta a disposición pública de servicios de comunicación electrónica o por redes de comunicación públicas. Crít. respecto del Proyecto de ley WOLTER, Jürgen, "Alternativen zum Regierungs-Entwurf 2007 zur Neuregelung der Ermittlungsmaßnahmen”, GA, (2007), pp. 183-200, pp. 195 ss., quien a causa de la jurisprudencia constitucional respecto del ámbito nuclear ve como obligatorio el anclamiento de la protección de la dignidad humana en la ley. Cfr. también JAHN, Beweiserhebungs- und Beweiserverwertungsverbote, cit. nota n ${ }^{\circ}$, C 33 s. Crit. KNIERIM, "Fallrepetitorium", cit. nota ${ }^{\circ}$ 109, p. $603 \mathrm{~s}$.
} 
la vista oral, -en cualquier caso cuando las declaraciones incriminan al acusado ${ }^{121}$ - con la consecuencia de que sus declaraciones anteriores ${ }^{122}$ no deben ser "leídas". ${ }^{123}$ En lo referente a la lectura pública de la declaración previa, se trata de una prohibición de utilización escrita, que además es de carácter autónomo, ya que existe independientemente de la legalidad de la producción de pruebas (interrogatorio en la investigación). ${ }^{124}$ Evidentemente, la opinión dominante no solo observa como impedimento la lectura de declaraciones anteriores, sino también aquella utilización en un sentido amplio, específicamente a través del interrogatorio de la persona que lo realizó ${ }^{125}$, siendo controvertido, sin embargo, si no debe ser admisible al menos que se oiga al juez de la investigación penal que participó en el interrogatorio del testigo ( $\$ 162$ ). La jurisprudencia adopta esta postura si el imputado ha sido instruido legalmente, aduciendo como argumento, entre otros, la mayor calidad del interrogatorio judicial frente al interrogatorio realizado por la Fiscalía o la Policía. ${ }^{126}$ Pero esta argumentación no es convincente y es contradictoria. Si no se quiere desistir de la declaración del testigo realizada en la etapa de investigación, únicamente se puede interpretar el $\S 252$ estrictamente en el sentido de una mera prohibición de lectura ${ }^{127}$, pero no se pueden suponer discrepancias cualitativas entre los interrogatorios de los imputados según la persona que haya realizado el interrogatorio. Estas discrepancias hoy en día no existen (cuanto menos en el proceso penal alemán) ni legalmente ${ }^{128}$ ni en la práctica. ${ }^{129} \mathrm{Si}$ la

${ }^{121} \mathrm{Si}$ se entiende prohibiciones de utilización como prohibiciones de cargo (cit. nota $\mathrm{n}^{\circ} 11 \mathrm{y}$ texto principal), declaraciones testimoniales en favor del acusado no pueden ser cubiertas por el $\S 252$ a limine (ROXIN/SCHÄFER/WIDMEIER, "Die Mühlenteichtheorie", cit. nota $n^{\circ} 11$, p. 660; de otra opinión es BVerfG 57, 250, 275).

${ }^{122}$ Informaciones hacia personas privadas así como manifestaciones espontáneas y voluntarias a personas oficiales no están contemplados por el $\S 252$ y son por tanto utilizables (BGH, NStZ, (2008), 585).

${ }^{123}$ Con mayor profundidad VOLK, Grundkurs, cit. nota ${ }^{\circ} 25, \S 27 \mathrm{~nm} .8 \mathrm{ss}$.

${ }^{124}$ Ignorado por FINGER, "Prozessuale Beweisverbote", cit. nota $n^{\circ}$ 13, p. 533 s., quien lo clasifica como prohibición no escrita dependiente. JÄGER, Beweisverwertung und Beweisverwertungsverbote, cit. nota $n^{\circ}$ 15, p. 268 habla de una "prohibición secundaria de práctica de pruebas" ("Zweiterhebungsverbot"). Como aquí ahora MURMANN, "Über den Zweck", cit. nota $\mathrm{n}^{\circ}$ 6, nm. 209; JAHN, Beweiserhebungs- und Beweiserverwertungsverbote, cit. nota $\mathrm{n}^{\circ} 1$, C. 36 .

${ }^{125}$ BEULKE, Strafprozessrecht, cit. nota $\mathrm{n}^{\circ} 13$, nm. 419. Cfr. también recientemente BGH, NStZ, (2007), p. 353: Prohibición de utilización también respecto de un hecho accesorio que manifestó el testigo víctima a un funcionario interviniente.

126 BGHSt 2, 99, 106 ss.; 21, 218, 219; 49, 72, 77; BGH, NStZ, (2007), 652; cfr. BEULKE, Strafprozessrecht, cit. nota $\left.\mathrm{n}^{\circ} 13\right), \mathrm{nm} .465$.

${ }^{127}$ Consecuente JÄGER, Beweisverwertung und Beweisverwertungsverbote, cit. nota $\mathrm{n}^{\circ}$ 15, p. 270.

${ }^{128}$ Anteriormente existía obligación de instrucción únicamente para el interrogatorio judicial en la etapa de investigación penal, pero actualmente dicha prescripción vale también para el interrogatorio policial y el realizado por el Fiscal ( $\S 161$ a I 2, 163a V). La distinción entre interrogatorio judicial y no judicial en el $\S$ 251 I, II y el privilegio del interrogatorio judicial en el $\$ 254$ es únicamente - dada la misma formación del fiscal y del juez y la posibilidad de cambiar entre el puesto de fiscal y juez en varios Estados federales una ficción legal y no afecta en nada a nuestro asunto.

${ }^{129}$ Crítico también BEULKE, Strafprozessrecht, cit. nota ${ }^{\circ} 13, \mathrm{~nm} .420$, pero en favor de una prohibición absoluta; JÄGER, Beweisverwertung und Beweisverwertungsverbote, cit. nota $\mathrm{n}^{\circ} 15$, p. 270 s.; EISENBERG, Beweisrecht, cit. nota $\mathrm{n}^{\circ}$ 4, nm. 1288 (la mayor neutralidad del juez no puede ser fundada con su posición, puesto que "la confiabilidad de la indagatoria" depende "más de la capacidad de la persona oficial que de su posición procesal"); JAHN, Beweiserhebungs- und Beweiserverwertungsverbote, cit. nota $\mathrm{n}^{\circ}$ 1, C. 36; otra opinión presenta sin embargo LESCH, Heiko, "Die Grundsätze der Mündlichkeit und Unmittelbarkeit im Strafverfahren”, JA, (1995), p. 691-703, p. 695 s., así como KÜHNE, Strafprozessrecht, 
AMBOS, Kai. "Las prohibiciones de utilización de pruebas en el proceso penal alemán - fundamentación teórica y sistematización”.

jurisprudencia, por lo demás, permite ${ }^{130}$ que a la persona que ha sido interrogada judicialmente se le pueda poner ante sí el acta procesal del interrogatorio para ayudar a su memoria conforme al $\S 253$, y - tal permiso únicamente contiene una referencia de conjunto al acta de interrogatorio practicado por la Policía o la Fiscalía ${ }^{131}$ - se introduce así en cualquier caso un acto procesal anterior en el juicio oral. ${ }^{132}$ De esta forma se socava la diferenciación entre el interrogatorio judicial y el interrogatorio no judicial, lo que presenta una evidente evasiva al $\S 252^{133}$, por lo menos si se ve en esta norma, de acuerdo a la opinión dominante, algo más que una simple prohibición de lectura. A fin de cuentas, se trata de una ponderación de bienes entre el interés en la persecución penal y la protección del testigo, ${ }^{134}$ con lo cual no se debe omitir que la cita frecuente del $\S 252$, particularmente en los procesos por delitos sexuales en contra de menores, ha reducido la presión en contra del testigo (víctima) ${ }^{135}$, y más aún si se trata del principal testigo de cargo.

Discutible es también la prescindibilidad o disponibilidad del § 252. Según la opinión de la jurisprudencia la lectura de la declaración anterior o la indagatoria de quien fuera antes sujeto interrogado (aún no judicialmente) puede realizarse sin problema alguno cuando el testigo con derecho a no declarar prescinde de este derecho emergente del $\S 252,{ }^{136}$ donde tal declaración de renuncia solo debería ser efectiva cuando es indudable y cuando el testigo tiene en claro que sin su consentimiento la indagatoria en cuestión no es utilizable. ${ }^{137}$ Este punto de vista es, sin embargo, apenas aceptable si se tiene en cuenta que el fin del $\S 252$ no es solo el reconocimiento de la predominancia de los vínculos de parentesco del testigo, sino también el conceder en general un juicio justo, ${ }^{138}$ en el cual la declaración de un testigo, que en la audiencia no puede ser preguntado por la defensa, tampoco pueda ser introducido de ninguna otra manera. Una renuncia al $\S 252$ puede ser, por tanto, admitida en vistas a una declaración anterior solo cuando este testigo pueda ser directamente interrogado sobre las manifestaciones finalmente introducidas. ${ }^{139}$

cit. nota $\mathrm{n}^{\circ} 4, \S 55 \mathrm{~nm} .945$ (“Juez por su función procesal penal, como también por su posición psicológica mediadora de la representación de intereses contrarios de Fiscal y Defensor" y por ello "donde reside la menor sospecha..., de forzar las investigaciones a costa de recortar derechos procesales").

${ }^{130}$ BGH, $N J W$, (2000), p. 1580; StV (2001), p. 386.

${ }^{131}$ Por ejemplo de la siguiente forma: el inculpado hace su declaración ante la Policía o la Fiscalía referente al contenido del interrogatorio del día del juicio oral. Cfr. también FINGER, "Prozessuale Beweisverbote", cit. nota $\mathrm{n}^{\circ} 13$, p. 534.

${ }^{132}$ DIEMER, Karlsruher Kommentar, cit. nota n ${ }^{\circ} 49, \S 252$ nm. 25.

${ }^{133}$ Acertadamente FINGER, "Prozessuale Beweisverbote", cit. nota n 13, p. 534.

${ }^{134}$ Cfr. también BGHSt. 45, 342.

${ }^{135}$ Cfr. RÖSSNER, Dieter, 30 Probleme aus dem Strafprozessrecht, 2. ed., Köln: Luchterhand, 2007, p. 78 s.; antes ya OTTO, "Grenzen und Tragweite", cit. nota n ${ }^{\circ}$ 2, p. 295, quien por ello exige la admisibilidad de la lectura del interrogatorio anterior en causas de tutela de menores (296).

${ }^{136}$ BGH, NStZ, (2007), p. 712 ss, p. 713; BGHSt 45, pp. 203 ss., p. $205=$ NJW, (2000), pp. 596 ss., p. 596 respecto al interrogatorio de un experto; SCHLÜCHTER, Ellen, "§ 252", en: RUDOLPHI, Hans-Joachim; WOLTER, Jürgen (Coord.), Systematischer Kommentar zur Strafprozessordnung und zum Gerichtsverfassungsgesetz, § $252 \mathrm{~nm}$. 22; KÜHNE, Strafprozessrecht, cit. nota n ${ }^{\circ} 4$, § $55 \mathrm{~nm} .943 .3$.

${ }^{137}$ BGH, NStZ, (2007), pp. 712 ss., p. 713; BGH, StV, (2007), pp. 401 ss., p. 402.

${ }^{138}$ Sobre una discusión similar sobre $§ 55$ véase infra $168 \mathrm{~s}$. y texto.

${ }^{139}$ Cfr. también MURMANN, "Über den Zweck", cit. nota n 6, nm. 215 con más referencias. 
Polít. crim., Vol. 4, $\mathrm{N}^{\circ} 7$ (Julio 2009) Art. 1, pp. 1-56.

[http://www.politicacriminal.cl/Vol_04/n_07/Vol4N7A1.pdf]

Problemática es también la admisibilidad en la audiencia principal de la lectura del escrito de un interrogatorio previo. Del principio de inmediatez en su formulación del $\S$ 250 parece desprenderse claramente en este sentido la prevalencia de la prueba personal por sobre la prueba técnica ( $\$ 250,2$ da. oración), incluso cuando el testigo interrogado se manifiesta de acuerdo con la lectura. En este sentido se pronunció también el 4to. Senado del $\mathrm{BGH}$ en contra de una lectura, porque el principio de inmediatez no podría ser restringido por una renuncia del testigo a su derecho a no prestar declaración. ${ }^{140} \mathrm{La}$ tensión que se advierte entre la obligación judicial de esclarecimiento (§ 244 II) y la inmediatez también se pone de manifiesto cuando un testigo hace uso de su derecho de negarse a proveer información (en general) de acuerdo al $\S 55$, y por tanto no puede ser interrogado en la audiencia principal. En esta constelación es discutido, si una lectura puede basarse en el $\S 251$ I Nro.2, porque "el testigo (...) por algún otro motivo no puede ser judicialmente interrogado en un tiempo previsible". Al respecto se discute qué impedimentos deben ser contemplado por esta norma. La opinión dominante considera al $\S 251$ I Nro. 2 aplicable sólo para casos en que el interrogatorio se ve impedido por motivos fácticos, pero no por motivos jurídicos ${ }^{141}$, de modo que la declaración anterior no podría ser considerada cuando se alega el derecho de no declaración de un testigo o el derecho de no brindar información. ${ }^{142}$ En el caso de un testigo que alega el $\S 55$ dijo el 2 do. Senado del BGH, que ya la letra del $§ 251$ Nro. 2 prohíbe asumir que haya un impedimento, pues tal testigo podría ser interrogado, cuanto menos respecto de su propia persona. También la historia legislativa habla a favor de una interpretación estricta del principio de inmediatez, puesto que las excepciones estarían precisamente únicamente previstas en los casos concretos del $\S 251$. En definitiva, sería una contradicción valorativa si protocolos de interrogatorios no judiciales y declaraciones testimoniales escritas realizadas bajo requisitos menos exigentes pudieran ser leídos como protocolos judiciales, que en realidad valen como más confiables. ${ }^{143}$ A esta argumentación se deja contraponer no obstante el deber del esclarecimiento judicial ( $\$ 244$ II). Si se observan como lo hace Murmann, ${ }^{144}$ los $\S \S 250$ ss. como concreción del deber de esclarecimiento judicial del $\S 244$ II, la diferenciación entre impedimentos de hecho y de derecho para el interrogatorio no aparecen muy convincentes, ${ }^{145}$ puesto que esta diferenciación implica una considerable limitación a la averiguación de la verdad. ${ }^{146}$ Ante ésto únicamente puede entenderse razonablemente el $\S 251$ Nro. 2 en el sentido de que la norma se refiere a la posibilidad de llevar adelante el interrogatorio sobre el hecho, y que un mero interrogatorio sobre la persona no puede ser suficiente por la simple razón de que no aporta información conducente al esclarecimiento del hecho. ${ }^{147}$ La contradicción valorativa mencionada por el $\mathrm{BGH}$ respecto del interrogatorio judicial y no judicial, está

\footnotetext{
${ }^{140}$ BGH, StV, (2008), p. $170=N S t Z$ 08, p. 293.

141 Véase también MEYER-GOßNER, Strafprozessordnung, cit. nota $\mathrm{n}^{\circ} 52$, § $251 \mathrm{Rn}$. 11; VOLK, Grundkurs, cit. nota ${ }^{\circ} 25, \S 27$ Rn. 4, KÜHNE, Strafprozessrecht, cit. nota ${ }^{\circ} 4, \S 55 \mathrm{~nm} .931 \mathrm{~s}$.

${ }^{142}$ BGH, StV, 07, pp. 564 ss., p. 565 sobre $§ 55$; BGH, NStZ, 08, pp. 293 s., p. 294 sobre $§ 52$.

${ }^{143}$ BGH, StV, 07, pp. 564 ss., p. 566.

${ }^{144}$ MURMANN, Uwe, “Anmerkung zu BGH, Urt. V. 27.4.2007 - 2 StR 490/06 (LG Köln)”, StV, (2008), pp. 339-341, p. 339 (sobre las mencionadas sentencias del 2do. y 4to. Senado).

Véase sobre estas ideas también MEYER, Jürgen, Der Urkundenbeweis in der Hauptverhandlung, Frankfurt am Main: Lang, 1999, pp. 143 ss.

${ }_{146}$ MURMANN, “Anmerkung”, cit. nota n ${ }^{\circ} 144$, p. 341.

${ }^{147}$ MURMANN, “Anmerkung”, cit. nota ${ }^{\circ} 144$, p. 340.
} 
AMBOS, Kai. "Las prohibiciones de utilización de pruebas en el proceso penal alemán - fundamentación teórica y sistematización”.

además prevista en la propia ley (desde el 2004), puesto que con la simple incorporación del término "también" en el apartado 2 de la norma, el legislador ha adoptado un tratamiento equivalente de los interrogatorios no judiciales contemplados en el ap. $1 \mathrm{y}$ de los interrogatorios judiciales contemplados en el ap. 2. La referencia a la voluntad del legislador histórico permanece por tanto un argumento contundente para una interpretación estricta de la inmediatez desde que ésta se ha concretado en los ejemplos introducidos (muerte, enfermedad, fragilidad) en los aps. 1 y 2 del $\S 251 .{ }^{148}$ Si el $\S 250$ realmente tuviera que ser entendido en relación al $\S 244$ II, ${ }^{149}$ la posibilidad de lectura debería ser siempre permitida cuando una prueba personal no fuera posible, total o parcialmente. ${ }^{150}$ Esto contradice, sin embargo, la sistemática de la regla-excepción de los $\S \S 250,251$, así como el importantísimo significado del principio de inmediatez para un proceso penal justo y acorde con los principios del Estado de Derecho. Incluso si se reconoce que el $\S 250$ se enraiza en la obligación de esclarecimiento judicial del $\S 244$ II, ${ }^{151}$ eso no iría en contra de otros fines inmanentes al $\S 250$, en especial, precisamente, el aseguramiento del principio de inmediatez. ${ }^{152}$ También debe prestarse atención a que sólo una interpretación independiente del principio de inmediatez se corresponde suficientemente con el principio de igualdad de armas del Art. $6 \mathrm{CEDH}^{153}$ y ante todo con el derecho de confrontación del Art. 6 III d CEDH. ${ }^{154}$ En consecuencia debe ser rechazada una ampliación teleológica o una aplicación análoga del $\S 251$ en casos de negación a brindar información con base en el $\S 55^{155}$

El § 160a I 2 prevé ahora una "prohibición de utilización" en caso de medidas investigativas que violen el derecho de no declaración de religiosos, defensores penales y parlamentarios. Para otros profesionales también ligados por el secreto profesional depende una eventual prohibición de utilización de pruebas de la proporcionalidad e importancia del delito en cuestión (§ 160a II 3). ${ }^{156}$ También existen otras prohibiciones de utilización probatoria en leyes especiales, por ejemplo, los $\S \S 51$ de la Ley del Registro Central Federal (Bundeszentralregistergesetz), 393 II de la Ley Tributaria (Abgabenordnung), 97 I 3 de la Ley concursal (Insolvenzordnung), y 4 de la Ley sobre los documentos del Servicio de Seguridad de la antigua RDA (Stasi-Unterlagen-Gesetz). Según el Art. 13 V frase 2 de la Grundgesetz (Constitución) los conocimientos que han

148 Véase para los antecedentes MITSCH, Wolfgang, "Protokollverlesung nach berechtigter Auskunftsverweigerung ( $§ 55$ StPO) in der Hauptverhandlung”, JZ, (1992), pp. 174-183, p. 180 s.; DÖLLING, Dieter, "Verlesbarkeit schriftlicher Erklärungen und Auskunftsverweigerung nach $\S 55$ StPO”, NStZ, (1988), pp. 6-10, p. 9.

149 Véase sobre esto también MEYER, Der Urkundenbeweis, cit. nota $\mathrm{n}^{\circ}$ 145, p. 136, 138; MITSCH, "Protokollverlesung", cit. nota ${ }^{\circ} 148$, p. 177.

${ }^{150}$ Véase para la última constelación BGH, StV, (2007), p. 567, donde en realidad había un impedimento de hecho para el interrogatorio.

${ }^{151}$ KÜHNE, Strafprozessrecht, cit. nota ${ }^{\circ} 4, \S 55 \mathrm{~nm} .914$.

${ }^{152}$ Véase aquí LANGKEIT, Jochen; CRAMER, Steffen, "Vorrang des Personalbeweises bei gemäß $§ 55$ StPO schweigenden Zeugen”, StV, (1996), pp. 230-234, p. 233.

${ }^{153}$ Cfr. AMBOS, Kai, "Der Europäische Gerichtshof für Menschenrechte und die Verfahrensrechte", ZStW, (2003), pp. 583-637, p. 592 ss.

${ }^{154}$ CORNELIUS, Kai, "Konfrontationsrecht und Unmittelbarkeitsgrundsatz", NStZ, (2008), pp. 244-248, p. 248.

${ }^{155}$ En igual sentido MITSCH, "Protokollverlesung”, cit. nota $\mathrm{n}^{\circ} 148$, p. 178.

${ }^{156}$ Cfr. KNIERIM, "Fallrepetitorium”, cit. nota n 109, p. 604 s. 
Polít. crim., Vol. 4, $\mathrm{N}^{\circ} 7$ (Julio 2009) Art. 1, pp. 1-56.

[http://www.politicacriminal.cl/Vol_04/n_07/Vol4N7A1.pdf]

sido obtenidos con fundamento en la introducción de medios técnicos en domicilios privados son utilizables únicamente a condición de la existencia de una orden judicial anterior (al respecto véase el registro domiciliario, así como infra 3.2.3.d.).

\section{Prohibiciones no escritas de utilización de pruebas.}

\subsection{Intentos de explicación.}

Las prohibiciones no escritas de utilización probatoria requieren de una fundamentación material, ya que no se basan en una prescripción legal. La búsqueda de tal fundamentación nos lleva de nuevo a la pregunta planteada anteriormente sobre el objeto de las prohibiciones de prueba, y que ya había motivado a Beling a la necesidad de una regulación de principio. ${ }^{157}$ No obstante, esta regulación no ha sido encontrada hasta ahora, más bien, existe un consenso general - al lado de la ya mencionada diferenciación entre producción de prueba y utilización de prueba ${ }^{158}$ - solamente en la constatación de que no se ha logrado hasta hoy reconducir las prohibiciones probatorias a una sola idea fundamental. ${ }^{159}$ Por lo demás, distintas teorías disputan la solución correcta de los supuestos que subyacen en los conflictos de ponderación, sin que, evidentemente, se haya podido alcanzar una respuesta satisfactoria a los diferentes niveles del problema. ${ }^{160}$

La teoría del ámbito o esfera de derechos (Rechtskreistheorie) anteriormente sostenida (aunque por poco tiempo) por la jurisprudencia, es cuestionable, ya que se desarrolló con fundamento en un problema especial (la vulneración de la obligación de instrucción de conformidad con el $\S 55$ II), y solamente cuestiona si "la violación afecta sustancialmente el ámbito de derechos del recurrente, o si la violación sólo es de segundo orden y en consecuencia carece de importancia para él." ${ }^{161}$ Abstracción hecha de la imprecisión de esta fórmula, la teoría implica una restricción de los derechos procesales del acusado en su acepción de derechos fundamentales, a pesar de que el acusado tiene derecho a un debido proceso legal y justo en su totalidad. ${ }^{162}$ La "afectación del ámbito de derechos"

157 BELING, Die Beweisverbote, cit. nota $\mathrm{n}^{\circ}$ 1, prólogo: “[Si] no me engaño, así es la teoría de las prohibiciones de prueba, que hasta hoy no ha sido tratada ex professo en ninguna otra parte y que todavía es apta para desarrollos ulteriores (...) En el futuro no se podrá abandonar la tarea de buscar principios reguladores en lugar de la casuística desarrollada hasta hoy“.

${ }^{158}$ Cfr. supra ap. 1 y notas 25 y ss.

159 Análisis profundo de la literatura en JÄGER, Beweisverwertung und Beweisverwertungsverbote, cit. nota $\mathrm{n}^{\circ} 15$, pp. 69 ss., concluyendo que hasta ahora no se logró "una fundamentación convincente de las prohibiciones de utilización”; en particular, igualmente VOLK, Grundkurs, cit. nota n 25, § 28 nm. 8, 13; BEULKE, Strafprozessrecht, cit. nota ${ }^{\circ} 13$, nm. 457; HELLMANN, Strafprozessrecht, cit. nota $\mathrm{n}^{\circ} 18, \mathrm{~nm}$ 782; ARLOTH, "Dogmatik in der Sackgasse", cit. nota n' 16, pp. 258, 261.

160 Completo y crítico sobre las diferentes teorías JAHN, Beweiserhebungs- und Beweiserverwertungsverbote, cit. nota $\mathrm{n}^{\circ} 1$, C 51 ss.

${ }^{161}$ BGHSt 11, pp. 213 ss., p. 215; crít. en BGHSt 19, pp. 325 ss., p. 332; BGHSt 38, pp. 214 ss., p. 219 s.; 42, 73, 77; crít. también HAUF, Claus-Jürgen, "Ist die 'Rechtskreistheorie' noch zu halten? - Eine neue Konzeption zur Frage von Verfahrensfehlern und Beweisverwertungsverboten”, NStZ, (1993), pp. 457-462; DENCKER, Friedrich, "Anmerkung zu BGH, Urt. v. 10.8.1994 - 3 StR 53/94 (LG Kleve)", StV, (1995), pp. 232-236; VOLK, Grundkurs, cit. nota $\mathrm{n}^{\circ} 25, \S 28 \mathrm{~nm}$. 9; BEULKE, Strafprozessrecht, cit. nota $\mathrm{n}^{\circ} 13$, nm. 459; JAHN, Beweiserhebungs- und Beweiserverwertungsverbote, cit. nota ${ }^{\circ} 1$, C 39 ss.;

${ }^{162}$ FEZER, Gerhard, "Grundfälle zum Verlesungs- und Verwertungsverbot im Strafprozeß”, JuS, (1978), pp. 325-331, p. 327; GEPPERT, Klaus, “Das Beweisverbot des $§ 252$ StPO”, Jura, (1988), pp. 305-314, p. 
AMBOS, Kai. "Las prohibiciones de utilización de pruebas en el proceso penal alemán - fundamentación teórica y sistematización”.

(Rechtskreisberührung) tampoco expresa automáticamente algo en relación con una eventual consecuencia de una prohibición de utilización probatoria. ${ }^{163}$

La doctrina del fin de protección de la norma (Schutzzwecklehre) cuestiona si el sentido y el fin de una disposición procesal infringida demandan explícitamente una prohibición de utilización. ${ }^{164}$ Esto supone, en primer lugar, que incondicionalmente existe una norma (una prohibición de la producción probatoria), de la cual se puede inferir un fin de protección. ${ }^{165}$ La existencia de tal norma, además de la trasgresión, plantea la pregunta de si su propósito justamente estriba en excluir del acerbo probatorio utilizable el resultado probatorio obtenido con la violación de la prohibición, ya que por cuenta de su eventual permanencia la prueba así obtenida entraña una profundización de la violación del derecho. ${ }^{166}$ Por consiguiente, metodológicamente se plantea el problema de si únicamente puede ser inferida desde el fin de protección de una norma de recolección probatoria la consecuencia de su utilización o no utilización probatoria. ${ }^{167}$ A modo de ejemplo: al testigo Z, quien es pariente del acusado, no se le advierte sobre su derecho a negarse a declarar ( $\$ 55$ II), lo que plantea el problema de si el $\S 55$ II únicamente sirve a la protección del testigo ante autoincriminaciones y la incriminación de parientes (por lo que no se produce ninguna prohibición de utilización de la declaración referente al acusado) ${ }^{168}$, o si también la norma tiene como objeto la protección del imputado ante eventuales afirmaciones falsas del testigo y con ello se fundamenta una prohibición de utilización. $^{169}$

La teoría del fin de protección aclara que en esencia se trata de una ponderación entre los intereses estatales de persecución penal y de averiguación de la verdad por una parte, y los intereses individuales del ciudadano, por otra. De esta forma, la doctrina se encuentra con la dominante teoría de ponderación (Abwägungslehre), la cual concreta los intereses

313; ROXIN, Strafverfahrenstrecht, cit. nota $\mathrm{n}^{\circ} 34, \S 24 \mathrm{~nm} .20$; VOLK, Grundkurs, cit. nota $\mathrm{n}^{\circ} 25, \S 28$ nm. 9; MURMANN, "Über den Zweck", cit. nota $n^{\circ}$ 6, nm. 207 (en relación con el § 55). Acertadamente crítico con el concepto de la "simple" prescripción de orden JAHN, Beweiserhebungs- und Beweiserverwertungsverbote, cit. nota $\mathrm{n}^{\circ} 1, \mathrm{C} 42$ ss.

${ }^{163}$ Para el reproche de circularidad de la teoría del ámbito de derechos véase JÄGER, Beweisverwertung und Beweisverwertungsverbote, cit. nota $\mathrm{n}^{\circ} 15$, p. 140.

${ }^{164}$ Cfr. BEULKE, Werner, "Hypothetische Kaulsalverläufe im Strafverfahren bei rechtswidrigen Vorgehen von Ermittlungsorganen“, ZStW, (1991), pp. 657-680, p. 657 ss.; de acuerdo también ARLOTH, "Dogmatik in der Sackgasse", cit. nota $n^{\circ} 16$, p. 260; sobre los distintos funcionamientos JAHN, Beweiserhebungs- und Beweiserverwertungsverbote, cit. nota $\mathrm{n}^{\circ} 1, \mathrm{C} 54$ ss.

${ }^{165}$ Cfr. VOLK, Grundkurs, cit. nota n ${ }^{\circ} 25, \S 28$ nm. 10; también KINDHÄUSER, Strafprozessrecht, cit. nota $\mathrm{n}^{\circ} 34, \S 23 \mathrm{~nm} .15$.

${ }^{166}$ Cfr. FEZER, Strafprozessrecht, cit. nota n 99, S. 219 con más referencias; también KINDHÄUSER, Strafprozessrecht, cit. nota $\mathrm{n}^{\circ} 34, \S 23 \mathrm{~nm}$. 14. A favor de una teoría autónoma de la intensificación del daño ("Schadensvertiefungslehre") GRÜNWALD, Gerald, "Beweisverbote und Verwertungsverbote im Strafverfahren", JZ, (1966), pp. 489-501, p. 490.

${ }^{167}$ Cfr. FEZER, Strafprozessrecht, cit. nota ${ }^{\circ}$ 99, p. 219 con más referencias; crítico al respecto JAHN, Beweiserhebungs- und Beweiserverwertungsverbote, cit. nota $\mathrm{n}^{\circ} 1, \mathrm{C} 57$.

168 Así, la opinión dominante (con base en la teoría del ámbito de derechos), cfr. VOLK, Grundkurs, cit. nota $\mathrm{n}^{\circ} 25, \S 21 \mathrm{~nm} .15$ s., $\S 28 \mathrm{~nm}$. 19; BEULKE, Strafprozessrecht, cit. nota ${ }^{\circ} 13$, nm. 464 ambos con más referencias.

${ }^{169}$ Así ROXIN, Strafverfahrenstrecht, cit. nota $\mathrm{n}^{\circ}$ 34, § 24 nm. 36; también JAHN, Beweiserhebungs- und Beweiserverwertungsverbote, cit. nota $\mathrm{n}^{\circ} 1, \mathrm{C} 73$. 
Polít. crim., Vol. 4, $\mathrm{N}^{\circ} 7$ (Julio 2009) Art. 1, pp. 1-56.

[http://www.politicacriminal.cl/Vol_04/n_07/Vol4N7A1.pdf]

a ponderar, tomando en cuenta - al referirse a la doctrina del propósito de protección - la gravedad del hecho imputado y el peso de la infracción procesal: ${ }^{170}$

"La decisión a favor o en contra de una prohibición de utilización ha de ser fundamentada en una ponderación amplia. En ella se comprende el peso de la infracción procesal así como su importancia para la esfera legalmente protegida del afectado, lo mismo que el peso de la consideración, según la cual la verdad no debe ser investigada a cualquier precio. Por otra parte, hay que considerar que las prohibiciones de utilización inciden en las posibilidades de averiguación de la verdad y que el Estado, de conformidad con la jurisprudencia constitucional, ha de garantizar con la Ley Fundamental una administración de justicia penal funcional, sin la cual la justicia no puede realizarse. Si la norma procesal que ha sido violada no favorece o no lo hace en primera línea al imputado, nos encontramos lejos de una prohibición de utilización; un ejemplo es la infracción contra el § 52 II StPO. Por otra parte, una prohibición de utilización se encuentra cerca, cuando la norma procesal violada está determinada para asegurar los fundamentos de la posición procesal del imputado o acusado en el proceso penal."

Esta doctrina, que en realidad tiene por fin lograr justicia en casos individuales, aporta en definitiva muy poco a la seguridad jurídica, e igual de escasa es su pretensión de fundamentación teórica. ${ }^{171}$ Jäger $^{172}$ ha constatado, en una investigación fundamental sobre la jurisprudencia del Tribunal Supremo Federal, que este "vacila entre la teoría del fin de protección y la doctrina de la ponderación sin sistema reconocible", con lo cual el Tribunal tiende a la teoría del fin de protección en los casos de errores procesales en los interrogatorios o en las medidas coercitivas relacionadas con la protección judicial del interrogado, mientras que en las demás injerencias recurre a la teoría de la ponderación. Jahn ve una "inflación de los parámetros de ponderación" y un recurso a uno u otro "según el estado de cosas” sin "mayor fundamentación". 173

El mismo Jäger pretende referirse - con una teoría de la prohibición de utilización probatoria referida materialmente al objeto probatorio (beweisgegenständliche Verwertungsverbotslehre) - a la "función de protección referida estrictamente al objeto de las normas de producción probatoria" (beweisgegenständliche Schutzfunktion der Erhebungsnorm). ${ }^{174}$ Un quebrantamiento del principio de abstracción ${ }^{175}$, y por ende de una prohibición de utilización entra en consideración, "cuando el sentido de la norma de producción de pruebas consiste en privar a la práctica de pruebas de un cierto objeto

\footnotetext{
${ }^{170}$ Cfr. más recientemente BGHSt 38, 214, 219 s; resumiendo también VOLK, Grundkurs, cit. nota ${ }^{\circ} 25$, $\S 28 \mathrm{~nm} .11$; crítico FEZER, Strafprozessrecht, cit. nota n 99, p. 219 s.

${ }^{171}$ Crít. en este sentido también JAHN, Beweiserhebungs- und Beweiserverwertungsverbote, cit. nota $\mathrm{n}^{\circ} 1$, C 59 s. (también con referencia a la teoría de las consecuencias del error de Rogall y al modelo del ámbito nuclear de Wolter).

172 JÄGER, Beweisverwertung und Beweisverwertungsverbote, cit. nota $\mathrm{n}^{\circ} 15$, p. 4 ss. (p. 67).

173 JAHN, Beweiserhebungs- und Beweiserverwertungsverbote, cit. nota $\mathrm{n}^{\circ} 1, \mathrm{C} 47 \mathrm{~s}$.

${ }_{174} \mathrm{~J}$ ÄGER, Beweisverwertung und Beweisverwertungsverbote, cit. nota $\mathrm{n}^{\circ} 15$, pp. 139 ss. y passim.

${ }^{175} \mathrm{Cfr}$. ya cit. nota $\mathrm{n}^{\circ} 35$ y texto.
} 
AMBOS, Kai. "Las prohibiciones de utilización de pruebas en el proceso penal alemán - fundamentación teórica y sistematización”.

probatorio." ${ }^{176}$ En consecuencia, la utilización se sujeta al "fin de protección de la norma en sentido estrictamente objetivo" ("gegenständlichen Schutzzweck der Norm"), es decir, al "ámbito de protección de la prohibición de la producción probatoria en sentido estrictamente objetivo" ("gegenständlichen Schutzumfang des Erhebungsverbots"), y se refiere al "objeto probatorio obtenido por la producción probatoria" ("durch die Erhebung erlangten Beweisgegenstand"). ${ }^{177}$ Es necesaria una "identidad del error en el sentido de una doble deficiencia con miras al objeto probatorio" ("Fehleridentität im Sinne eines gegenständlichen Doppelmangels"), es decir, el alcance de la prohibición de utilización secundaria debe consecuentemente corresponder a la prohibición de producción primaria. ${ }^{178}$ No es decisivo el ámbito de protección personal de la norma de producción, sino su ámbito de protección referido objetivamente. ${ }^{179}$ La ponderación entre la justicia material y procesal debe producirse a través de una concordancia práctica, concretamente a través de un sobreseimiento por sentencia procesal, para evitar una sentencia condenatoria de contenido materialmente erróneo como consecuencia de simples errores (formales) de procedimiento. ${ }^{180}$

La doctrina de la pretensión de dominio informativo personal (Informationsbeherrschungsanspruch ${ }^{\text {)181 }}$, fundamenta la prohibición de utilización probatoria en primera línea en una pretensión de restitución secundaria, que compete al titular de la información por la vulneración de su derecho primario a la autodeterminación informativa; de allí se deduce en algún sentido un fundamento de "lógica y justicia". ${ }^{182}$ Si se tratara en caso de la pretensión de restitución de una supresión de los resultados informativos injustificados, a través de la no utilización de las informaciones procuradas u obtenidas ilegalmente, se captaría la acción informativa injustificada en forma de investigaciones en contra de los derechos humanos, que no necesariamente acarrean un resultado violatorio informativo, apoyándose en la idea de la legitimación estatal de penalización. Esta indignidad del Estado se produce cuando no respeta un determinado estándar mínimo de ética (el de los derechos humanos). ${ }^{183} \mathrm{~A}$ pesar de la crítica exteriorizada respecto a esta teoría ${ }^{184}$, esta puede ser a menudo invocada complementariamente en aquellos casos en los cuales se está en presencia de

\footnotetext{
${ }^{176} \mathrm{~J}$ ÄGER, Beweisverwertung und Beweisverwertungsverbote, cit. nota $\mathrm{n}^{\circ} 15$, p. 139. Cuando el sentido de la norma de producción probatoria estriba en privar la práctica probatoria de un determinado objeto de prueba.

177 Ibid.

${ }^{178}$ Ibid., pp. 139, 167.

${ }^{179}$ Ibid., p. 140, es decir, no "a quien la norma de producción probatoria concede un derecho", sino "cual ámbito de protección material" ella "define".

${ }^{180}$ Cfr. más detallado JÄGER, Beweisverwertung und Beweisverwertungsverbote, cit. nota $\mathrm{n}^{\circ} 15, \mathrm{pp} .255$ ss., 281.

181 Fundamental AMELUNG, Knut, Informationsbeherrschungsrechte im Strafprozess: dogmatische Grundlagen individualrechtlicher Beweisverbote, Berlin: Duncker \& Humblot, 1990; modificando el mismo, AMELUNG, “Zum Streit”, cit. nota ${ }^{\circ} 15$, pp. 1259 ss.

${ }^{182}$ AMELUNG, "Zum Streit", cit. nota n' 15, p. 1265.

${ }^{183}$ Resumiendo AMELUNG, "Zum Streit”, cit. nota n 15, pp. 1260 ss.

${ }^{184}$ Fundamental JÄGER, Beweisverwertung und Beweisverwertungsverbote, cit. nota $\mathrm{n}^{\circ} 15$, pp. 100 ss., 140 s., así como las referencias de AMELUNG, "Zum Streit", cit. nota n 15, p. 1259 con nota 3.
} 
Polít. crim., Vol. 4, $\mathrm{N}^{\circ} 7$ (Julio 2009) Art. 1, pp. 1-56.

[http://www.politicacriminal.cl/Vol_04/n_07/Vol4N7A1.pdf]

una violación procesal a la autodeterminación informativa del acusado ${ }^{185}$, por lo que debería ser atribuida a este la última decisión acerca de la utilización de prueba, por ser él el único autorizado a disponer de las informaciones en cuestión. Una prohibición de utilización absoluta e inflexible, por ejemplo en referencia a anotaciones de diarios personales, no lleva a ningún resultado adecuado, puesto que no tiene en cuenta la voluntad posiblemente opuesta del acusado. ${ }^{186}$ Finalmente, es fruto de esta doctrina haber puesto en el centro de la atención la importancia de las informaciones como objeto de prueba. ${ }^{187}$

Con la teoría de las facultades probatorias ahora expuesta por Jahn debe ser asegurado y concretado constitucionalmente el derecho de la utilización de pruebas. ${ }^{188} \mathrm{El} \S 244$ II contendría - en concordancia con la teoría de reserva legal - una autorización - real para la introducción de medios probatorios decisivos que, sin embargo, desde el punto de vista de las consecuencias jurídicas - en concordancia con el principio de prevalencia de la ley (art. 20 II Hs. 2 GG) - deberían ser sometidos a un control general de proporcionalidad. La utilización probatoria debería ser por tanto siempre adecuada, necesaria y medida, para lo cual en el nivel de la "medida" la dignidad humana - y la garantía de su esencia (art. 1 I, 19 II, 79 III GG) deberían devenir en límites cualitativos de la utilización probatoria. Sin embargo, esta teoría tampoco puede presentar un catálogo cerrado de prohibiciones de utilización, sino que debe ser determinado en cada caso "en forma independiente mediante la aplicación de la norma correspondiente", lo que "en el marco de los derechos fundamentales individuales pertenece al contenido de la garantía de la dignidad humana". ${ }^{189}$ Así, de todos modos, la perspectiva de los derechos fundamentales orientada a lograr un proceso justo es puesta por delante de enfoques meramente cuantitativos.

En conclusión, resulta que al final todas las decisiones se basan en una ponderación entre los intereses de la persecución penal y los intereses del imputado ${ }^{190}$, con lo cual la doctrina de la ponderación debería ser concretada a fines de evitar una impresión de $\operatorname{arbitrariedad}^{191}$ con el apoyo de otras doctrinas, sobre todo la doctrina del fin de protección y la teoría de las facultades. Dichas teorías, por lo general, no conducen a

185 Sin embargo, la teoría de Amelung ya fue descubierta antes de identificar un derecho a la autodeterminación informativa y, por lo tanto, se desarrolló independientemente de ello (cfr. AMELUNG, "Zum Streit", cit. nota n ${ }^{\circ} 15$, p. 1265 con nota 25 ).

${ }^{186}$ Cfr. VOLK, Grundkurs, cit. nota n ${ }^{\circ} 25, \S 28 \mathrm{~nm} .12$.

${ }^{187}$ En este sentido también JÄGER, Beweisverwertung und Beweisverwertungsverbote, cit. nota $\mathrm{n}^{\circ} 15, \mathrm{p}$. 104.

${ }^{188}$ JAHN, Beweiserhebungs- und Beweiserverwertungsverbote, cit. nota ${ }^{\circ} 1$, C 66 ss., 127.

${ }^{189}$ Así también JAHN, Beweiserhebungs- und Beweiserverwertungsverbote, cit. nota $\mathrm{n}^{\circ} 1, \mathrm{C} 72$.

190 Cfr. también ROXIN, Strafverfahrenstrecht, cit. nota $\mathrm{n}^{\circ} 34, \S 24 \mathrm{~nm}$. 23; de modo similar HELLMANN, Strafprozessrecht, cit. nota $\mathrm{n}^{\circ}$ 18, nm. 784; ARLOTH, "Dogmatik in der Sackgasse", cit. nota $\mathrm{n}^{\circ}$ 16, p. 260. Así también JAHN, Beweiserhebungs- und Beweiserverwertungsverbote, cit. nota $\mathrm{n}^{\circ} 1$, C 79 respecto de prohibiciones de utilización independientes, para lo cual de todas maneras quiere aplicar la teoría de la reciprocidad en el marco de su teoría de las facultades.

${ }^{191}$ Crítico en general ARLOTH, "Dogmatik in der Sackgasse", cit. nota n 16, p. 260; KINDHÄUSER, Strafprozessrecht, cit. nota $\mathrm{n}^{\circ} 34, \S 23 \mathrm{~nm} .17$. 
AMBOS, Kai. "Las prohibiciones de utilización de pruebas en el proceso penal alemán - fundamentación teórica y sistematización”.

otros resultados. ${ }^{192}$ La decisión "correcta", de todos modos, tiene que darse caso por caso, por lo que una cierta casuística no parece evitable. ${ }^{193}$ La ponderación debe efectuarse desde el punto de vista judicial, pues el juez de instancia es quien debe decidir en el juicio oral si puede todavía subsanar la infracción procesal o ha de aceptar irrevocablemente una prohibición de utilización. ${ }^{194}$ La decisión legislativa a favor de una prohibición de producción probatoria no anticipa la ponderación en sí. En realidad, el contenido normativo de las disposiciones de producción probatoria debe ser consultado a efectos de interpretar la cuestión de su utilización ${ }^{195}$, sin embargo, raras veces dará por resultado una deducción inequívoca, ya que se trata de normas de producción probatorias y no de disposiciones de utilización de prueba. De lo contrario, en todos los casos de prohibiciones de utilización probatoria dependientes debería ser excluida la utilización $a$ limine como consecuencia de la infracción legal, y ello desautorizaría fácticamente el interés público en la persecución penal.

Como directriz general se podrá suponer una prohibición de utilización, en principio, cuando se trate de una infracción legal de especial gravedad en el sentido de los estándares de los derechos humanos ${ }^{196}$ anteriormente mencionados y/o si la infracción se manifiesta como un bien calculado o consciente menosprecio de las disposiciones procesales. El derecho a un proceso justo (fair trial) ${ }^{197}$ e igualmente el indispensable control disciplinario de las instancias de persecución penal imponen en este caso la noutilización. ${ }^{198}$ La objeción según la cual el medio de prueba también hubiese podido ser obtenido legalmente (el así llamado curso causal hipotético de investigación) ${ }^{199}$ no varía en nada la no utilización probatoria, puesto que la infracción procesal resulta irreversible, añadiendo a ello que los requisitos del procedimiento investigativo hipotético no están esclarecidos y el procedimiento de investigación difícilmente puede predecirse de manera

192 Sintomática la aplicación concreta de la teoría de JÄGER, Beweisverwertung und Beweisverwertungsverbote, cit. nota $\mathrm{n}^{\circ} 15$, p. 143 ss. o también la casuística aportada por JAHN, Beweiserhebungs- und Beweiserverwertungsverbote, cit. nota $\mathrm{n}^{\circ} 1$, C 73 s.; ver también referencias individuales supra y en la notas siguientes.

193 Así también, en lo sustancial, las opinones resumidas por JÄGER, Beweisverwertung und Beweisverwertungsverbote, cit. nota $\mathrm{n}^{\circ} 15$, pp. 106 ss. como teorías de ponderación y combinación ("Abwägungs- und Kombinationstheorien").

${ }^{194}$ Cfr. FEZER, Strafprozessrecht, cit. nota ${ }^{\circ}$ 99, p. 217.

195 Cfr. FEZER, Strafprozessrecht, cit. nota $\mathrm{n}^{\circ}$ 99, p. 220; en este sentido también BEULKE, Strafprozessrecht, cit. nota $\mathrm{n}^{\circ}$ 13, nm. 458; ARLOTH, "Dogmatik in der Sackgasse", cit. nota $\mathrm{n}^{\circ}$ 16, p. 260; con la misma tendencia RÖSSNER, 30 Probleme, cit. nota ${ }^{\circ} 135$, p. 75 s.

${ }^{196}$ Véase cit. nota ${ }^{\circ}$ s 82 y s.

197 Sobre esto, como prohibición probatoria independiente JAHN, Beweiserhebungs- und Beweiserverwertungsverbote, cit. nota $\mathrm{n}^{\circ} 1, \mathrm{C} 80 \mathrm{~s}$.

198 Igualmente HELLMANN, Strafprozessrecht, cit. nota $\mathrm{n}^{\circ} 18$, nm. 78; KINDHÄUSER, Strafprozessrecht, cit. nota $\mathrm{n}^{\circ} 34, \S 23 \mathrm{~nm}$. 10; también FINGER, "Prozessuale Beweisverbote", cit. nota $\mathrm{n}^{\circ}$ 13 , p. 535.

199 Crítica fundamental de DENCKER, Verwertungsverbote, cit. nota $\mathrm{n}^{\circ} 16$, pp. 80 ss.; JÄGER, Beweisverwertung und Beweisverwertungsverbote, cit. nota $\mathrm{n}^{\circ} 15$, p. 230 s., 234; DALLMEYER, Jahn, "Zum heutigen Stand der beweisrechtlichen Berücksichtigung hypothetischer Ermittlungsverläufe im deutschen Strafverfahrensrecht", NStZ, (2005), pp. 297-303, p. 297; crítico también ROXIN, Strafverfahrenstrecht, cit. nota $\mathrm{n}^{\circ} 34, \S 24 \mathrm{~nm} .21$; VOLK, Grundkurs, cit. nota $\mathrm{n}^{\circ} 25, \S 28 \mathrm{~nm}$. 14; a favor KÜHNE, Strafprozessrecht, cit. nota ${ }^{\circ} 4$, nm. 909.2; ARLOTH, "Dogmatik in der Sackgasse", cit. nota ${ }^{\circ}$ 16 , p. $260 \mathrm{~s}$. 
Polít. crim., Vol. 4, $\mathrm{N}^{\circ} 7$ (Julio 2009) Art. 1, pp. 1-56.

[http://www.politicacriminal.cl/Vol_04/n_07/Vol4N7A1.pdf]

fiable. ${ }^{200}$ Además, esta objeción conduce a un relativismo carente de fundamento y en última instancia a un abandono de las normas procesales que autorizan las medidas coercitivas, ya que se les despoja de cualquier efecto, en cierto modo como si se tratara de una "dogmática sin consecuencias". ${ }^{201}$ Por ello ha afirmado acertadamente el BGH en relación con una desatención consciente del control judicial (en los $\S \S 102$ ss.) que mediante el recurso a este argumento auxiliar el requisito legal "siempre quedaría minado" y "el control judicial, en definitiva, hasta devendría absurdo. En caso de tolerar desobediencias burdas al requisito del control judicial surgiría incluso un estímulo para que las investigaciones sin juez de instrucción sean más fáciles y posiblemente más prometedoras en sus resultados (...). Con ello se estaría renunciando a una exigencia esencial de un proceso de investigación propio de un Estado de Derecho, cual es, que las pruebas no pueden ser obtenidas mediante violación consciente del derecho ni mediante una equivalente desatención del derecho."202

\subsection{Ejemplos de prohibiciones de utilización de pruebas dependientes.}

\subsubsection{Falta de instrucción del imputado.}

El principio según el cual el inculpado no debe ser obligado a cooperar en la comprobación de su culpabilidad - "nemo tenetur se ipsum accusare" -, o sea el derecho a no declarar, se encuentra cimentado constitucionalmente (art. 1 I, 20 III Grundgesetz) $^{203}$, así como en la normativa del derecho internacional de los derechos humanos (art. $6 \mathrm{CEDH}){ }^{204}$ se trata (de cierto modo) de la contracara de la presunción de inocencia regulada en el art. 6 2do. ap. $\mathrm{CEDH}^{205} \mathrm{Su}$ silencio básicamente no puede ser utilizado en su contra. ${ }^{206} \mathrm{El}$ inculpado ha de ser adecuadamente informado sobre su derecho a no declarar ( $\$ 136$ I 2), incluso cuando se infiera que el inculpado conoce su derecho a permanecer en silencio o ha comparecido ante el tribunal con un defensor. ${ }^{207}$ La obligación de informar sobre el derecho a no declarar presupone por tanto, en primer lugar, la calidad de acusado, la cual requiere - subjetivamente - de la voluntad de persecución de las autoridades de la instrucción penal, y que esta a su vez objetivamente - se debe manifestar en un acto de voluntad, es decir, en el formal interrogatorio ${ }^{208}$ como acusado ${ }^{209}$ ("teoría mixta subjetiva-objetiva del acusado"). ${ }^{210}$ En

\footnotetext{
${ }^{200}$ Cfr. la crítica profunda de JAHN, Beweiserhebungs- und Beweiserverwertungsverbote, cit. nota $\mathrm{n}^{\circ} 1, \mathrm{C}$ 74 ss., 127, para el cual, además, falta un fundamento jurídico.

${ }^{201}$ KÜHNE, Strafprozessrecht, cit. nota ${ }^{\circ} 4$, nm. 908, p. 462.

202 BGH, NJW, (2007), pp. 2269, 2273; siguiéndolo OLG Hamburg, StV, (2008), p. 457. Sobre la problemática en más detalle infra 3.2.3.d en la nota 271.

${ }^{203}$ BEULKE, Strafprozessrecht, cit. nota ${ }^{\circ} 13, \mathrm{~nm} .467$.

${ }^{204}$ Saunders vs. Reino Unido, Eur. Ct. H.R. Application no. 19187/91,17.12.1996, para. 68 s.; TEDH, StV, (2006), pp. 617 ss., pp. 620 ss.

205 MEYER-LADEWIG, Jens, Europäische Menschenrechtskonvention, 2. ed., Baden-Baden: NomosVerl.-Ges., 2006, art. $6 \mathrm{~nm}$. 52. Véase con respecto a los tribunales penales internacionales: AMBOS, Kai "The Right of Non Self-incrimination of Witnesses Before the ICC", Leiden Journal of International Law, 15 (2002), pp. 155 ss., p. 156 s..

${ }^{206}$ Sobre la discutida utilización del silencio parcial del acusado MURMANN, "Über den Zweck", cit. nota $\mathrm{n}^{\circ} 6, \mathrm{~nm} .192 \mathrm{~s}$. con más referencias.

${ }^{207}$ BGHSt 38, pp. 214 ss., p. $220=N J W$, (1992), pp. 1463 ss., p. 1465 ; BGHSt 47 pp. 172 ss., p. 173.

${ }^{208}$ Sobre este concepto ver cit. nota $n^{\circ} 73$.
} 
AMBOS, Kai. "Las prohibiciones de utilización de pruebas en el proceso penal alemán - fundamentación teórica y sistematización”.

caso que faltara el acto de voluntad subjetivo y que el comportamiento de las autoridades investigativas se mostrase hacia afuera (objetivamente) como una medida de investigación con base en un inicio de sospecha, aparecerá por tanto la falta de un acto de voluntad como arbitrario, pero de todas maneras y en vistas al aseguramiento de los derechos del acusado debe darse por sentada la calidad de acusado. ${ }^{211}$ Manifestaciones espontáneas y declaraciones en el marco de un interrogatorio informativo no están, sin embargo, contemplados por el $\S 136 .^{212}$

La omisión de la instrucción conduce a una prohibición de utilización. ${ }^{213}$ Lo mismo resulta en caso de omisión de la instrucción referente al derecho de consultar a un defensor ( $\$ 136$ I 2, 137); pero no se llega al mismo resultado cuando la policía omite indicar al inculpado- informado sobre su derecho de consultar a un defensor - que su falta de recursos no excluye la consulta de un abogado. ${ }^{214}$ Finalmente, surge también una prohibición de utilización en caso de falta de instrucción en el juicio oral ( $\$ 243$ IV 1). ${ }^{215}$ Para el caso del $\S 136$ a III esto significa que la prohibición de valoración probatoria que allí está explícitamente dispuesta (véase ya supra III. 1.) puede ser fundada mediante una conclusión a fortiori ("Erst-Recht-Schlu $\beta$ "). Esto es así, dado que si ya por la falta del asesoramiento necesario respecto del derecho de guardar silencio se está en un caso de prohibición de valoración probatoria, más aún debe valer ésto para los casos en que el acusado es coaccionado a declarar mediante métodos prohibidos por el $§ 136 \mathrm{a}$ I.

Sin embargo, las declaraciones pueden ser utilizadas de manera excepcional, si el inculpado ha reconocido (con seguridad) su derecho a no prestar declaración, ${ }^{216}$ si el

\footnotetext{
${ }^{209}$ Para el interrogatoio del sospechoso como testigo no es necesaria ninguna información (BGH, NStZ, (2007), pp. 653 ss., p. 654). sospechoso fundan básicamente la calidad de acusado del sospechoso afectado por la medida, ya que aquellas generalmente tienen por objetivo ir contra éste a causa de un hecho delictivo; la posición de acusado del sospechoso es por tanto obvia cuando un registro, según el $\S 102 \mathrm{StPO}$, sirve para obtener elementos de prueba apropiados para su elevación."), 654 ; BGH 38, pp. 214 ss., p. $228=$ NJW (1992), pp. 1463 ss., p. 1466); también MURMANN, "Über den Zweck”, cit. nota n 6, nm. 199.

${ }^{212}$ Cfr. VOLK, Grundkurs, cit. nota ${ }^{\circ} 25, \S 9 \mathrm{~nm}$. 11; FINGER, "Prozessuale Beweisverbote", cit. nota n ${ }^{\circ}$ 13 , p. 534 con más referencias.

${ }^{213}$ BGHSt 38, 214= NJW, 92, p. 1463; FEZER, Strafprozessrecht, cit. nota ${ }^{\circ}$ 99, p. 221; ROXIN, Strafverfahrenstrecht, cit. nota $\mathrm{n}^{\circ} 34, \S 24 \mathrm{~nm}$. 24, 29; KÜHNE, Strafprozessrecht, cit. nota $\mathrm{n}^{\circ} 4, \mathrm{~nm}$. 909.1; MEYER-MEWS, "Beweisverwertungsverbote", cit. nota $\mathrm{n}^{\circ}$ 36, p. 40; MURMANN, "Über den Zweck", cit. nota ${ }^{\circ}$ 6, nm. 201; JAHN, Beweiserhebungs- und Beweiserverwertungsverbote, cit. nota ${ }^{\circ} 1$, C 73.

${ }^{214}$ BGH, StV , (2006), p. 566 y 567. Ver también FINGER, "Prozessuale Beweisverbote", cit. nota n 13, p. 535 con mas referencias.

${ }^{215}$ Cfr. FINGER, "Prozessuale Beweisverbote", cit. nota n ${ }^{\circ} 13$, p. $534 \mathrm{~s}$.

${ }^{216}$ BGHSt 38, $214(224)=$ BGH, NJW, (1992), 1463 (1465); BGHSt 47, 172, 173. Esta perspectiva es también acertadamente trabajada por MITSCH, Wolfgang, "Beschuldigenstatus und Belehrungspflicht", $N S t Z$, (2008), pp. 49-50, pero apenas conciliable con BGH, $N S t Z$, (2007), p. 653, ya que aquí (cfr. ya cit. nota $\mathrm{n}^{\circ} 209$ ss.) el 1er. Senado ha dicho que "la sola información al acusado de que ante la policía no debe decir nada, y que de acuerdo al $\S \S 55$ II, 163a V StPo tampoco tiene que dar ninguna información que pudiera perjudicarlo, (...) en general no [puede] reemplazar la obligatoria información sobre el amplio y completo derecho de negarse a declarar".
} 
defensor consiente la utilización, si no se opone a ella hasta el interrogatorio del acusado en el juicio oral ( $\$ 257$ ) (solución de oposición previa), ${ }^{217}$ o si el error es salvado mediante una tardía información del derecho a no declarar y el interrogatorio es iniciado nuevamente desde el principio. ${ }^{218} \mathrm{El}$ que el inculpado desprecie o desatienda su derecho al silencio (advertido), por ejemplo cuando se le interroga nuevamente sobre el asunto, aunque pretenda hacer las declaraciones subsiguientes dependientes de un contacto con el defensor, no llevan automáticamente en todos los casos a una prohibición de utilización de las declaraciones así obtenidas si el inculpado no ha sido engañado en el sentido del $\S$ 136a y ha hablado voluntariamente con los agentes de investigación penal. ${ }^{219}$

Sin embargo, la excepción a la no utilización por el consentimiento del defensor y la solución de no alegación previa hasta el primer interrogatorio del acusado resultan cuestionables, pues si bien el derecho de abstenerse a prestar declaración y la advertencia acerca de éste son expresiones del derecho a la autodeterminación informativa; sólo quien es advertido del derecho, es decir, el acusado o inculpado, puede desistir de él y no el defensor en representación suya; además es cuestionable si la tarea del defensor - y no del tribunal por su obligación de asistencia - es la de subsanar el error procesal, puesto que se trata de asegurar que el proceso se realice dentro de los parámetros del Estado de Derecho. ${ }^{220}$ En un procedimiento inquisitorio, como el alemán guiado por un juez, es tarea del tribunal y no de los participantes del proceso asegurar un procedimiento ordenado. $^{221}$ Finalmente cae también el argumento principal para la solución de la contradicción si las pruebas de descargo siempre son consideradas utilizables, ${ }^{222}$ puesto

\footnotetext{
${ }^{217}$ BGH, BGHR StPO $\S 100$ a prohibición probatoria de utilización 11; BGHSt 50, pp. 206 ss., p. 215 s.= $N J W$, (2005), p. $3295=N S t Z$, (2005), p. 700; BGHSt 51, $1=N J W$, (2006), p. $1361=N S t Z$, (2006), p. 402; dejando abierta la cuestión BGH, NJW, (2007), pp. 2269 ss., p. 2273. Según BGH, NStZ, (2007), p. 719, debe ser suficiente cuando la contradicción es rechazada en la sentencia. Una información previa sobre la cuestión de la posibilidad de utilización tampoco sería necesaria desde el punto de vista del proceso justo.

${ }^{218}$ Cfr. VOLK, Grundkurs, cit. nota n ${ }^{\circ} 25, \S 9 \mathrm{~nm} .11$.

${ }^{219} \mathrm{BGH}, \mathrm{NJW}$, (2006), pp. 1008 ss., p. 1009, en la que el tribunal podría dejar abierto el punto en cuestión pero obiter ha huido de una acertada valoración de la utilización (1010). La decisión únicamente puede ser encontrada en relación con este caso concreto, habiendo sostenido el Tribunal Estadual in casu la imposibilidad de reclamar contra la conducta comprobada de los funcionarios de investigación penal. (LG Göttingen, Auto de 19 de abril de 2004, 6 Ks 7/03).

${ }^{220}$ Cfr. ya en ROXIN, Claus, "Gegenwart und Zukunft der Verteidigung im rechtsstaatlichen Strafverfahren", en: EBERT, Udo et al. (Coord.), Festschrift für Ernst-Walter Hanack zum 70. Geburtstag am 30. August 1999, Berlin: de Gruyter, 1999, pp. 1-25, p. 21 s.; ibid., Strafverfahrensrecht, cit. nota ${ }^{\circ} 34$, $\S 24 \mathrm{~nm}$. 25; sust. VOLK, Grundkurs, cit. nota $\mathrm{n}^{\circ} 25, \S 28 \mathrm{~nm}$. 22; PRITTWITZ, "Richtervorbehalt", cit. nota $\mathrm{n}^{\circ} 19$, pp. 492 ss.; crít. también MURMANN, "Über den Zweck", cit. nota $\mathrm{n}^{\circ}$ 6, nm. 203; JAHN, Beweiserhebungs- und Beweiserverwertungsverbote, cit. nota $\mathrm{n}^{\circ} 1, \mathrm{C} 111$ s., 128 , quien aboga por una solución afirmativa. Si se considera al abogado defensor como órgano de la justicia, tiene obligación de evitar y eventualmente subsanar errores procesales. Si se le considera como mero representante de los intereses de su cliente no tiene esta obligación (cfr. sobre esta diferenciación BEULKE, Strafprozessrecht, cit. nota $\mathrm{n}^{\circ} 13, \mathrm{~nm} .150$ ss. con más referencias).

${ }^{221}$ Crit. también WEIGEND, Thomas, "Festgenommene Ausländer haben ein Recht auf Benachrichtigung ihres Konsulates", StV, (2008), pp. 39-44, p. 43, según lo cual el BGH hace del acusado un "garante para que $[\ldots]$ el tribunal proceda en forma debida."

${ }^{222}$ Véase cit. nota ${ }^{\circ} 11$ y texto.
} 
AMBOS, Kai. "Las prohibiciones de utilización de pruebas en el proceso penal alemán - fundamentación teórica y sistematización”.

que la utilización de las aún restantes pruebas de cargo será siempre en contra del acusado y no necesita por tanto ser expresamente contradicha. ${ }^{223}$

La prohibición de utilización no tiene validez en beneficio de terceros. Cuando, por ejemplo, se archiva un proceso contra un inculpado (B) que fue interrogado sin instrucción previa y se requiere dar lectura a su interrogatorio dentro de otro proceso de conformidad con el $\S 2511$ No. 2 - por causa del fallecimiento de B, por lo que ya no puede ser interrogado como testigo -, la prohibición de utilización que originariamente surgió en favor de $\mathrm{B}$, ya no tiene ningún efecto para la(s) persona(s) acusada(s) dentro de otro proceso. En consecuencia, el interrogatorio de B puede ser introducido en forma de lectura en el juicio oral. ${ }^{224}$

La frustración del derecho a estar presente en el interrogatorio judicial durante la fase de investigación ( $\$ \S 168 \mathrm{c}$ II, 168 d I) conduce, en opinión de la jurisprudencia, solo a una atenuación del valor probatorio, ${ }^{225}$ admitiéndose la introducción del protocolo judicial (defectuoso) del interrogatorio en el juicio oral de acuerdo con el $\S 251$ II. ${ }^{226}$ Por otra parte, sin embargo, la infracción contra la obligación de notificación del § 168c V debería acarrear una prohibición de utilización. ${ }^{227}$ Esto resulta contradictorio, ya que el imputado pierde en ambos casos su derecho a ser escuchado (Art. 103 I Grundgesetz, Art. 6 Convención Europea de Derechos Humanos) y no puede incidir en el resultado de la prueba. Esto favorece también en ambos casos una prohibición de utilización. ${ }^{228}$

3.2.2. Instrucción deficiente de testigos con derecho a negarse a declarar o de dar ciertas informaciones $(\S \S 52-55)$.

Las declaraciones de parientes obtenidas sin la advertencia previa acerca de su derecho a negarse a declarar ( $\$ 52$ III) básicamente no pueden ser utilizadas, es decir, que a estas ni se les debe dar lectura, ni deben ser reconstruidas a través del interrogatorio de la persona que lo practicó. Esto se infiere del fin de protección del $\S 52$, esto es, no poner en riesgo los vínculos familiares. ${ }^{229}$ Por esta misma razón la declaración del pariente no

${ }^{223}$ ROXIN, "Beweisverwertungsverbot", cit. nota ${ }^{\circ} 11$, p. 618

${ }^{224}$ Cfr. VOLK, Grundkurs, cit. nota n ${ }^{\circ} 25, \S 28 \mathrm{~nm}$. 23; BEULKE, Strafprozessrecht, cit. nota $\mathrm{n}^{\circ} 13, \mathrm{~nm}$. 468; crítico ROXIN, Strafverfahrenstrecht, cit. nota ${ }^{\circ} 34, \S 24$ nm. 26.

${ }^{225}$ BGHSt 46, p. 93.

${ }^{226}$ BGH, StV, (1997), p. 512: si se informa al acusado sobre la valoración diferente del protocolo; en contra ACHENBACH, Hans, " $\$ 168 ”$, en: WASSERMANN, Rudolf (Coord.), Alternativkommentar zur Strafprozessordnung in 3 Bänden, Neuwied, 1988, § 168c nm. 18; crít. tambien VOLK, Grundkurs. cit. nota $\mathrm{n}^{\circ} 25, \S 28 \mathrm{~nm} .26$.

${ }^{227}$ MEYER-GOßNER, Strafprozessordnung, cit. nota $\mathrm{n}^{\circ} 52, \S 168 \mathrm{c} \mathrm{nm}$. 6. Si no tiene lugar la notificación del acusado para la fecha acordada, no puede verse en ello una concluyente decisión del juez de instrucción de que la citación del acusado ponga en peligro la investigación y, con ello, según el § 268c, ap. 5, oración 2 tenga que quedar sin efecto. Los motivos para tal decisión deben estar dados más bien en el acta. (SchlHOLG, StV, (2008), p. 401).

${ }^{228}$ Con igual resultado FEZER, Strafprozessrecht, cit. nota n ${ }^{\circ} 99$, p. 221; ROXIN, Strafverfahrenstrecht, cit. nota $\mathrm{n}^{\circ}$ 34, § 24 nm. 31; KÜHNE, Strafprozessrecht, cit. nota ${ }^{\circ}$ 4, nm. 909.1; MEYER-MEWS, "Beweisverwertungsverbote", cit. nota $\mathrm{n}^{\circ}$ 36, p. 41; FINGER, "Prozessuale Beweisverbote", cit. nota ${ }^{\circ}$ 13, p. 535; también JÄGER, Beweisverwertung und Beweisverwertungsverbote, cit. nota $\mathrm{n}^{\circ} 15$, p. 194 ss.

${ }^{229}$ ROXIN, Strafverfahrenstrecht, cit. nota $n^{\circ} 34, \S 24 \mathrm{~nm} .32$; VOLK, Grundkurs, cit. nota n ${ }^{\circ} 25, \S 28 \mathrm{~nm}$. 15. Puede, sin embargo, ser suficiente para la instrucción según el $\S 52$ II 1 que se informe el testigo de su (posible) derecho de negar la declaración (BGH, NStZ, (2006), p. 647 s.) 
Polít. crim., Vol. 4, $\mathrm{N}^{\circ} 7$ (Julio 2009) Art. 1, pp. 1-56.

[http://www.politicacriminal.cl/Vol_04/n_07/Vol4N7A1.pdf]

puede desempeñar ningún papel probatorio, sin que para ello importe si el tribunal en el momento del interrogatorio del testigo conocía o no la relación de parentesco del interrogado; ${ }^{230}$ eventualmente el testigo tiene que ser instruido adicionalmente sobre su relación de parentesco con el acusado. ${ }^{231}$ No obstante, la utilización es posible en dos casos: por una parte, después del fallecimiento del testigo; ${ }^{232}$ por otra, si el testigo ha declarado pese a conocer su derecho de abstenerse, pues en este caso su declaración no es producto de la omisión de advertencia sobre el derecho. ${ }^{233}$

En los casos de personas de confianza, en los cuales por regla general se puede asumir el conocimiento del derecho a abstenerse del testimonio ( $\$ 53)$; entra en consideración una infracción procesal solamente cuando el tribunal (que tiene la obligación de asistencia) no hace las advertencias de rigor a una persona de confianza, la cual cree que está obligada a declarar o si, erróneamente, se le informa que está dispensada del deber de guardar silencio y que por esa razón debe declarar obligatoriamente (§ 53 II). Solamente en estos casos son incuestionables las prohibiciones de utilización. ${ }^{234} \mathrm{Si}$ la persona de confianza declara pese al conocimiento de su derecho de abstenerse de declarar, no se produce una prohibición de utilización según la opinión dominante, puesto que únicamente cuenta con el derecho de abstenerse a declarar, pero no con la obligación de abstenerse a declarar. ${ }^{235}$ Sin embargo, esta argumentación despierta dudas con respeto a la relación entre la persona de confianza y el imputado (cliente, paciente, etc.) que puede ser lesionada mediante una declaración de tal índole, tomando en cuenta, además, que esta relación está protegida penalmente ( $\$ 203$ Código Penal: vulneración de secretos personales). Si se toma en consideración el fin de protección del $\S 53$, esta relación de confianza también incluye la protección procesal - paralelamente a la situación de protección material - de tal manera que se puede argumentar que la antijuridicidad material de la declaración conlleva su no utilización procesal. ${ }^{236}$ Contrariamente, se acude al fin de protección en caso de la declaración testimonial sin autorización conforme al $\S 54$, con el objeto de rechazar una prohibición de utilización, ya que el propósito de la disposición - la salvaguardia del deber de reserva de funcionarios públicos - se encuentra irrevocablemente frustrado con la declaración. ${ }^{237}$

\footnotetext{
${ }^{230}$ BGHSt 14, pp. 159 ss., p. 160.

${ }^{231} \mathrm{BGH}$, NStZ, (2006), p. $647 \mathrm{~s}$.

${ }^{232}$ BGHSt 22, p. 35; de otra opinión ROXIN, Strafverfahrenstrecht, cit. nota $\mathrm{n}^{\circ} 34, \S 24 \mathrm{~nm}$. 32; VOLK, Grundkurs, cit. nota $\mathrm{n}^{\circ} 25, \S 28$ nm. 15; BEULKE, Strafprozessrecht, cit. nota $\mathrm{n}^{\circ} 13$, nm. 461; con el mismo resultado JÄGER, Beweisverwertung und Beweisverwertungsverbote, cit. nota $\mathrm{n}^{\circ}$ 15, $\mathrm{p} .146$.

${ }^{233}$ Cfr. BGHSt 38, pp. 214 ss., p. 225; BGHSt 40, pp. 336 ss., p. 339; BGH, NStZ, (1990), p. 549 s.; NStZ$R R$, (2004), p. 212.

${ }^{234}$ VOLK, Grundkurs, cit. nota ${ }^{\circ} 25, \S 28 \mathrm{~nm} .16$.

${ }^{235}$ BGHSt 9, 59, 62; 15, 200, 202; 18, 146, 147; a favor VOLK, Grundkurs, cit. nota n ${ }^{\circ} 25, \S 28 \mathrm{~nm} .17$; HELLMANN, Strafprozessrecht, cit. nota ${ }^{\circ} 18, \S 3 \mathrm{~nm}$. 29; KINDHÄUSER, Strafprozessrecht, cit. nota $\mathrm{n}^{\circ} 34, \S 23$ nm. 20; FINGER, "Prozessuale Beweisverbote", cit. nota ${ }^{\circ} 13$, p. 533.

${ }^{236}$ Así BEULKE, Strafprozessrecht, cit. nota $\mathrm{n}^{\circ} 13$, nm. 462 con más referencias.

${ }^{237}$ Cfr. VOLK, Grundkurs, cit. nota n ${ }^{\circ} 25, \S 28$ nm. 18; KINDHÄUSER, Strafprozessrecht, cit. nota $\mathrm{n}^{\circ} 34$, $\S 23$ nm. 21; FINGER, "Prozessuale Beweisverbote", cit. nota $n^{\circ}$ 13, p. 533; de otra opinión FEZER, Strafprozessrecht, cit. nota $\mathrm{n}^{\circ} 99$, p. 223.
} 
AMBOS, Kai. "Las prohibiciones de utilización de pruebas en el proceso penal alemán - fundamentación teórica y sistematización”.

El proyecto de ley mencionado supra ${ }^{238}$ preveía originariamente - en un nuevo $\S 53 b-$ una prohibición absoluta de producción y utilización probatoria para el caso de numerosas medidas investigativas tanto encubiertas como abiertas que afectaban a religiosos, defensores o parlamentarios ( $\$ 53$ I Nros. 1, 2, 4); respecto de las demás personas de confianza ( $\$ 53$ Nros. $3,3 \mathrm{a}, 3 \mathrm{~b}, 5)$ fue propuesta una prohibición probatoria relativa (control de proporcionalidad). Los parientes $(§ 52)$ no debían estar protegidos. $^{239}$

Ya fue anteriormente señalado ${ }^{240}$ que la falta de instrucción del testigo con derecho a negarse a dar ciertas informaciones $(\S 55)$ no debe acarrear una prohibición de utilización de prueba, puesto que, de acuerdo con la opinión tradicional del Tribunal Supremo Federal, con tal infracción no se afecta el ámbito de derechos del imputado. ${ }^{241}$ Sin embargo, si se considera igualmente protegido con el $\S 55$ el interés del acusado de "declarar testimonialmente, libre de conflictos y de modo verídico", ${ }^{242}$ también es factible fundamentar una prohibición de utilización de pruebas. En todo caso surge una prohibición de utilización de pruebas si el testigo se convierte en inculpado y se opone a la utilización en un juicio oral posterior, ${ }^{243}$ pues entonces vale precisamente lo dicho para los casos de no información del acusado (supra 3.2.1)).

\subsubsection{Ejecución ilícita de medidas coercitivas.}

a) Infracción contra la prohibición de comiso (§ 97 I).

La prohibición de comiso del $\S 97$ I complementa el derecho a guardar silencio de los $\S \S$ 52, 53 y 53a. En consecuencia, su vulneración conlleva una prohibición de utilización de prueba $^{244}$ en todos los casos en los que los objetos sujetos a la prohibición se encuentren en poder de los testigos. Si los objetos están en poder del inculpado, o si el titular del

\footnotetext{
${ }^{238}$ Ver cit. nota $\mathrm{n}^{\circ} 120$.

239 Las mencionadas prohibiciones de utilización probatoria respecto de quienes deben guardar secreto profesional no fueron consideradas en la recomendación final de la Comisión Jurídica del Bundestag y, por tanto, tampoco en la ley finalmente sancionada (cfr. BT-Drucks. 16/6979; BGBl. (2007) I, 3198). Cfr. sobre el Proyecto de ley WOLTER, "Alternativen", cit. nota ${ }^{\circ} 120$, pp. 184 ss., quien, por su parte, también propone nuevas prohibiciones probatorias - haciendo referencia al "Alternativ-Entwurf Zeugnisverweigerungsrechte" ("Proyecto alternativo sobre los derechos de no declaración de testigos") (AE-ZVR, 1992-1996) y al Proyecto de Ley del "Mannheimer Arbeitskreis Strafprozessrecht und Polizeirecht" ("Proyecto de Ley del Grupo de trabajo en Derecho Penal y Derecho Procesal de Mannheim”) (ASP-E, 2002) - (pp. 187 ss., pp. 190 ss.) y entiende evaluable "un derecho de negarse a prestar declaración testimonial, entre otras cosas, para la protección del 'ámbito nuclear de la vida privada"" (sobre esto 3. 2. en nota 112) (199).

${ }^{240}$ Ap. 3.2.1, y cit. nota $\mathrm{n}^{\circ} 168$ y ss.

${ }^{241}$ BGHSt GrS 11, S. 213, 215; MEYER-GOßNER, Strafprozessordnung, cit. nota n ${ }^{\circ} 52$, § 55 nm. 17.

${ }^{242}$ ROXIN, Strafverfahrenstrecht, cit. nota $\mathrm{n}^{\circ} 34, \S 24 \mathrm{~nm} .36$.

243 BGH NZV 2001, 527; OLG Celle, NStZ, 2002, 386; MEYER-GOßNER, Strafprozessordnung, cit. nota $\mathrm{n}^{\circ}$ 52, § 55 nm. 17; ROGALL, Klaus, “§ 133”, en: RUDOLPHI, Hans-Joachim; WOLTER, Jürgen, Systematischer Kommentar zur Strafprozessordnung und zum Gerichtsverfassungsgesetz, 2008, antes de $\S$ 133 nm. 188; FINGER, "Prozessuale Beweisverbote", cit. nota n 13, p. 533.

${ }^{244}$ NACK, Armin, en Karlsruher Kommentar zur Strafprozessordnung, 6. ed. München: Beck, 2008, §97 nm. 9; FEZER, Strafprozessrecht, cit. nota ${ }^{\circ} 99$, p. 221; ROXIN, Strafverfahrenstrecht, cit. nota $\mathrm{n}^{\circ} 34, \S$ 24 nm. 34; VOLK, Grundkurs, cit. nota $n^{\circ} 25$, 28 nm. 20; BEULKE, Strafprozessrecht, cit. nota $\mathrm{n}^{\circ} 13$, nm. 463; KÜHNE, Strafprozessrecht, cit. nota ${ }^{\circ} 4$, nm. 909.1.
} 
Polít. crim., Vol. 4, $\mathrm{N}^{\circ} 7$ (Julio 2009) Art. 1, pp. 1-56.

[http://www.politicacriminal.cl/Vol_04/n_07/Vol4N7A1.pdf]

derecho a abstenerse del testimonio es el mismo inculpado, no tiene validez la prohibición de la utilización. ${ }^{245}$

b) Práctica ilícita de exámenes corporales (§ 81a).

Independientemente de la prohibición de utilización de prueba contemplada en el $\S 81$ a III, referente a una utilización ilícita para otro proceso diferente al que se sigue contra el inculpado, el tema de los exámenes corporales se considera una prohibición de utilización no escrita y dependiente en aquellos casos en los que el examen corporal (especialmente la prueba de sangre) no es realizada por un médico forense, o cuando ha sido ordenada por una persona no competente (en este sentido se trata de una prohibición relativa de producción probatoria). La opinión dominante, sin embargo, tradicionalmente la rechaza, ya que por un lado el $\S 81$ a solo pretende proteger ante daños a la salud - y la punibilidad de la conducta ( $\S \S 223,239$ StGB) de por sí asegura este fin de protección -; pero por otro lado una infracción contra el $\S 81$ a no disminuye el valor de la prueba ni tampoco cabe predicarlo por razón de la persona que la practica. ${ }^{246}$ De la jurisprudencia más reciente se dejan extraer en este sentido mayores exigencias. En primer lugar ha resaltado el Tribunal Constitucional que para el caso del § 81a - así como para los registros domiciliarios (sobre esto infra d)) y para medidas privativas de la libertad - debe llevarse a cabo con posterioridad un efectivo control judicial de las órdenes expedidas por la Fiscalía en casos de urgencia; ${ }^{247}$ con esto ha reforzado la relación regla-excepción de la orden judicial y la competencia fiscal (o policial) en casos de urgencia. Sólo en casos en que peligre el éxito de la investigación habría también una competencia de expedir órdenes por parte de la Fiscalía y - a nivel inferior - de sus investigadores. Las autoridades de investigación penal deberían por tanto intentar regularmente conseguir una orden del juez competente, antes de que ellas mismas ordenen la extracción de sangre. La puesta en peligro del éxito de la investigación - que funda la competencia de emergencia - debería ser fundada con hechos que refieran a un caso de urgencia y que queden documentados en las actas de la investigación, en tanto la urgencia no sea evidente. ${ }^{248} \mathrm{El}$ $\mathrm{BGH}$ ha dicho en relación con el $\S 102$ ss. - haciendo referencia a esta jurisprudencia constitucional - que una desobediencia intencional o una ignorancia burda de la obligación de la orden judicial no debería quedar sin sanción; ${ }^{249}$ la jurisprudencia (de

\footnotetext{
${ }^{245}$ BGHSt 25, 168, 170 s.; PFEIFFER, Gerd, Strafprozessordnung, 5. ed., München: Beck, $2005, \S 97 \mathrm{~nm}$. 1; en particular, igualmente JÄGER, Beweisverwertung und Beweisverwertungsverbote, cit. nota $\mathrm{n}^{\circ} 15$, $\mathrm{p}$. 203.

${ }^{246}$ BGHSt 24, pp. 125 ss., p. 128; OLG Karlsruhe, StV, (2005), p. 376; a favor FEZER, Strafprozessrecht, cit. nota $\mathrm{n}^{\circ}$ 99, p. 222; ROXIN, Strafverfahrenstrecht, cit. nota $\mathrm{n}^{\circ} 34$, § 24 nm. 37; VOLK, Grundkurs, cit. nota $\mathrm{n}^{\circ} 25, \S 28 \mathrm{~nm}$. 27; BEULKE, Strafprozessrecht, cit. nota $\mathrm{n}^{\circ} 13, \mathrm{~nm} .477$ (sin embargo, con una fundamentación dudosa se dice que no se pueden esperar perjuicios a la salud); en particular, igualmente KÜHNE, Strafprozessrecht, cit. nota $\mathrm{n}^{\circ} 4$, nm. 909.2; JÄGER, Beweisverwertung und Beweisverwertungsverbote, cit. nota $\mathrm{n}^{\circ} 15$, pp. 196 ss.

${ }^{247}$ BVerfG, NJW, (2007), p. 1345 s. = StV (2007), p. 281 s.

${ }^{248}$ BVerfG, NJW, (2007), p. 1346 entre otros haciendo referencia a BVerfGE 103, pp. 142 ss., p. 155 s., 160.

${ }^{249}$ BGH, NJW, (2007), pp. 2269 ss., p. $2272=$ NStZ, (2007), pp. 601 ss., p. $603=$ StV, (2007), pp. 337 ss., p. 338 s.); sobre esto infra nota 271 s. y texto.
} 
AMBOS, Kai. "Las prohibiciones de utilización de pruebas en el proceso penal alemán - fundamentación teórica y sistematización”.

Corte) ha trasladado esto al $\S 81 \mathrm{a} .{ }^{250}$ Con Roxin se deja incluso extraer de la decisión del $\mathrm{BGH}$ el principio general de que el Estado en ningún caso puede sacar provecho de las infracciones intencionales de sus funcionarios $\mathrm{y}$, que por tanto en estos casos, entre los cuales se cuenta también la grosera desatención a la obligación de la orden judicial, debe partirse siempre de la prohibición de utilización probatoria. ${ }^{251}$ Con esto se establece, en definitiva, una conexión con la idea antes expresada, que en caso de violaciones jurídicas particularmente graves (infracción sabida o intencional de la norma o aplicación con medios ilegales) debe asumirse una infracción al principio del juicio justo, ${ }^{252}$ del cual se desprende una prohibición de utilización probatoria. ${ }^{253}$ De todo esto se sigue para el $\S$ 81a, que en caso de que falte la fundamentación y documentación de la pretendida competencia de urgencia en las actas de la investigación, debe ser asumida por regla una infracción grave contra la obligación de la orden judicial y por tanto debe asumirse la prohibición de la utilización de las pruebas. ${ }^{254}$

Si bien la mencionada jurisprudencia ${ }^{255}$ ha aceptado la prohibición de utilización probatoria en un solo caso, ${ }^{256}$ ha seguido sin embargo los principios postulados por el BGH sobre la obligacón de orden judicial en el $\S 102$ ss. Ejemplar fue en este sentido la jurisprudencia del OLG Stuttgart ${ }^{257}$ como primera decisión de un Tribunal Superior dada luego de la decisión del BGH. El OLG rechazó la apelación del afectado contra la utilización de los resultados de una extracción de sangre realizada por un policía en el marco de su competencia de urgencia, aunque "no había peligro para el éxito de la investigación en caso de retraso (...)". ${ }^{258}$ No obstante, este rechazo fue fundado en que la

${ }^{250}$ OLG Stuttgart, NStZ, (2008), p. 238; OLG Hamburg, StV, (2008), pp. 454 ss., p. 456 s.; LG Itzehoe, StV, (2008), pp. 457, p. 458 s.; LG Flensburg, StV, (2008), p. 459 s. Crit. sobre esta jurisprudencia PRITTWITZ, "Richtervorbehalt", cit. nota n¹9, pp. 487 ss., quien critica que el BGH rehúse al "culpable obediente" (p. 494). Sobre la traslación a la obligación de orden judicial del § 81a cfr. AMELUNG, Knut, "Die Entscheidung des BVerfG zur 'Gefahr im Verzug' i.S. des Art. 13 II GG', NStZ, (2001), pp. 337-343, p. 342.

${ }^{251}$ ROXIN, "Beweisverwertungsverbot”, cit. nota $\mathrm{n}^{\circ} 11$ p. 617 (continuando su idea previa en ROXIN, Claus, “Anmerkung zum Urteil des BGH vom 17.2.1989 - 2 StR 402/88”, NStZ, (1989), pp. 376-379); respecto del. § 81a también PRITTWITZ, "Richtervorbehalt”, cit. nota n¹9, p. 491 s., p. 494.

252 BGHSt 24, 125, 131; sust. ROXIN, Strafverfahrenstrecht, cit. nota $\mathrm{n}^{\circ} 34$, $\$ 24$ nm. 37; VOLK, Grundkurs, cit. nota ${ }^{\circ} 25, \S 28 \mathrm{~nm}$. 27; BEULKE, Strafprozessrecht, cit. nota ${ }^{\circ} 13$, nm. 477; cfr. también FINGER, "Prozessuale Beweisverbote", cit. nota $\mathrm{n}^{\circ} 13$, p. 536 con referencia (nota 75 s.) a los casos particularmente problemáticos de extracción de fluídos corporales, suministro de vomitivos y de cateter; sobre una prohibición de utilización probatoria en casos de suministro de vomitivos por infracción del Art. 3 CEDH y del principio de juicio justo (art. 6 CEDH) EGMR StV 2006, 617 ss. (Jalloh vs. Germany); también J ̈̈GER, Beweisverwertung und Beweisverwertungsverbote, cit. nota ${ }^{\circ} 15, \mathrm{~S} .212$ ss.; sobre Jalloh vs. Germany y el derecho procesal penal alemán SAFFERLING, Christoph J.M., "Die zwangsweise Verabreichung von Brechmittel: Die StPO auf dem menschenrechtlichen Prüfstand”, Jura, (2008), pp. 100108; sobre el principio nemo tenetur en este contexto cfr. EIDAM, Die Strafprozessuale Selbstbelastungsfreiheit, cit. nota $\mathrm{n}^{\circ} 58$, pp. 123 ss.

${ }^{253}$ Cfr. sobre esto también BGH, NJW, 2007, p. 2271 con referencia a BGHSt 24, pp. 125 ss., p. 131.

${ }^{254}$ Cfr. también PRITTWITZ, "Richtervorbehalt", cit. nota n¹9, p. 492.

${ }^{255}$ Cit. nota $\mathrm{n}^{\circ} 250$.

${ }^{256}$ LG Flensburg, $S t V$, (2008), p. 459, sin embargo, al poco tiempo retractado (StV, (2008), p. 459 s.).

${ }^{257}$ OLG Stuttgart, NStZ, (2008), p. 238.

258 Ibid. El motivo para la orden de extracción de sangre en el marco de un control de tránsito fue la sospecha, reforzada por el pre-test de droga, de que el sujeto en cuestión conducía el automóvil no obstante 
Polít. crim., Vol. 4, $\mathrm{N}^{\circ} 7$ (Julio 2009) Art. 1, pp. 1-56.

[http://www.politicacriminal.cl/Vol_04/n_07/Vol4N7A1.pdf]

orden dada por el oficial de policía para la extracción de sangre, in casu, ni fue hecha conscientemente equivocada, ni objetivamente arbitraria, sino que se basó en la "equivocada falsa apreciación" de que la espera llevaría a una pérdida de la prueba por la rápida desconcentración del estupefaciente en el cuerpo del afectado (lo que de acuerdo a los hechos comprobados por el Tribunal no se hubiera dado). ${ }^{259}$ El Senado consideró, por tanto, que la orden de urgencia era ilegal, pero no quizo conectar a ella la prohibición de utilización probatoria por falta de conciencia del equívoco o de arbitrariedad. Señaló, sin embargo, obiter, que la argumentación desarrollada en los muy frecuentes casos de conducción bajo los efectos del alcohol apenas si podría llevar al rechazo de la prohibición de utilización probatoria, porque la posibilidad de comprobar la concentración de alcohol en sangre por conteo posterior es, en general, conocida y contradice básicamente la necesidad impostergable de la orden y realización de la extracción de sangre. ${ }^{260}$ Que con ello "legiones de oficiales de policía habrían excedido sus competencias en las últimas décadas y los Tribunales penales intervinientes en los procesos inmediatamente iniciados no lo [habrían] advertido" ${ }^{261}$ no cambia en nada respecto de las dudas que genera esta práctica, y hace la necesidad de una prohibición de utilización todavía más clara. En este sentido cabe recordar que el Tribunal Constitucional también vio necesario para los casos de registro domiciliario poner un fin al procedimiento de las autoridades de investigación penal, "el cual sin exageración puede calificarse como una violación a la ley practicada durante más de 100 años." 262

c) Vigilancia ilícita de las telecomunicaciones ( $§ 100 \mathrm{a}, \mathrm{b}, \mathrm{g}, \mathrm{h})$.

Exceptuando la prohibición explícita de la utilización ilícita de pruebas (v. supra ap. 2.2), se ha de considerar la no utilización de los conocimientos obtenidos a través de la vigilancia de las telecomunicaciones, cuando se desatiendan los presupuestos materiales que requiere la orden, por ejemplo cuando la orden se expidió sin que exista sospecha de la comisión de un delito del catálogo, o fue expedida con violación del principio de subsidiariedad o la vigilancia resultaba ilícita en otro sentido, en particular el caso de la vigilancia de conversaciones del defensor en contra de lo establecido en el $\S 148 .{ }^{263} \mathrm{~A}$ pesar de que existe un margen de apreciación, la jurisprudencia solo quiere reconocer una prohibición de utilización en caso de arbitrariedad objetiva o de una grave apreciación errónea. ${ }^{264}$ Además debería ser subsanable la deficiencia de una orden de vigilancia por la

estar bajo la influencia de estupefacientes (Cannabis con contenido THC, anfetaminas y cocaína). Esta sospecha fue confirmada por el resultado del test de sangre.

${ }^{259}$ OLG Stuttgart, NStZ, (2008), p. 239.

${ }^{260}$ OLG Stuttgart, NStZ, (2008), p. 239.

261 Así crítico GÖTZ, Hanjörg, "Kein Beweisverwertungsverbot bei fehlerhafter Annahme von Gefahr in Verzug", NStZ, (2008), pp. 239-240.

${ }^{262}$ AMELUNG, "Die Entscheidung", cit. nota n² 250, p. 337.

${ }^{263}$ BEULKE, Strafprozessrecht, cit. nota ${ }^{\circ} 13$, nm. 475; VOLK, Grundkurs, cit. nota n ${ }^{\circ} 25, \S 10$ nm. 46.

${ }^{264}$ BGHSt 41, 30, 34; 47, 362, 366; a favor ROXIN, Strafverfahrenstrecht, cit. nota ${ }^{\circ} 34, \S 24 \mathrm{~nm} .39$; también BERNSMANN, Klaus, "Anmerkung zu BGH, Urt. v. 16.2.1995 - 4StR 729/94 (BGHSt. 41, 30)", NStZ, (1995), pp. 512-513; KÜPPER, Georg, “Anmerkung zu BGH, Urt. v. 16.2.1995 - 4StR 729/94 (BGHSt. 41, 30)”, JR, (1996), pp. 214-216; SCHLOTHAUER, “Anmerkung zu BGH v. 7.5.2003”, cit. nota $\mathrm{n}^{\circ}$ 71, p. 208; más estricto a favor de una prohibición de utilización JÄGER, Beweisverwertung und Beweisverwertungsverbote, cit. nota $\mathrm{n}^{\circ} 15$, p. 205 y s., identificando "limitaciones relacionadas con el 
AMBOS, Kai. "Las prohibiciones de utilización de pruebas en el proceso penal alemán - fundamentación teórica y sistematización”.

inexistencia de un delito del catálogo que acepta la injerencia, cuando a la vez ha surgido otra sospecha dirigida a un delito del catálogo. ${ }^{265}$ Las infracciones en contra de los presupuestos formales de la orden $(\S \S 100 \mathrm{~b}, 101)$ no justifican una prohibición de utilización, excepto si de antemano hace falta una autorización del juez o del fiscal $(\S \S$ $100 \mathrm{~b}){ }^{266}$ pues aquí existe una falta grave en el sentido del $\S 44$ de la Ley de Procedimiento Administrativo (Verwaltungsverfahrensgesetz). ${ }^{267}$ En este caso, la (eventual) prohibición de utilización de pruebas debe alegarse en el juicio oral (solución de oposición previa). ${ }^{268}$

d) Registro ilícito de domicilio ( $§ 102$ ss.)

Ante la significativa importancia del derecho fundamental a la inviolabilidad del domicilio (Art. 13 Ley Fundamental, véase supra ap. 2.3) y las - antes mencionadas ${ }^{269}$ exigencias jurídico-constitucionales estrictas para afectarlo, es necesario considerar la competencia inmediata ("riesgo en la demora") por parte de la fiscalía y los agentes de investigación policial ( $\$ 105$ I frase 1) para ordenar el registro domiciliario. ${ }^{270}$ A este respecto se plantea la cuestión de si el uso desacertado de la competencia en casos de urgencia acarrea una prohibición de utilización de los medios probatorios hallados en el marco del registro. De todos modos, esto debe contestarse afirmativamente ante una desobediencia consciente o un burdo desconocimiento de los requisitos de la obligación de orden judicial. ${ }^{271}$ En este sentido, en especial la evitación consciente de la orden judicial y la asunción arbitraria de peligro en el retraso, como también la lesión arbitraria del derecho a estar presente, deben ser reconocidas como infracciones graves que perjudican la claridad - principio del juicio justo - del proceso. ${ }^{272}$

La necesidad de aceptar una prohibición de utilización de pruebas sigue en estos casos la importancia antes mencionada del reconocimiento constitucional de la obligación de orden judicial, puesto que esta es "tan esencial para el proceso de investigación gravado por los principios del Estado de Derecho, que faltas graves contra él no pueden ser

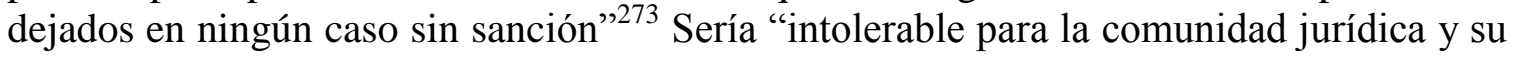
idea del derecho, si la protección del domicilio asegurada constitucionalmente mediante

objeto de prueba" ("beweisgegenstandsbezogene Beschränkungen") en la prohibición de práctica probatoria.

${ }^{265}$ BGHSt 48, p. 240. Crítico BEULKE, Strafprozessrecht, cit. nota n ${ }^{\circ} 13$, nm. 475 con más referencias en nota $58 \mathrm{~s}$.

${ }^{266}$ BEULKE, Strafprozessrecht, cit. nota ${ }^{\circ} 13, \mathrm{~nm} .475$ con más referencias.

267 Sobre esta situación paralela con el derecho administrativo ver JÄGER, Beweisverwertung und Beweisverwertungsverbote, cit. nota $\mathrm{n}^{\circ} 15, \mathrm{p} .238$.

${ }^{268} \mathrm{BGH}, N J W$, (2006), p. 1361 ; ya crítico cit. nota $\mathrm{n}^{\circ} 218$ s. y el texto.

${ }^{269}$ Supra b) en nota $247 \mathrm{~s}$.

${ }^{270}$ BVerfG, NStZ, (2001), p. 382; así también BGH, NJW, (2007), pp. 2269 ss., p. 2272 (véase cit. nota n ${ }^{\circ}$ 249). Las autoridades de investigación penal, por tanto, tampoco deben esperar entretanto la solicitud de orden judicial hasta que se configure el riesgo en la demora (BVerfG StV (2003), p. 206).

${ }^{271}$ BGH, NJW, (2007), p. $2269=$ StV , (2007), pp. 337 ss., p. $339=N S t Z$, (2007), pp. 601 ss., p. 603. Cfr. también OLG Hamm, NStZ, (2007), p. 355.

272 BGH, NJW, (2007), p. 2271 s.; Juzgado Penal (AG) Bremen, StV, (2008), p. 588 (derecho a estar presente).

${ }^{273} \mathrm{BGH}, N J W$, (2007), p. 2272. 
Polít. crim., Vol. 4, $\mathrm{N}^{\circ} 7$ (Julio 2009) Art. 1, pp. 1-56.

[http://www.politicacriminal.cl/Vol_04/n_07/Vol4N7A1.pdf]

el control judicial pudiera ser siempre dejada sin efecto arbitrariamente, sin que esto aparejase consecuencia alguna." 274

Si faltara desde el principio una autorización de registro válida a causa de una errada pretensión de competencia de urgencia, existiría entonces una derogación posterior si la autorización original no hubiera sido ejecutoriada dentro de los seis meses siguientes a su expedición. ${ }^{275}$ A favor de una prohibición de utilización, en estos casos habla la importancia del derecho fundamental al amparo domiciliario, ${ }^{276}$ en contra de la aplicación correspondiente de los principios de la vigilancia de telecomunicación (citados anteriormente), según los cuales solo una infracción material justifica una prohibición de utilización. $^{277}$

e) Investigaciones secretas.

La situación en este ámbito es poco clara, puesto que la $S t P O$ únicamente contiene reglas para investigadores encubiertos (Verdeckte Ermittler), esto es, para funcionarios policiales que investigan infiltrados de manera encubierta ( $\$ 110 \mathrm{a}$ II), entre otros la prohibición de utilización anteriormente mencionada referente a otros procesos penales ( $\$$ 477 II 2); con respeto a otras personas que investigan secretamente (informantes, particulares al servicio de la policía que actúan como personas de contacto o V-Leute, personas que no investigan públicamente) solo es aplicable el $\S 163$ I frase 2 como fundamento legal no específico. ${ }^{278}$ Por el carácter secreto de las investigaciones se asemejan estas a las medidas para la vigilancia de las telecomunicaciones (anteriormente citadas), de tal manera que las reglas mencionadas a este efecto son aplicables a este caso de forma respectiva. Por consiguiente, una prohibición de utilización se considera - en cuanto a los agentes encubiertos - en caso de ausencia de los presupuestos materiales o del consentimiento judicial o fiscal. ${ }^{279}$ Sin embargo, deben utilizarse los medios probatorios que fueron conseguidos dentro de los primeros tres días hábiles de la medida, ya que el consentimiento fiscal (posterior) puede obtenerse "dentro de tres días hábiles" ( $\$ 110$ b I); incluso si el consentimiento judicial posterior, necesario según $\S 110$ b II, no puede obtenerse en este término de tiempo, se permite igualmente la utilización de los medios probatorios obtenidos en los primeros tres días. ${ }^{280}$ Se reconoce una prohibición de utilización de prueba, si otros investigadores estatales, que no son agentes encubiertos,

\footnotetext{
${ }^{274} \mathrm{BGH}, \mathrm{NJW},(2007)$, p. 2272

${ }^{275}$ Según BVerfG, $N J W,(1997)$, p. 2165 , el mandato pierde su validez a partir de este momento.

${ }^{276}$ En favor el AG Braunschweig, StV, (2001), p. 394 s.; FINGER, "Prozessuale Beweisverbote", cit. nota $\mathrm{n}^{\circ} 13$, p. 536.

${ }^{277}$ En este sentido BGHSt 41, pp. 30 ss., p. 34, alegando que una prohibición de utilización solamente existe en caso de arbitrariedad objetiva o una decisión manifestamente falsa; del mismo modo BGH, StV, (2003), p. 3 s.; en la misma línea JÄGER, Beweisverwertung und Beweisverwertungsverbote, cit. nota ${ }^{\circ}$ 15 , p. 203 s.

${ }^{278}$ MEYER-GOßNER, Strafprozessordnung, cit. nota $\mathrm{n}^{\circ}$ 52, § 110a nm. 4, § $163 \mathrm{~nm} .34 \mathrm{a}$.

${ }^{279}$ BGHSt 42, p. 103; BEULKE, Strafprozessrecht, cit. nota $\mathrm{n}^{\circ} 13$, nm. 481a; VOLK, Grundkurs, cit. nota $\mathrm{n}^{\circ} 25, \S 28 \mathrm{~nm}$. 30; KÜHNE, Strafprozessrecht, cit. nota $\mathrm{n}^{\circ}$ 4, nm. 909.1.

${ }^{280}$ BGHSt 41, 64, 66; a favor BEULKE, Werner; ROGAT, Stefan, “Anmerkung zu BGH, Urt. V. 7.3.1995

- 1 StR 685/94 (BGHSt. 41, 64), JR, (1996), pp. 515-521, p. 520; ROGALL, Klaus, “Anmerkung zu Urteil”, JZ, (1996), p. 260.
} 
AMBOS, Kai. "Las prohibiciones de utilización de pruebas en el proceso penal alemán - fundamentación teórica y sistematización”.

logran por engaño entrar en domicilios ajenos, porque de esta manera eluden el requerimiento de la autorización judicial según $\S 110 \mathrm{~b}$ II no. $2 .^{281}$

El proceder de personas que investigan secretamente también debe medirse según las garantías propias del Estado de Derecho referentes al derecho a guardar silencio y otras prescripciones procesales del StPO (ante todo $\S \S 136,136 \mathrm{a}$ ), de modo que en caso de infracción también de allí puede extraerse una prohibición de utilización de pruebas.

\section{(1) Principio Nemo Tenetur.}

En caso que las medidas investigativas secretas (también) estén dirigidas a obtener declaraciones autoincriminantes del acusado, puede haber aquí una infracción del - ya tantas veces mencionado ${ }^{282}$ - principio nemo tenetur.

Sin embargo el gran Senado penal del BGH en su decisión "Hörfalle" 283 exceptuó a medidas que tienen su interés principal no en la coerción sino en lo secreto de la investigación, del ámbito de protección del principio nemo tenetur, donde sin embargo aceptó que tal procedimiento en algunas constelaciones particularmente problemáticas (p. ej. Lockspitzelfälle - trampa provocadora -, Romeo-Fälle - trampa Romeo -) podría "estar muy cerca" de infringir tal principio. ${ }^{284}$

Si por este principio sólo debe ser asegurado que la declaración sea hecha libre de coerción, no contemplando la autoincriminación motivada por el Estado (error), ${ }^{285}$ las conversaciones (informales) con agentes encubiertos o con quienes colaboran privadamente con las autoridades penales investigativas no estarían abarcadas por el principio, pues en estos casos el acusado no se ve sometido a coerción alguna. ${ }^{286}$

Sin embargo, según la jurisprudencia de la CEDH, el ámbito de aplicación del principio no se limita a estos casos. ${ }^{287}$ El principio se vería socavado ("undermined") más bien en

281 Dejando abierto BGH, NStZ, (1997), p. 449; a favor de una prohibición ROXIN, Claus, "Zum Einschleichen polizeilicher Scheinaufkäufer in Privatwohnungen”, StV, (1998), pp. 43-45, p. 45; JÄGER,

Beweisverwertung und Beweisverwertungsverbote, cit. nota $\mathrm{n}^{\circ} 15, \mathrm{p} .206 \mathrm{~s}$.

${ }^{282}$ Cfr. sobre todo supra 2.1.4.) con nota 9495 y 3.2.1.) con nota 203 s.

${ }^{283}$ Véase sobre esta decisión supra en apartado 2.1.

${ }^{284}$ BGHSt 42, pp. 139 ss., p. $156=$ NJW, (1996), pp. 2940 ss., p. 2943.

285 Sobre el ámbito de protección discutido cfr. JAHN, Beweiserhebungs- und Beweiserverwertungsverbote, cit. nota $\mathrm{n}^{\circ} 1, \mathrm{C} 79$ s. con más referencias.

${ }^{286}$ BGHSt 42, p. 152 s. $=$ NJW, (1996), p. 2943 s.

${ }^{287}$ EGMR, Allan vs. Gran Bretaña, para. 50: "While the right to silence and the privilege against selfincrimination are primarily designed to protect against improper compulsion by the authorities and the obtaining of evidence through methods of coercion or oppression in defiance of the will of the accused, the scope of the right is not confined to cases where duress has been brought to bear on the accused or where the will of the accused has been directly overborne in some way." En este caso (en alemán en StV, (2003), p. 257) la policía había puesto a propósito en la celda del apelante, quien estaba en prisión preventiva por sospecha de homicidio, a otro preso que estaba dispuesto a colaborar. Éste había recibido el encargo de lograr que el apelante le confiara información sobre su participación en el caso de homicidio. La indicación respecto del encargo era "to "push him for what you can"” (para. 13). La posterior declaración testimonial de este informante sobre los datos que (supuestamente) el apelante le había dado sobre su presencia en el lugar de los hechos, fue utilizado en el proceso en contra del apelante. 
Polít. crim., Vol. 4, $\mathrm{N}^{\circ} 7$ (Julio 2009) Art. 1, pp. 1-56.

[http://www.politicacriminal.cl/Vol_04/n_07/Vol4N7A1.pdf]

los casos en que las autoridades de investigación logran obtener mediante engaño que el sospechoso haga confesiones $\mathrm{u}$ otras manifestaciones que en un interrogatorio normal no hubieran conseguido. ${ }^{288}$

Si el derecho a no declarar del Art. $6 \mathrm{CEDH}$ en definitiva es lesionado por este procedimiento, dependería de todos modos de las circunstancias del caso concreto. En adhesión a una decisión de la Corte Suprema canadiense, ${ }^{289}$ se refiere la CEDH en este sentido a dos aspectos. Por una parte, si "the informer was acting as an agent of the State at the time the accused made the statement" y por otra, si "it was the informer who caused the accused to make the statement." El primer aspecto dependería de "whether the exchange between the accused and the informer would have taken place, and in the form and manner in which it did, but for the intervention of the authorities." En el segundo supuesto, depende de "whether the conversation between him and the accused was the functional equivalent of an interrogation, as well as on the nature of the relationship between the informer and the accused." 290

En consecuencia, la CEDH ha completado de este modo - con buenos fundamentos - la protección frente a autoincriminaciones forzadas, ya que presenta una protección frente a al entorno de autoincriminación, que se da en los casos de escuchas del acusado por parte de un informante colocado por el Estado.

Esta protección entra en juego de todas formas, cuando en la conversación entre el acusado y el informante - ya sea con base en la relación particular entre éste y el acusado, o por otras circunstancias de las preguntas - se ejerce tal presión en el acusado que es probable que éste termine confiando información al informante. Por tanto, no es necesario que la libertad de decisión del acusado haya sido anulada totalmente. ${ }^{291}$

Haciendo referencia a esta jurisprudencia el 3er. Senado del BGH confirmó recientemente la violación del principio nemo tenetur en un caso, dando por no utilizable la información así obtenida. En el caso en cuestión un agente encubierto logró que el acusado, tras largo insistir y aprovechando la relación de confianza que se había establecido con éste - quien se había amparado en su derecho de negarse a declarar -, hiciera declaraciones, obteniendo así informaciones sobre las circunstancias del hecho

\footnotetext{
${ }^{288}$ EGMR, Allan vs. Gran Bretaña, para. 50: "use subterfuge to elicit, from the suspect, confessions or other statements of an incriminatory nature, which they were unable to obtain during such questioning ..." (Resaltado K.A.).

${ }^{289}$ Supreme Court of Canada, Sentencia del 21 de junio de 1990, R. vs. Hebert en [1990] 2 Supreme Court Reports 151.

${ }^{290}$ EGMR, Allan vs. Gran Bretaña, para. 51 (Resaltado K.A.).

${ }^{291}$ Cfr. GAEDE, Karsten, "Anmerkung zu EGMR, Urt. D. 4. Sektion v. 5.11.2002 - Beschwerde Nr. 48539/99" (Fall Allan v. Großbritannien; zur Publikation in Rep. 2002-IX ausgewählt), StV, (2003), pp. 257-263, p. 261, quien por lo demás presenta en general la idea de que puede hablarse de una autoincriminación "provocada" del acusado en el sentido de la CEDH, cuando el informante mediante aprovechamiento de una relación personal significativa o por motivos derivados de las circunstancias trabaja con miras a la obtención de la información. Pues aquí no se concreta el riesgo general de brindar información a un colaborador de la policía, sino que se concretan las medidas especiales de investigación del Estado. En detalle sobre esta decisión de la CEDH también ESSER, Robert, "Anmerkung zu EGMR, Urt. D. 4. Sektion v. 5.11.2002 - Beschwerde Nr. 48539/99”, JR, (2004), p. 98.
} 
AMBOS, Kai. "Las prohibiciones de utilización de pruebas en el proceso penal alemán - fundamentación teórica y sistematización”.

mediante preguntas que semejaban una indagatoria. ${ }^{292}$ El Senado también vio motivos para controlar - sobre la base de la decisión de la CEDH -, "si se puede plegar a la aparentemente más restrictiva - decisión del Gran Senado para asuntos penales respecto del alcance del principio nemo tenetur". En su decisión concreta, sin embargo, no se alejó de aquella; ${ }^{293}$ pues in casu ya habrían sido excedidos los límites propios del Estado de Derecho que habían sido definidos en la "Hörfallentscheidung" (sentencia sobre la emboscada auditiva) respecto del interrogatorio que semeja una indagatoria sin que esté dada la intención de llevar adelante una investigación. ${ }^{294}$

Si bien hay que estar de acuerdo con el resultado del Senado, la jurisprudencia alemana de los tribunales superiores queda rezagada respecto de la jurisprudencia de la CEDH, ${ }^{295}$ ya que con la construcción de una "casi violación"296 (que no representa suficiente presión) del principio nemo tenetur deja abierto el camino para una ponderación de bienes, ${ }^{297}$ mientras que la CEDH asume también en los casos de declaraciones obtenidas mediante engaño una violación al principio nemo tenetur. Y esta violación nunca puede ser justificada por un interés público. ${ }^{298}$

A pesar de este hallazgo discute Rogall la discrepancia entre la jurisprudencia de la $\mathrm{CEDH}$ y el $\mathrm{BGH}$, puesto que no debe asumirse que la $\mathrm{CEDH}$ - mediante la fórmula "libre de error" - haya pretendido dar al principio nemo tenetur un contenido que no estaría justificado por sus antecedentes. En definitiva también en el caso Allan v. GBcomo en el caso decidido por el 3er. Senado - había una situación coercitiva. Sólo para este caso la CEDH habría confirmado una violación a la libertad de autoincriminación y ésto sería compatible con la jurisprudencia del BGH, entre otros en BGHSt 44, p. 129. La diferencia residiría no tanto en el alcance del ámbito de protección, sino en una distinta comprensión del concepto de coerción. Este no debe ser interpretado en forma demasiado estricta y - contra la CEDH - no debe ser extendido por ejemplo al "soltar"

${ }^{292} \mathrm{BGH}, N J W$, (2007), p. 3138 (Leitsatz - parte resolutiva -) = NStZ, (2007), p. $714=J Z,(2008)$, p 258.

293 BGH, NJW, (2007), p. $3140=N S t Z$, (2007), p. 715.

${ }^{294}$ Por lo tanto, en los motivos del fallo el Senado se refiere también a la circunstancia de que el interrogatorio al acusado, que ya se encontraba por otro asunto en prisión, tuvo lugar durante una salida transitoria. Estableció además, que el contacto establecido en prisión entre el agente encubierto y el acusado era el único contacto del acusado fuera de la prisión y que este, por tanto, para conseguir "aflojes" en sus condiciones de prisión, dependía de la colaboración del agente encubierto. El Senado determinó, por tanto, que la infracción en estas circunstancias era aún más grave, ya que "las autoridades de la persecución penal se aprovecharon adrede de la carga particular de la situación de detención para lograr que el acusado se abriera a ellas" y que la libertad de decisión del acusado habría estado tan seriamente restringida por las circunstancias generales, que su situación "estaba cercana a la particular situación forzada de un detenido en prisión preventiva al que se le coloca un soplón de la policía en la celda". Esto valdría en particular, porque el agente encubierto no se habría limitado a "preguntar aprovechando la confianza que el acusado le tenía, sino que avasalladoramente" lo habría compelido a que le brinde información. (BGH, NJW, (2007), p. 3141 s. = NStZ, (2007), p. 715 s.).

${ }^{295}$ Cfr. también GAEDE, “Anmerkung zu EGMR”, cit. nota n 291, p. 262.

${ }^{296}$ VERREL, Die Selbstbelastungsfreiheit, cit. nota ${ }^{\circ}$ 58, p. 156.

${ }^{297}$ Cfr. también ROGALL, Klaus, "Anmerkung", NStZ, (2008), p. 112; crít. sobre el proceder el Gran Senado también ROXIN, Claus, "Anmerkung", NStZ (1997), 18-21, p. 20 s.

${ }^{298}$ Cfr. EGMR, Saunders vs. GB, Sentencia del 17.12.1996, para. 74: "The public interest cannot be invoked to justify the use of answers compulsorily obtained in a non-judicial investigation to incriminate the accused during the trial proceedings." 
Polít. crim., Vol. 4, $\mathrm{N}^{\circ} 7$ (Julio 2009) Art. 1, pp. 1-56.

[http://www.politicacriminal.cl/Vol_04/n_07/Vol4N7A1.pdf]

informaciones. ${ }^{299} \mathrm{Si}$ bien es correcto en esta perspectiva que tampoco la CEDH considera suficiente a cada conversación "secreta" impulsada por el Estado a través de un informante como violación al art. $6 \mathrm{CEDH}$, sino que exige una infracción que ejerza una "presión psicológica" sobre el acusado - sea por tratarse de una relación cercana existente o por la forma de las preguntas - que ponga en cuestión la libre voluntad con que la información fue brindada. ${ }^{300}$ Finalmente, sin embargo, la $\mathrm{CEDH}$ estipula como criterio definitorio ya no precisamente la "modalidad de cómo se influye en la libertad de autoincriminación", sino, acertadamente, la envergadura del perjuicio en la esfera de los derechos fundamentales del afectado. ${ }^{301}$ La característica de cada "sonsacar" - también dentro de una celda - sigue siendo el engaño. Pero si se confirma que también mediante un procedimiento - más bien engañoso que coercitivo - de los oficiales de investigación se puede afectar marcadamente la esfera protegida por el Art. $6 \mathrm{CEDH}$, parece ser la consecuencia correcta (en concordancia con la $\mathrm{CEDH}^{302}$ ) que, de acuerdo con ello el ámbito de protección del principio nemo tenetur sea extendido a formas de comportamiento más allá de la fuerza directa, ${ }^{303}$ en lugar de reinterpretar conductas marcadas por el engaño como si se tratara de aquellas regidas por la fuerza.

¿Incumplimiento de la obligación de instrucción (\$ 136, 163a)?

$\mathrm{Si}$ agentes encubiertos $\mathrm{y}$ otros investigadores (particulares) secretos realizan efectivamente interrogatorios ${ }^{304}$, surge también la cuestión problemática, considerando la instrucción previa, de que cumplir con la práctica de la advertencia evidentemente significaría el final de la investigación secreta. Incluso en caso de un interrogatorio intencionadamente similar a una indagatoria del acusado, la jurisprudencia rechaza que se trate de una violación a la obligación de instrucción de los $\S \S 163 a, 136$, porque su fin "proteger al acusado de la equivocada idea, posiblemente causada por haber percibido el carácter oficial de un interrogatorio, de que está obligado a declarar" - no podría ser

\footnotetext{
${ }^{299}$ ROGALL, “Anmerkung”, cit. nota n ${ }^{\circ} 297$, p. 112 s.

${ }^{300}$ EGMR, Allan vs. Gran Bretaña, para. 52.

${ }^{301}$ DUTTGE, Gunnar, "Anmerkung zu BGH, Urteil vom 26.07.2006 - 3 StR 104/07 - Verwertung von Angaben des Beschuldigten gegenüber einem Verdeckten Ermittler“, JZ, (2008), pp. 262 ss., p. 262.

${ }^{302}$ En este sentido la CEDH; entre otros también EIDAM, Die Strafprozessuale Selbstbelastungsfreiheit, cit. nota $\mathrm{n}^{\circ}$ 58, p. 65 ss.; GAEDE, “Anmerkung zu EGMR”, cit. nota n 291, p. 262; MEYER-MEWS, Hans, „Anmerkung zu BGH, Urt. v. 26. 7. 2007 (3 StR 104/07)“, NJW, (2007), pp. 3138 ss., p. 3143; ESSER, „Anmerkung“, cit. nota ${ }^{\circ}$ 291, p. 107; RENZIKOWSKI, Joachim, “Anmerkung zu BGH, Urt. v. 26. 7. 2007 - 3 StR 104/07 Verwertungsverbot bei vernehmungsähnlicher Befragung durch Verdeckten Ermittler", JR, (2008), pp. 160-167, p. 165.

${ }^{303}$ Para esto DUTTGE, Gunnar, "Anmerkung", cit. nota $n^{\circ} 301$, p. 262, quien mediante "un recurso a la problemática jurídico-material de la delimitación entre 'engaño reforzador de la amenaza' y 'amenaza reforzadora del engaño' busca posibilitar la separación hasta ahora no lograda claramente entre coerción y engaño (en el marco del § 136a), p. 263; véase para la relación con la falta de error también BOSCH, Nikolaus, "Reichweite des nemo-tenetur-Grundsatzes bei verdeckten Ermittlungen", JA, (2007), pp. 903906, p. 905; ROXIN, Claus, "Nemo tenetur: die Rechtsprechung am Scheideweg", NStZ, (1995) pp. 465469, p. 466; en contra VERREL, Die Selbstbelastungsfreiheit, cit. nota $\mathrm{n}^{\circ}$ 58, p. 278; muy bien también MITSCH, Wolfgang, "Tod auf Mallorca - Verwertungsverbot wegen unzulässiger verdeckter Ermittlungsmethoden", JURA, (2008), pp. 211-215, p. 214 s., cuando le reprocha al 3er. Senado haber "recubierto" las medidas de investigación encubierta con la limitación favorable al acusado que hace en su decisión.

${ }^{304}$ Sobre el concepto de interrogatorio ver cit. nota $\mathrm{n}^{\circ} 73$.
} 
AMBOS, Kai. "Las prohibiciones de utilización de pruebas en el proceso penal alemán - fundamentación teórica y sistematización”.

violado por un interrogatorio informal, precisamente a falta de una percepción subjetiva de la obligación de declarar. ${ }^{305}$ Esta idea tiene por fundamento, naturalmente, la recién criticada interpretación estricta del principio nemo tenetur.

Una violación de eventuales obligaciones de instrucción (§ 136, §§ 52, 252) tampoco puede simplemente dar por resultado una prohibición de utilización, sino solamente en caso de una elusión intencional y consciente, cuando el investigador secreto precisamente por esta razón fue "encargado" con la investigación de un sospechoso. ${ }^{306} \mathrm{La}$ jurisprudencia, por ejemplo, permite interrogar al agente encubierto como testigo de referencia (Zeuge vom Hörensagen, hearsay evidence) en el juicio oral acerca de su conversación con una persona con derecho a abstenerse de declarar testimonialmente. ${ }^{307}$

En todo caso, los investigadores secretos de ninguna forma deben traspasar las prohibiciones del $\S 136 a^{308}$ Sin embargo, también aquí se desprende de una visión conjunta con los $\S 110$ a ss., que la prohibición de engaño contenida en el $\S 136 a$ (indistinto si análoga o directa) en el marco de investigaciones encubiertas solo puede ser aplicado restrictivamente. El $\S 110$ a II permite al agente encubierto engañar respecto de su identidad. Si se quisiera ver en este engaño, (respecto de la identidad) explícitamente permitido por el legislador, un engaño "prohibido" en el sentido del § 136a, se estaría en una situación de contradicción con la ley. ${ }^{309}$ Que la prohibición de engaño, sin embargo, incluso en las investigaciones encubiertas no es abolida totalmente, ya se advierte en el $\S$ 110c, 2da. oración. Allí se estipula que la aceptación del propietario del inmueble a que se ingrese a su domicilio no puede ser obtenida mediante la utilización de un engaño que vaya más allá de la farsa (Legende) (como p. ej. el presentarse como oficial o como "gasista" 310 ). Del hecho que el legislador haya regulado expresamente este caso especial no puede concluirse, no obstante, que en todos los demás casos esté permitido cualquier tipo de engaño. ${ }^{311}$ Más bien se ve que el legislador consideró necesaria una regulación explícita en vistas al Art. 13 GG, sin querer limitar a este caso la prohibición del § 136a en el marco de investigaciones encubiertas. ${ }^{312} \mathrm{Si}$ se debiera partir, luego de lo antes dicho

\footnotetext{
${ }^{305}$ BGHSt 42, pp. 139 ss., p. 147 s. = NJW (1996), p. 2941 s.; véase sobre esta decisión cit. nota n 286.

${ }^{306}$ BEULKE, Strafprozessrecht, cit. nota $\mathrm{n}^{\circ} 13$, nm. 481d, f; VOLK, Grundkurs, cit. nota ${ }^{\circ} 25, \S 28 \mathrm{~nm}$. 33; véase sobre las ideas de violación WOLTER, "Beweisverbote und Umgehungsverbote", cit. nota $n^{\circ}$ 100, p. 972 ss.

307 BGHSt 40, 211, 216; a favor FINGER, "Prozessuale Beweisverbote", cit. nota n 13, p. 536; crítico WOLTER, "Beweisverbote und Umgehungsverbote", cit. nota $\mathrm{n}^{\circ} 100,969$ ss.

${ }^{308}$ Cfr. supra ap. III. 1., así como BEULKE, Strafprozessrecht, cit. nota $\mathrm{n}^{\circ} 13$, nm. 481e; VOLK, Grundkurs, cit. nota $\mathrm{n}^{\circ} 25, \quad \S \quad 28$ nm. 34; similar JÄGER, Beweisverwertung und Beweisverwertungsverbote, cit. nota $\mathrm{n}^{\circ} 15$, pp. 178 ss., quien en principio defiende la existencia de un engaño en el sentido del $\S 136 a$.

${ }^{309}$ Cfr. ROGALL, “Anmerkung”, cit. nota n² 297, p. 111; DUTTGE, Gunnar, "Anmerkung”, cit. nota n ${ }^{\circ}$ 301, p. 262.

${ }^{310}$ MEYER-GOßNER, Strafprozessordnung, cit. nota $\mathrm{n}^{\circ} 52, \S 110 \mathrm{c} \mathrm{nm} .1$.

311 Cfr. también ROGALL, "Anmerkung”, cit. nota ${ }^{\circ} 297$, p. 111, quien, sin embargo, fuera de esta limitación asume la suspensión de la prohibición de engaño, aunque sólo si no se trata al mismo tiempo de engaños que en el interrogatorio abierto estarían prohibidos por el § 136a , p. 113.

${ }^{312}$ Cfr. también DUTTGE, Gunnar, "Anmerkung", cit. nota $\mathrm{n}^{\circ} 301$, quien generalizando los límites trazados en el $\S 110$ c para. 2, 2da. oración, asume siempre una prohibición de engaño en el sentido del $\S$ 136a, cuando el agente encubierto no se limita a un engaño sobre su verdadera identidad, "sino que refuerza
} 
Polít. crim., Vol. 4, $\mathrm{N}^{\circ} 7$ (Julio 2009) Art. 1, pp. 1-56.

[http://www.politicacriminal.cl/Vol_04/n_07/Vol4N7A1.pdf]

respecto del principio nemo tenetur, de que también los engaños pueden servir para influir en alto grado sobre la libre voluntad del acusado, entonces no puede seguirse la conclusión del $\mathrm{BGH}$, de que los interrogatorios encubiertos del acusado no serían comparables con los otros métodos mencionados en el $\S 136 a^{313}$ Más bien debería controlarse siempre si se está ante una mentira de las autoridades investigativas que aún pueda ser permitida, o si fue excedido el límite y se pasó a un engaño prohibido en el sentido del $\S 136$ a. Por lo tanto, apoyándose en los criterios dados por la CEDH se puede asumir que hay un engaño prohibido cuando el engaño - más allá del encubrimiento de las intenciones investigativas - precisamente pretende y es adecuado para superar la resistencia del acusado a brindar información autoincriminante; y por tanto la predisposición de declarar del acusado se ve así "ayudada."314

\subsection{Ejemplos de prohibiciones probatorias autónomas.}

Con las prohibiciones autónomas estamos en presencia de una injerencia en un derecho independiente de la legalidad o ilegalidad de la producción de la prueba - que permite que el interés en la persecución penal pase a un segundo plano. Tal derecho solamente puede derivarse de los derechos fundamentales, en particular de los derechos individuales concebidos en sentido amplio. Por lo tanto, se puede también hablar de prohibiciones de utilización probatoria de orden jurídico-constitucional. ${ }^{315} \mathrm{Si}$ existe tal prohibición, también entra en consideración un efecto anticipado con respecto a la producción probatoria, que también debe ser considerada ilícita (en sentido constitucional). ${ }^{316}$

De conformidad con la teoría de las esferas del Tribunal Constitucional Federal ${ }^{317}$, debe distinguirse entre el ámbito social (primera esfera), la esfera meramente privada (segunda esfera) y la esfera íntima (tercera esfera). Mientras que la injerencia en esta última como núcleo de carácter intangible de la vida privada - acarrea siempre una prohibición de utilización, en la primera esfera no existe ninguna prohibición, y en la segunda debe efectuarse un control de proporcionalidad con especial acento en la proporcionalidad en sentido estricto (ponderación entre la gravedad de la injerencia y los intereses de persecución penal). La teoría de las esferas ha encontrado parcialmente cimiento legal, por ejemplo en las recientes regulaciones relativas a las escuchas encubiertas en residencias particulares ("großer Lauschangriff", § 100d, supra ap. 2. 2.), pero más allá de ello, la teoría no ofrece criterios seguros de delimitación. Dicha teoría privilegia una asignación de la medida coercitiva a una de las denominadas esferas orientada en sus resultados, según se pretenda admitir o rechazar una utilización. ${ }^{318}$ Por lo demás, la construcción de la teoría no ha sido una pretensión original del Tribunal Supremo, sino que éste ha decidido casos de injerencias en la esfera íntima con su doctrina de

o logra la predisposición de declarar del observado con más engaños (innecesarios para llevar adelante la farsa) y con ello 'apoya' o 'ayuda' la decisión del sospechoso de brindar información autoincriminante".

${ }^{313}$ BGHSt 42, pp. 139 ss., p. $149=$ NJW, (1996), p. 2942.

${ }^{314}$ DUTTGE, Gunnar, "Anmerkung”, cit. nota n' 301, p. 264.

${ }^{315}$ FEZER, Strafprozessrecht, cit. nota n ${ }^{\circ} 99$, p. 215.

${ }^{316}$ FEZER, Strafprozessrecht, cit. nota ${ }^{\circ} 99$, p. 216.

${ }^{317}$ BVerfGE 34, 238, 245 ss.; 109, 279

318 Crítico también VOLK, Grundkurs, cit. nota $\mathrm{n}^{\circ} 25, \S 28 \mathrm{~nm}$. 39; JAHN, Beweiserhebungs- und Beweiserverwertungsverbote, cit. nota $\mathrm{n}^{\circ} 1, \mathrm{C} 83 \mathrm{~s}$. 
AMBOS, Kai. "Las prohibiciones de utilización de pruebas en el proceso penal alemán - fundamentación teórica y sistematización”.

ponderación y con miras al caso concreto. ${ }^{319}$ En forma similar, en la literatura se rechaza una prohibición absoluta de utilización por la simple protección de la intimidad en vista de la referencia social de ciertos contenidos, por ejemplo los de un diario personal, que en última instancia son jurídico-penalmente relevantes. ${ }^{320}$

La discrecionalidad que con ésto queda de manifiesto se muestra justamente en los casos de los diarios íntimos. Aquí se decide caso por caso, no obstante se pudiera pensar que los registros consignados en un diario per se pertenecen a la esfera de la intimidad y que con ello se debe descartar su utilización. En este sentido, se rechazó la utilización de un diario para poder obtener la condena por falso testimonio, ${ }^{321}$ pero fue admitido a efectos de la condena de un homicida de mujeres reincidente que había confiado a su diario sus intenciones de matar. ${ }^{322}$ En ambos casos el resultado, en principio, se fundamentó en una convincente ponderación realizada en el marco de la segunda esfera (privada), pero el problema reside en la atribución de ambos casos a la misma esfera, pues en cualquier evento la constatación de una anomalía psíquica grave, como por ejemplo el deseo de cometer un homicidio, cuenta para la (tercera) esfera de la intimidad, y no por el hecho de que este deseo interno también sea exteriorizado ha de contar para la mera (segunda) esfera privada. ${ }^{323}$ También es contradictorio que el Tribunal Supremo atribuya a la esfera de la intimidad (por primera vez) el monólogo dirigido de un inculpado en una habitación de hospital y declare inutilizables la grabación secreta de este en virtud de la violación del art. $13 \mathrm{I} \mathrm{iVm}$ art. $1 \mathrm{I}, 2$ I de la Constitución, ${ }^{324}$ ya que en este último caso también se trata de la exteriorización de pensamientos y sentimientos absolutamente internos - como en el caso del diario - con la única diferencia - aparte de la violación adicional del art. 13 de la Ley Fundamental - de que en el caso del diario los pensamientos están registrados por escrito y en el caso del monólogo están exteriorizados oralmente. La diferente forma, sin embargo, no cambia el contenido y por esa razón tampoco se justifica una consideración jurídica distinta (en un caso simple esfera de la vida privada y utilización, en el otro esfera de la intimidad y ninguna utilización). ${ }^{325}$

\section{4. ¿Efecto reflejo o extensivo?}

Con la noción de efecto extensivo se plantea la cuestión de si más allá del efecto directo sobre una prohibición de utilización correspondiente a un medio de prueba inadmitido, también debe ser prohibida la utilización del medio de prueba indirecto. Por lo tanto, el efecto extensivo supone una prohibición de utilización directa, cuyo alcance se extiende más allá; no se trata de un posible efecto continuo de las circunstancias que fundan la

\footnotetext{
${ }^{319}$ Cfr. FEZER, Strafprozessrecht, cit. nota ${ }^{\circ}$ 99, S. 216 s. con más referencias.

${ }^{320} \mathrm{Cfr}$. JÄGER, Beweisverwertung und Beweisverwertungsverbote, cit. nota $\mathrm{n}^{\circ} 15$, p. $216 \mathrm{~s}$.

${ }^{321}$ BGHSt 19, p. 325.

${ }^{322}$ BGHSt 34, p. 397.

${ }^{323}$ Igualmente VOLK, Grundkurs, cit. nota n 25, § 28 nm. 39; FINGER, "Prozessuale Beweisverbote", cit. nota $\mathrm{n}^{\circ}$ 13, p. 537; crit. también MURMANN, "Über den Zweck", cit. nota $\mathrm{n}^{\circ}$ 6, nm. 218; JAHN, Beweiserhebungs- und Beweiserverwertungsverbote, cit. nota $\mathrm{n}^{\circ} 1, \mathrm{C} 84$.

${ }^{324} \mathrm{BGH}, \mathrm{NJW},(2005)$, p. 3295.

325 Crítico también MURMANN, "Über den Zweck”, cit. nota n 6, nm. 219; de otra opinión FINGER, "Prozessuale Beweisverbote", cit. nota n 13, p. 537.
} 
Polít. crim., Vol. 4, $\mathrm{N}^{\circ} 7$ (Julio 2009) Art. 1, pp. 1-56.

[http://www.politicacriminal.cl/Vol_04/n_07/Vol4N7A1.pdf]

prohibición de utilización del mismo medio de prueba inadmitido. ${ }^{326}$ A modo de ejemplo: ¿debe ser igualmente inutilizable el arma de la comisión de un hecho delictivo (medio de prueba indirecto) encontrada con base en una confesión (medio de prueba directo inutilizable) forzada por la tortura ( $\$ 136 a)$ ? ¿No debe ser obligatoriamente prohibida la utilización del documento (medio de prueba indirecto) encontrado con base en la declaración de un testigo (medio de prueba directo inutilizable) al cual no se le han hecho las instrucciones de rigor sobre su derecho a no declarar $(\S 52)$ ?

Desde el punto de vista estrictamente conceptual la respuesta parece clara, pues obviamente la utilización indirecta de un medio de prueba obtenido lícitamente posibilita igualmente su utilización y debería por consiguiente sufrir también una prohibición de utilización. ${ }^{327}$ Pero esta óptica conceptual es demasiado formal. Desde una perspectiva material salta a la vista que los ejemplos expuestos se diferencian respecto de la forma de la práctica probatoria, de la gravedad de la infracción procesal y del delito reprochado. A este respecto ya se ha hecho mención de aspectos importantes de una teoría de la ponderación que pretenda decidir sobre el efecto extensivo caso por caso. ${ }^{328}$ En esta dirección también argumenta Jäger, cuando, reconociendo en principio una prohibición del efecto extensivo, aboga por limitaciones normativas, en tanto la práctica probatoria viciada no haya tenido ningún efecto sobre los medios de prueba (indirectos). ${ }^{329}$

También Jahn diferencia según el caso - claramente en el sentido de su teoría de las facultades ${ }^{330}$ - de acuerdo a los efectos de la infracción, y asume siempre el efecto extensivo en caso de violaciones a los derechos humanos. ${ }^{331}$

Mayor seguridad jurídica - pero no necesariamente mayor practicabilidad - prometen los puntos de vista extremos de la jurisprudencia, por una parte, y de la doctrina (al parecer) dominante, por la otra. De acuerdo con la jurisprudencia ${ }^{332}$, argumentos contundentes en

\footnotetext{
${ }^{326}$ Sobre esta diferenciación ver JÄGER, Beweisverwertung und Beweisverwertungsverbote, cit. nota ${ }^{\circ}$ 15, p. 112; MURMANN, "Über den Zweck", cit. nota $\mathrm{n}^{\circ}$ 6, nm. 230. Para los efectos posteriores debe asumirse una prohibición de utilización, en tanto tal prohibición no haya sido cancelada mediante una información calificada (ebd.); JAHN, Beweiserhebungs- und Beweiserverwertungsverbote, cit. nota $\mathrm{n}^{\circ} 1, \mathrm{C}$ 91. - Sobre los "efectos previos" de la prohibición de utilización sobre la prohibición de producción cfr. JAHN, Beweiserhebungs- und Beweiserverwertungsverbote, cit. nota ${ }^{\circ} 1, \mathrm{C} 84$ ss.

327 Así ya HENKEL, Strafverfahrensrecht, cit. nota $\mathrm{n}^{\circ}$ 2, p. 271. Cfr. aquí también JAHN, Beweiserhebungs- und Beweiserverwertungsverbote, cit. nota $\mathrm{n}^{\circ} 1$, C 92 ("Utilización significa introducción de conocimiento en el proceso").

${ }^{328}$ SENGE, en Karlsruher Kommentar, cit. nota $\mathrm{n}^{\circ} 1$, antes de $\S 48 \mathrm{~nm} .45$ ss.; DIEMER, Karlsruher Kommentar, cit. nota $\mathrm{n}^{\circ} 49, \S 136 \mathrm{a} \mathrm{nm}$. 42; GLEß, Strafprozessordnung, cit. nota ${ }^{\circ} 8$, § 136a nm. 66; MAIWALD, Manfred, "Zufallsfunde bei zulässiger strafprozessualer Telephonüberwachung - BGH, NJW 1976, 1462”, JuS, (1978), pp. 379-385, p. 384; ROGALL, Klaus, JZ, (1997), pp. 944 ss., p. 948; HELLMANN, Strafprozessrecht, cit. nota n ${ }^{\circ} 18, \mathrm{~nm}$. 484; MURMANN, "Über den Zweck", cit. nota $\mathrm{n}^{\circ}$ 6, nm. 233; HALLER/CONZEN, Das Straverfahren, cit. nota n ${ }^{\circ} 25$, nm. 574. En detalle sobre la dogmática de la teoría de la ponderación MERGNER, Tobias, Fernwirkung von Beweisverwertungsverboten, Universität Köln: Köln, 2005, pp. 84 ss.

${ }^{329}$ JÄGER, Beweisverwertung und Beweisverwertungsverbote, cit. nota $\mathrm{n}^{\circ} 15$, pp. 226 ss.

${ }^{330}$ Cit. nota $\mathrm{n}^{\circ} 188$ y texto principal.

${ }^{331}$ JAHN, Beweiserhebungs- und Beweiserverwertungsverbote, cit. nota ${ }^{\circ} 1, \mathrm{C} 94$ s., 127.

${ }^{332}$ BGHSt 27, pp. 355 ss., p. 358; BGHSt 32, pp. 68 ss., p. 71; BGHSt 34, pp. 362 ss., p. 364; NJW, (2006), p. 1361; BVerfG, NStZ, (2006), p. 46; igualmente PETERS, Strafproze $\beta$, cit. nota n ${ }^{\circ} 20$, p. 337 s.; RANFT,
} 
AMBOS, Kai. "Las prohibiciones de utilización de pruebas en el proceso penal alemán - fundamentación teórica y sistematización”.

consideración al proceso penal en su conjunto demandan el rechazo, en principio, ${ }^{333}$ de la teoría del efecto extensivo. ${ }^{334}$ De conformidad con la doctrina, existen argumentos contundentes en consideración a la teoría de la prohibición de utilización probatoria que demandan el reconocimiento, en principio, de la teoría del efecto extensivo, ${ }^{335}$ y como consecuencia de ésto, de cuando en cuando los medios de prueba que hubiesen podido ser obtenidos (incluso legalmente) se sustraen a la prohibición de utilización (teoría del curso causal hipotético). ${ }^{336}$ Casi no se discute, sin embargo, si y hasta qué punto aquello puede ser comprobado. ${ }^{337}$ Las posiciones fundamentales tienen aún mucho por hacer con la construcción teórica de las prohibiciones de utilización probatoria (supra introducción), con lo cual nos encontramos nuevamente al principio de nuestras reflexiones. Si a las prohibiciones de prueba se les atribuye la ya frecuentemente nombrada función de control disciplinario, ello habla a favor del reconocimiento de un efecto extensivo, pues ¿de qué otra forma se debería desacostumbrar a las autoridades de persecución penal y en especial a la policía de la práctica probatoria ilícita, si no es a través de la consecuente inutilización (directa e indirecta) de las pruebas obtenidas de esta forma? Las reflexiones que avancen en estas cuestiones deben ser reservadas a una investigación especial.

Otfried, "Bemerkungen zu den Beweisverboten im Strafprozeß”, en: Festschrift für Günter Spendel zum 70. Geburtstag am 11. Juli 1992, Berlin: de Gruyter, 1992, pp. 719 ss., p. 735; LESCH, Heiko Hartmut, Strafprozessrecht, 2. ed., Neuwied: Luchterhand, 2001, § 3 nm. 170.

333 Excepción BGHSt 29, pp. 244 ss., p. 247: reconocimiento de un efecto extensivo en cuanto a una violación del $\S 7$ III (ahora $§ 6$ II 3 en relación con el $§ 7$ VI) del Ley sobre el Art. 10 Constitución (G 10) con miras a hechos no contenidos en el catálago.

${ }^{334}$ En este sentido también las resoluciones de la $D J T$, cit. nota ${ }^{\circ} 19$, mayoritariamente rechazando el efecto extensivo, aceptando expresamente el uso mediato (p. ej. para fundar un inicio de sospecha), números 7. a), 8 a) y b) (con 65:1 votos, 11 abstenciones, y 39:31:5). Afirmativamente incluso también respecto de la utilización transnacional en casos de ilegalidad en la producción de la prueba en el Estado solicitado (Resolución 16 a), 35:13:5).

335 DENCKER, Verwertungsverbote, cit. nota $\mathrm{n}^{\circ}$ 16, p. 79 s.; SPENDEL, Günter, "Beweisverbote im Strafprozeß”, NJW, (1966), pp. 1102-1108, p. 1105; FEZER, Strafprozessrecht, cit. nota ${ }^{\circ}$ 99, p. 224; ROXIN, Strafverfahrenstrecht, cit. nota $\mathrm{n}^{\circ} 34, \S 24 \mathrm{~nm} .47$ con más referencias; KÜHNE, Strafprozessrecht, cit. nota ${ }^{\circ} 4$, nm. 911; VOLK, Grundkurs, cit. nota $\mathrm{n}^{\circ} 25, \S 28 \mathrm{~nm}$. 43; en el resultado también BEULKE, Strafprozessrecht, cit. nota $n^{\circ} 13, \mathrm{~nm} .482$ quien enfatiza el ámbito de protección de la norma procesal violada, así como AMELUNG, "Zum Streit", cit. nota ${ }^{\circ} 15$, p. 1262, con base en su teoría de los derechos de dominio de información.

${ }^{336}$ FEZER, Strafprozessrecht, cit. nota $n^{\circ} 99$, p. 224; ROXIN, Strafverfahrenstrecht, cit. nota $n^{\circ} 34, \S 24$ nm. 47; con la misma tendencia BEULKE, Strafprozessrecht, cit. nota ${ }^{\circ} 13, \mathrm{~nm} .483$.

${ }^{337}$ Crítico en general KÜHNE, Strafprozessrecht, cit. nota n 4, nm. 911; ver también cit. nota $n^{\circ} 199$. 
Polít. crim., Vol. 4, $\mathrm{N}^{\circ} 7$ (Julio 2009) Art. 1, pp. 1-56.

[http://www.politicacriminal.cl/Vol_04/n_07/Vol4N7A1.pdf]

\section{BIBLIOGRAFÍA}

\section{Libros}

AMBOS, Kai, Internationales Strafrecht, 2. ed. München: Beck, 2008, § 10 nm. 62, 81 y ss.

AMELUNG, Knut, Informationsbeherrschungsrechte im Strafprozess: dogmatische Grundlagen individualrechtlicher Beweisverbote, Berlin: Duncker \& Humblot, 1990.

BELING, Ernst, Die Beweisverbote als Grenzen der Wahrheitsfindung im Strafprozess, Breslau: Schletter, 1903.

BENNECKE, Hans; BELING, Ernst, Lehrbuch des Dt. Reichs-Strafprozessrechts, Breslau: Schletter, 1900, §§83 3., p. 327.

BEULKE, Werner, Strafprozessrecht, 10. ed., Heidelberg: Müller, 2008, nm. 454.

BOCKEMÜHL, Jan, Private Ermittlungen im Strafprozeß: ein Beitrag zu der Lehre von den Beweisverboten, Baden-Baden: Nomos Verl.-Ges, 1996.

DANNER, Mark, Torture and Truth: America, Abu Ghraib and the War on Terror, Nueva York: New York Review Books, 2004.

DENCKER, Friedrich, Verwertungsverbote im Strafprozeß: ein Beitrag zur Lehre von den Beweisverboten, Köln: Heymann, 1977, pp. 59 y ss.

DIEMER, Herbert, Karlsruher Kommentar zur Strafprozessordnung, 6. ed. München: Beck, 2008, § 136a nm. 9.

EIDAM, Lutz, Die strafprozessuale Selbstbelastungsfreiheit am Beginn des 21. Jahrhunderts, Frankfurt am Main: Lang, 2007, pp. 235 y ss.

EISENBERG, Ulrich, Beweisrecht der StPO, 6. ed., parte 1, cap. 3, München: Beck, 2008, nm. 330.

FEZER, Gerhard, Grundfragen der Beweisverwertungsverbote, Heidelberg: Müller, 1995, pp. 20 y ss.

, Strafprozessrecht, 2. ed., München: Beck, 1995, p. 222.

GLEß, Sabine, en LÖWE-ROSENBERG, Strafprozessordnung und das Gerichtsverfassungsgesetz, Tomo 2, 26. ed, Berlin: de Gruyter, 2007.

HALLER, Klaus; CONZEN, Klaus, Das Strafverfahren: eine systematische Darstellung mit Originalakte und Fallbeispielen, 6ta. ed., Heidelberg, Neckar: Müller, 2008, nm. 548.

HASSEMER, Winfried; MATUSSEK, Karin, Das Opfer als Verfolger : Ermittlungen des Verletzten im Strafverfahren, Frankfurt am Main: Lang, 1996, p. 77.

HELLMANN, Uwe, Strafprozessrecht, 2. ed., Berlin: Springer, 2006, § 3 nm., p. 83 s.

HENKEL, Heinrich, Strafverfahrensrecht, Stuttgart: Kohlhammer, 1968, p. 271.

JÄGER, Christian, Beweisverwertung und Beweisverwertungsverbote im Strafprozess, München: Beck, 2003.

KINDHÄUSER, Urs, Strafprozessrecht, Baden-Baden: Nomos, 2006, § 23 nm. 11.

KÜHNE, Hans-Heiner, Strafprozessrecht, eine systematische Darstellung des deutschen und europäischen Strafverfahrensrechts, 7. ed., Heidelberg: Müller, 2007, nm. 880.

LANGBEIN, John, Torture and the Law of Proof: Europe in the ancient regime, Chicago: University of Chicago Press, 2006 (reimpresión), pp. IX, XI.

LESCH, Heiko Hartmut, Strafprozessrecht, 2. ed., Neuwied: Luchterhand, 2001, § 3 nm. 
AMBOS, Kai. "Las prohibiciones de utilización de pruebas en el proceso penal alemán - fundamentación teórica y sistematización”.

LÖFFELMANN, Markus, Die normativen Grenzen der Wahrheitserforschung im Strafverfahren, Berlin: De Gruyter Recht, 2008.

MEYER, Jürgen, Der Urkundenbeweis in der Hauptverhandlung, Frankfurt am Main: Lang, 1999, pp. 143 y ss.

MEYER-GOßNER, Lutz, Strafprozessordnung mit GVG und Nebengesetzen, 51. ed., München: Beck, 2008, § 136 nm. 9.

MEYER-LADEWIG, Jens, Europäische Menschenrechtskonvention, 2. ed., BadenBaden: Nomos-Verl.-Ges., 2006, art. 6 nm. 52.

MEYER-WIECK, Hannes, Der große Lauschangriff, Berlin: Duncker \& Humblot, 2005.

MURMANN, Uwe, Prüfungswissen Strafprozessrecht, München: Beck, 2008, nm. 184.

PETERS, Karl, Strafprozeß: Ein Lehrbuch, 4ta. ed., Heidelberg: Müller, Jur. Verl., 1985, $\S 41$ II 1.

ROGALL, Klaus, “Abwägungen im Recht der Beweisverbote”, en: Festschrift für ErnstWalter-Hanack zum 70. Geburtstag am 30.August 1999, Berlin: de Gruyter, 1999, pp. 293-309.

RÖSSNER, Dieter, 30 Probleme aus dem Strafprozessrecht, 2. ed., Köln: Luchterhand, 2007, p. 78.

ROXIN, Claus, Strafverfahrensrecht: ein Studienbuch, 25. ed., München: Beck, 1998, § $24 \mathrm{~nm} .19$.

SCHMIDT, Eberhard, Lehrkommentar zur Strafprozeßordnung und zum Gerichtsverfassungsgesetz , t. II, Göttingen: Vandenhoeck \& Ruprecht, 1970, § $136 \mathrm{a}$ nm. 21.

SCHUSTER, Frank Peter, Verwertbarkeit im Ausland gewonnener Beweise im deutschen Strafprozess, Berlin: Duncker \& Humblot, 2006, p. 70 y s.

VERREL, Die Selbstbelastungsfreiheit im Strafverfahren: ein Beitrag zur Konturierung eines überdehnten Verfahrensgrundsatzes, München: Beck, 2001, p. 51 y s.

VOLK, Klaus, Grundkurs StPO, 6. ed., München: Beck, 2008, § 28 nm. 1 y ss.

WOLFF, Heinrich A., Selbstbelastung und Verfahrenstrennung, Berlin: Duncker \& Humblot, 1997, p. 136.

\section{Artículos}

ACHENBACH, Hans, "§168”, en: WASSERMANN, Rudolf $\quad$ (Coord.), Alternativkommentar zur Strafprozessordnung in 3 Bänden, Neuwied, 1988, § 168c nm. 18.

ALLGAYER, Peter, "Die Verwendung von Zufallserkenntnissen aus Überwachungen der Telekommunikation gem. $\S \S 100$ af. StPO (und anderen Ermittlungsmaßnahmen)", Neue Zeitschrift für Strafrecht (NStZ), (2006), pp. 603-608.

AMBOS, Kai, "Die transnationale Verwertung von Folterbeweisen", Srafverteidiger (StV), (2009), pp. 151-161.

"Der Europäische Gerichtshof für Menschenrechte und die Verfahrensrechte", Zeitschrift für die gesamte Strafrechtswissenschaft (ZStW), (2003), pp. 583-637.

, "Europarechtliche Vorgaben für das deutsche Strafverfahren", NStZ (2002), pp. 628-633. 
Polít. crim., Vol. 4, $\mathrm{N}^{\circ} 7$ (Julio 2009) Art. 1, pp. 1-56.

[http://www.politicacriminal.cl/Vol_04/n_07/Vol4N7A1.pdf]

, "The Right of Non Self-incrimination of Witnesses Before the ICC", Leiden Journal of International Law, 15 (2002), pp. 155 y ss.

AMELUNG, Knut, "Die Entscheidung des BVerfG zur 'Gefahr im Verzug' i.S. des Art. 13 II GG”, NStZ, (2001), pp. 337-343.

"Zum Streit über die Grundlagen der Lehre von den Beweisverwertungsverboten“, en: Festschrift für Claus Roxin, Berlin: de Gruyter, 2001, pp. 1259-1280.

ARLOTH, Frank, "Dogmatik in der Sackgasse - Zur Diskussion um die Beweisverwertungsverbote", Goldammer's Archiv für Strafrecht (GA), (2006), pp. 258-261.

BEULKE, Werner; ROGAT, Stefan, “Anmerkung zu BGH, Urt. V. 7.3.1995 - 1 StR 685/94 (BGHSt. 41, 64), Juristische Rundschau (JR), (1996), pp. 515-521.

BEULKE, Werner, "Hypothetische Kaulsalverläufe im Strafverfahren bei rechtswidrigen Vorgehen von Ermittlungsorganen“, ZStW (1991), pp. 657-680.

BOSCH, Nikolaus, "Reichweite des nemo-tenetur-Grundsatzes bei verdeckten Ermittlungen", Juristische Arbeitsblätter (JA), (2007), pp. 903-906.

BUNG, Jochen, "Objektiv unzulässiger oder intentionaler Zwang als Voraussetzung eines Beweisverwertungsverbots nach $\S 136$ a Abs. 3 Satz 2 i.V.m. Abs. 1 Satz 2 stopp", StV, (2008), pp. 495-499.

CORNELIUS, Kai, "Konfrontationsrecht und Unmittelbarkeitsgrundsatz", NStZ, (2008), pp. 244-248.

DALLMEYER, Jahn, "Zum heutigen Stand der beweisrechtlichen Berücksichtigung hypothetischer Ermittlungsverläufe im deutschen Strafverfahrensrecht", NStZ, (2005), pp. 297-303.

DENCKER, Friedrich, "Anmerkung zu BGH, Urt. v. 10.8.1994 - 3 StR 53/94 (LG Kleve)", StV, (1995), pp. 232-236.

DÖLLING, Dieter, "Verlesbarkeit schriftlicher Erklärungen und Auskunftsverweigerung nach $\S 55$ StPO”, NStZ, (1988), pp. 6-10.

DUTTGE, Gunnar, “Anmerkung zu BGH, Urteil vom 26.07.2006 - 3 StR 104/07 Verwertung von Angaben des Beschuldigten gegenüber einem Verdeckten Ermittler“, Juristen Zeitung (JZ), (2008), pp. 262 y ss.

ESSER, Robert, "Verurteilung aufgrund von Aussagen anonymer Zeugen (Besprechung von EGMR vom 17.11.2005 - Haas/Deutschland)", NStZ, (2007), pp. 106-109.

, “Anmerkung zu EGMR, Urt. D. 4. Sektion v. 5.11.2002 - Beschwerde Nr. 48539/99”, JR, (2004), p. 98.

FEZER, Gerhard, "Grundfälle zum Verlesungs- und Verwertungsverbot im Strafprozeß”, Juristische Schulung (JuS), (1978), pp. 325-331.

GAEDE, Karsten, "Anmerkung zu EGMR, Urt. D. 4. Sektion v. 5.11.2002 - Beschwerde Nr. 48539/99” (Fall Allan v. Großbritannien; zur Publikation in Rep. 2002-IX ausgewählt), StV, (2003), pp. 257-263, p. 261.

GEPPERT, Klaus, “Das Beweisverbot des § 252 StPO”, Jura, (1988), pp. 305-314.

GÖTZ, Hanjörg, "Kein Beweisverwertungsverbot bei fehlerhafter Annahme von Gefahr in Verzug", NStZ, (2008), pp. 239-240.

GRÜNWALD, Gerald, "Beweisverbote und Verwertungsverbote im Strafverfahren”, JZ, (1966), pp. 489-501. 
AMBOS, Kai. “Las prohibiciones de utilización de pruebas en el proceso penal alemán - fundamentación teórica y sistematización”.

HASSEMER, Winfried, "Pacta sunt servanda - auch im Strafprozeß?”, JuS, (1989), pp. 890-895.

HEGHMANNS, Michael, Comentario al libro Der große Lauschangriff de Hannes Meyer-Wieck (Berlin: Duncker \& Humblot, 2005), GA, (2006), pp. 826-828.

HAUF, Claus-Jürgen, "Ist die 'Rechtskreistheorie' noch $\mathrm{zu}$ halten? - Eine neue Konzeption zur Frage von Verfahrensfehlern und Beweisverwertungsverboten", NStZ, (1993), pp. 457-462.

INGER, Thorsten, "Prozessuale Beweisverbote - Eine Darstellung ausgewählter Fallgruppen", JA, (2006), pp. 529-539.

JAHN, Matthias, "Beweiserhebungs- und Beweisverwertungsverbote im Spannungsfeld zwischen den Garantien des Rechtsstaates und der effektiven Bekämpfung von Kriminalität und Terrorismus", en: Verhandlungen zum 67. Deutschen Juristentag Erfurt 2008, tomo I, Gutachten Teil C, Erfurt: C. H. Beck, 2008, C 21.

JOERDEN, Jan C., "Verbotene Vernehmungsmethoden - Grundfragen des $\S 136 \mathrm{a}$ StPO”, JuS, (1993), pp. 927-931.

KELKER, Brigitte, "Die Rolle der Staatsanwaltschaft im Strafverfahren”, ZStW (2006), pp. 389-426.

KNIERIM, Thomas, "Fallrepetitorium zur Telekommunikationsüberwachung nach neuem Recht", StV, (2008), pp. 599-606.

KÖLBEL, Ralf, “Geständnisverwertung bei missglückter Absprache”, NStZ, (2003), pp. 232-236, pp. 234 y ss.

KUCKEIN, Jürgen, "Zur Verwertbarkeit des Geständnisses bei einer gescheiterten Verständigung im Strafverfahren", en: Festschrift für Meyer-Goßner, München: Beck, 2001, pp. 63-72.

KUCKEIN, Jürgen; PFISTER, Wolfgang, "Verständigung im Strafverfahren Bestandaufnahme und Perspektiven -“, en: GEIß, Karlmann et al. (Coord.), Festschrift aus Anlaß des fünfzigjährigen Bestehens von Bundesgerichtshof, Bundesanwaltschaft und Rechtsanwaltschaft beim Bundesgerichtshof, Köln et al.: Carl Heymanns, 2000, p. 641-661

KÜPPER, Georg, “Anmerkung zu BGH, Urt. v. 16.2.1995 - 4StR 729/94 (BGHSt. 41, 30)", JR, (1996), pp. 214-216.

LANGKEIT, Jochen; CRAMER, Steffen, "Vorrang des Personalbeweises bei gemäß 55 StPO schweigenden Zeugen", StV, (1996), pp. 230-234.

LESCH, Heiko H., "Die Grundsätze der Mündlichkeit und Unmittelbarkeit im Strafverfahren", JA, (1995), p. 691-703, p. 695 y ss.

LIE LIEN, Taipei, "Analytische Untersuchung der Ursachen des andauernden Streits um Absprachen - Kritik an den bisherigen Legitimationsmodellen der Absprachen aus sprachanalytischer Sicht", GA, (2006), pp. 129-147.

MAIWALD, Manfred, "Zufallsfunde bei zulässiger strafprozessualer Telephonüberwachung - BGH, NJW 1976, 1462”, JuS (1978), pp. 379-385.

MEYER-MEWS, Hans, „Anmerkung zu BGH, Urt. v. 26. 7. 2007 (3 StR 104/07)“, NJW, (2007), pp. 3138 y ss.

MEYER-MEWS, Hans, "Beweisverwertungsverbote im Strafverfahren”, JuS (2004), p. 39-42.

MITSCH, Wolfgang, "Beschuldigenstatus und Belehrungspflicht”, NStZ, (2008), pp. 4950. 
Polít. crim., Vol. 4, $\mathrm{N}^{\circ} 7$ (Julio 2009) Art. 1, pp. 1-56.

[http://www.politicacriminal.cl/Vol_04/n_07/Vol4N7A1.pdf]

, "Tod auf Mallorca - Verwertungsverbot wegen unzulässiger verdeckter Ermittlungsmethoden”, Jura, (2008), pp. 211-215.

"Protokollverlesung nach berechtigter Auskunftsverweigerung ( $\S$

55 StPO) in der Hauptverhandlung", JZ, (1992), pp. 174-183.

MURMANN, Uwe, "Anmerkung zu BGH, Urt. V. 27.4.2007 - 2 StR 490/06 (LG Köln)", StV, (2008), pp. 339-341.

, “Über den Zweck des Strafprozesses", GA, (2004), pp. 65 y ss.

MÜSSIG, Bernd, "Beweisverbote im Legitimationszusammenhang von Strafrechtstheorie und Strafverfahren", GA (1999), pp. 119 - 14.

OTTO, Harro, "Grenzen und Tragweite der Beweisverbote im Strafverfahren", GA (1970), pp. 289-305.

PETERS, Karl, "Beweisverbote im Strafprozess", en: Verhandlungen zum 46. DJT (Deutscher Juristentag), t. I, Parte 3 A, München, 1967, pp. 91, 94.

PFEIFFER, Gerd, Strafprozessordnung, 5. ed., München: Beck, 2005, § 97 nm. 1.

PRITTWITZ, Cornelius, "Richtervorbehalt, Beweisverwertungsverbot und Widerspruchslösung bei Blutentnahmen gem. § 81 a Abs. 2 StPO”, StV, (2008), pp 486-494

RANFT, Otfried, "Bemerkungen zu den Beweisverboten im Strafprozeß”, en: Festschrift für Günter Spendel zum 70. Geburtstag am 11. Juli 1992, Berlin: de Gruyter, 1992, pp. 719 y ss.

ROGALL, Klaus, “§ 133”, en: RUDOLPHI, Hans-Joachim; WOLTER, Jürgen, Systematischer Kommentar zur Strafprozessordnung und zum Gerichtsverfassungsgesetz, 2008, antes de $§ 133$ nm. 188. "“Anmerkung zu Urteil”, JZ, (1996), p. 260.

, "Gegenwärtiger Stand und Entwicklungstendenzen der Lehre von den strafprozessualen Beweisverboten”, ZStW (1979), pp. 1-44.

RÖNNAU, Thomas, "Die neue Verbindlichkeit bei den strafprozessualen Absprachen", Zeitschrift für Wirtschafts- und Steuerstrafrecht (wistra), (1998), pp. 49-53.

ROXIN, Claus; SCHÄFER, Gerhard; WIDMEIER, Gunter, "Die Mühlenteichtheorie, Überlegungen zur Ambivalenz von Verwertungsverboten“, StV, (2006), pp. 655660.

ROXIN, Claus, "Beweisverwertungsverbot bei bewußter Mißachtung des Richtervorbehalts", NStZ (2007), pp. 616 y ss. , "Beschuldigtenstatus und qualifizierte Belehrung", JR (2008), pp. 1619.

"Gegenwart und Zukunft der Verteidigung im rechtsstaatlichen Strafverfahren”, en: EBERT, Udo et al. (Coord.), Festschrift für Ernst-Walter Hanack zum 70. Geburtstag am 30. August 1999, Berlin: de Gruyter, 1999, pp. 1 25 .

"Zum Einschleichen polizeilicher Scheinaufkäufer in Privatwohnungen", StV, (1998), pp. 43-45.

pp. 465-469.

"Nemo tenetur: die Rechtsprechung am Scheideweg", NStZ, (1995)

" “Anmerkung zum Urteil des BGH vom 17.2.1989 - 2 StR 402/88”, NStZ, (1989), pp. 376-379. 
AMBOS, Kai. "Las prohibiciones de utilización de pruebas en el proceso penal alemán - fundamentación teórica y sistematización”.

SAFFERLING, Christoph J.M., "Die zwangsweise Verabreichung von Brechmittel: Die StPO auf dem menschenrechtlichen Prüfstand", Jura, (2008), pp. 100-108.

SCHLOTHAUER, Reinhold, "Strafprozessuale Verwertung selbstbelastender Angaben im Verwaltungsverfahren", en: Festschrift für Gerhard Fezer, Berlin: de Gruyter Recht, 2008, pp. 267-287.

SCHLOTHAUER, Reinhold, “Anmerkung zu BGH, Urt. v. 7.5.2003 - 5 StR 556/02 (LG Hamburg)”, StV, (2003), pp. 481-483.

SCHLÜCHTER, Ellen, “§ 252”, en: RUDOLPHI, Hans-Joachim; WOLTER, Jürgen (Coord.), Systematischer Kommentar zur Strafprozessordnung und zum Gerichtsverfassungsgesetz, § $252 \mathrm{~nm} .22$.

SCHMIDT, Eberhard, "Anmerkung zu OGHBrZ.", Süddeutsche Juristenzeitung (SJZ) (1949), C 347 y ss., p. 450.

SENGE, Lothar, en: Karlsruher Kommentar zur Strafprozessordnung, 6. ed. München: Beck, 2008.

SINGELNSTEIN, Tobias, "Strafprozessuale Verwendungsregelungen zwischen Zweckbindungsgrundsatz und Verwertungsverboten", ZStW, (2008), pp. 854-893.

STRATE, Gerhard, "Rechtshistorische Fragen der Beweisverbote", JZ (1989), pp. 176179.

STÜBINGER, Stephan, "Lügendetektor ante portas - Zu möglichen Auswirkungen neurowissenschaftlicher Erkenntnisse auf den Strafprozess", Zeitschrift für Internationale Strafrechtsdogmatik (ZIS), (2008), pp. 538-555.

WEIGEND, Thomas, "Festgenommene Ausländer haben ein Recht auf Benachrichtigung ihres Konsulates", StV, (2008), pp. 39-44.

, "Abgesprochene Gerechtigkeit - Effizienz durch Kooperation im Strafverfahren?”, JZ, (1990), pp. 774-782 y ss.

WOLTER, Jürgen, "Alternativen zum Regierungs-Entwurf 2007 zur Neuregelung der Ermittlungsmaßnahmen”, GA, (2007), pp. 183-200

"Beweisverbote und Umgehungsverbote zwischen Wahrheitsforschung und Ausforschung", en: GEIß, Karlmann et al. (Coord.), Festschrift aus Anlaß des fünfzigjährigen Bestehens von Bundesgerichtshof, Bundesanwaltschaft und Rechtsanwaltschaft beim Bundesgerichtshof, Köln et al.: Carl Heymanns, 2000, pp. 963-1010. 